\title{
ABSTRACT
}

\section{Title of Document: $\quad$ GETTING ON THE SAME PAGE: HOW LEADERS BUILD TRUST CONSENSUS IN TEAMS AND ITS CONSEQUENCES}

\section{Ashley Fulmer, Doctor of Philosophy, 2012}

\section{Directed By: $\quad$ Dr. Cheri Ostroff, Department of Psychology}

Existing organizational research has demonstrated that team members' trust in leaders is positively related to a team's bottom-line outcomes. However, little is known about how collective trust in leaders develops among team members. To address this gap, the present study examines the effects of multiple emergent processes on the extent to which team members exhibit consensus in trust in their leader. In particular, it was proposed that the most important factors for the emergence, and the degree of consensus, of collective trust in leaders should have the same referent target as the collective construct (i.e., the leader) and concern behaviors that involve interactions between the leader and team members. Thus, the leader behavior and interactions variables of showing concern, leading by example, and monitoring were expected to exert stronger influence on the consensus in trust in leaders than leader attributes (ability and integrity) and team factors (open communication and demographic diversity). Further, the degree of consens us in trust in leaders was predicted to have both an independent and interaction effect with the mean level of trust in leaders in influencing team performance and voice behavior. Three waves of survey data were collected from teams with new leadership in a large academic military institution. Data from 719 team members from 105 teams were used to test these predictions by analyzing consensus concurrently and changes in consens us over time. The results generally supported the relative importance of leader showing concern and 
leading by example on the degree of consensus in trust in leaders in the concurrent model. For changes in consensus, leading by example was particularly important. In addition, while consensus was not independently related to the team performance and voice behaviors, it interacted with the mean level in influencing the outcomes in both the concurrent and change models. Taken together, the findings suggest that some leader behaviors are important for the development of collective trust or consensus in trust in leaders, and further suggest that consensus can act as a boundary condition for the effect of the mean level of trust in leaders on team outcomes. By focusing on the consensus in trust in leaders, this research begins to shed light on how consensus in trust develops among team members with respect to their leader and has implications for understanding trust, leadership, and emergence. 


\title{
GETTING ON THE SAME PAGE: HOW LEADERS BUILD TRUST CONSENSUS IN TEAMS AND ITS CONSEQUENCES
}

\author{
by \\ C. Ashley Fulmer \\ Dissertation submitted to the Faculty of the Graduate School of the \\ University of Maryland, College Park, in partial fulfillment \\ of the requirements for the degree of \\ Doctor of Philosophy \\ 2012
}

Advisory Committee:

Dr. Cheri Ostroff, Chair

Dr. Donald Ferrin

Dr. Michele Gelfand

Dr. Paul Hanges

Dr. Hui Liao 
(C) Copyright by

C. Ashley Fulmer

2012 


\section{Acknowledgements}

A dissertation is a journey of discovery. I set out with a goal to explore an aspect of trust in organizations that was little understood. Now at the end of this journey, I realize that, more than anything, I have learnt about myself and the people that I am fortunate to have around me. I have discovered how they have enabled me throughout this journey and my graduate career, and how much I am indebted to them.

My first and foremost thanks go to Cheri Ostroff, my advisor and mentor. Cheri has been instrumental at every step of the dissertation and my graduate career. Throughout both, she encouraged me to take on challenges, helped me navigate the unfamiliar and sometimes tumultuous waters, and always kept me on course. I would not have been able to complete either without her selfless and tireless guidance. Most importantly, I have benefited greatly from her dedication to students, without which the journey would have been near impossible.

I am equally indebted to my other advisor and mentor, Michele Gelfand. Michele's wisdom and energy have been a constant beacon throughout my graduate career. Her passion for research, for science, and for life inspires me daily and has propelled me to expand my horizons and reach for high standards. From the beginning, Michele has always believed in me and has made me see what I can achieve. Her sage advice and vision has transformed my research and myself time and again. I could not have gotten here without her support, care, and guidance.

My deepest gratitude goes to the both of them for their genuine concern about my professional and personal development and for always being there for me. 
During my graduate career, I have also relied greatly on Paul Hanges for his encouragement and support. His patient listening and explaining has pointed the way for me numerous times. I would also like to thank Don Ferrin and Hui Liao, who have been supportive in all phases of the dissertation process. I sincerely appreciate their thoughtful comments, sharp insights, and kind understanding.

I am also extremely grateful for the invaluable assistance and insightful feedback from Lou Cox, Wesley Huey, Brian Chontosh, and David Smith. Without them, this research would not have been possible. My special thanks go to their enthusiasm and support. In addition, I have had the fortune to have assistance from extremely talented undergraduate students, including Ethan Wieselthier, Micah Colston, Eva Lenoir, Nicolas Jimenez, Farrah Al-Mansoor, Jack Grey, and Thomas Hardy. My thanks also go to my colleagues from the department, including Laura Severance, Elizabeth Salmon, Janetta Lun, and Carol Gorham, among others.

Most importantly, I thank my husband, Gavin Fulmer, for his unwavering understanding and staunchest support. None of this would have happened without his being by my side. He has been my steadfast anchor throughout this journey. 


\section{TABLE OF CONTENTS}

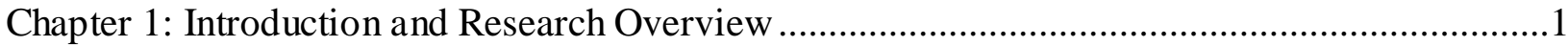

Chapter 2. Theory and Research on Trust in Leaders ........................................................ 11

Definition of Trust in Leaders............................................................................. 11

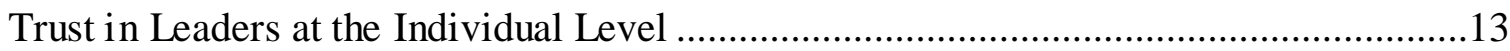

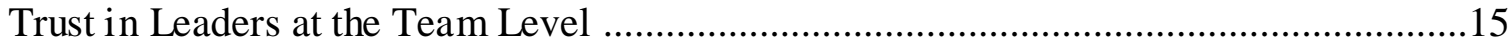

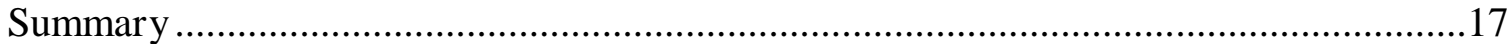

Chapter 3. Theory and Research on Emergence …............................................................19

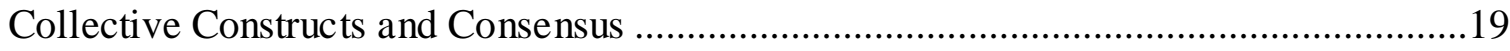

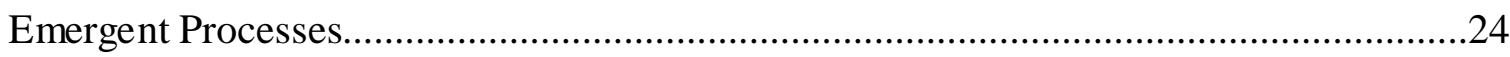

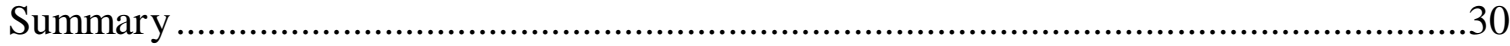

Chapter 4. Building Team Trust in Leaders: Theoretical Model and Hypotheses .......................32

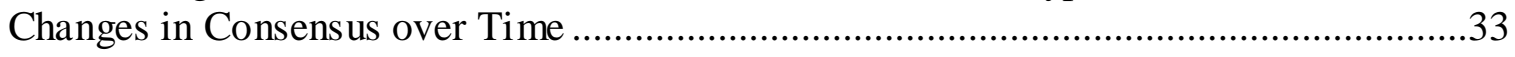

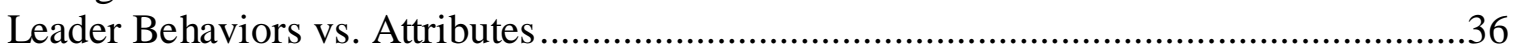

Emergent Process and Consensus Target Match ...................................................45

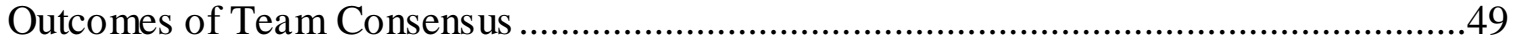

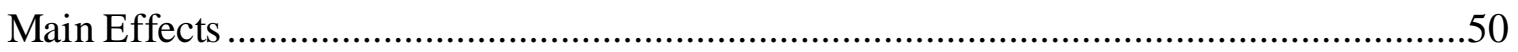

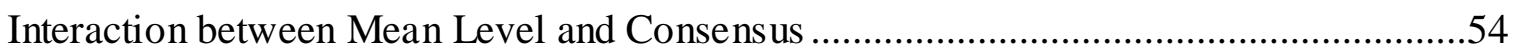

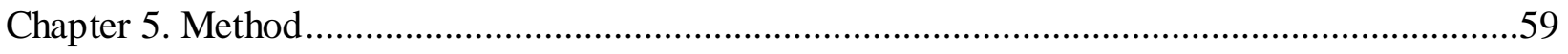

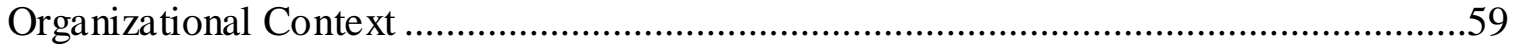

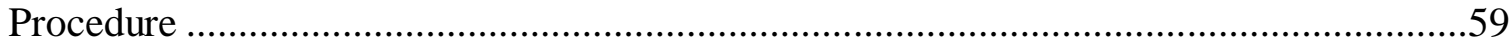

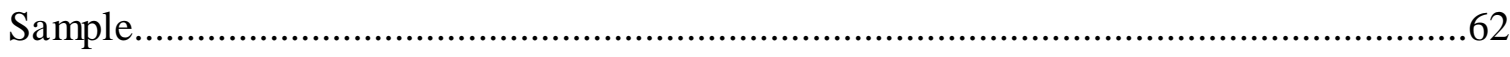

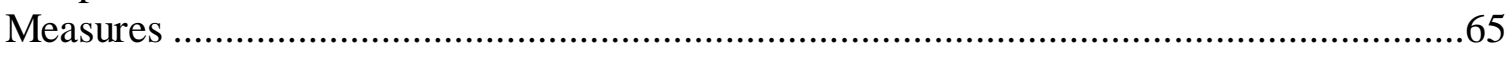

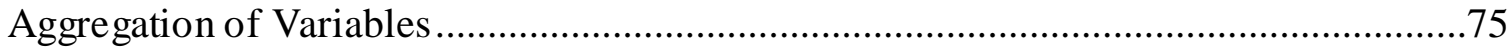

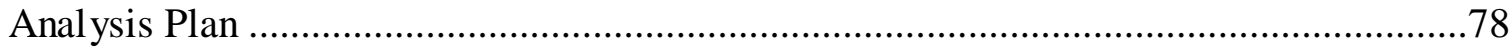

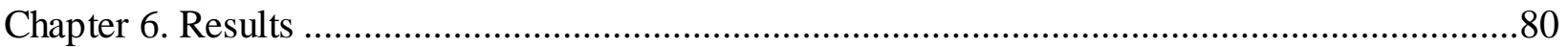

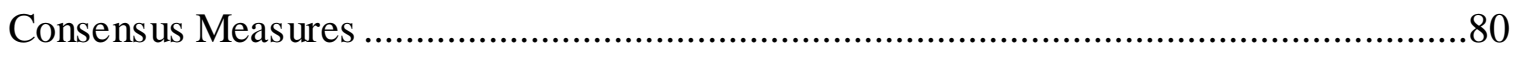

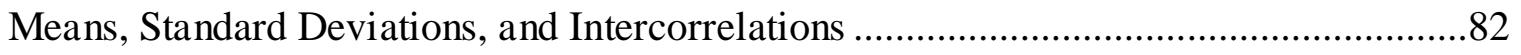

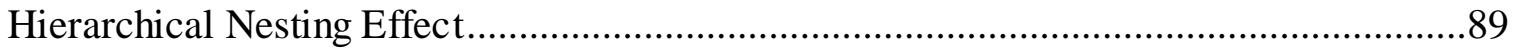

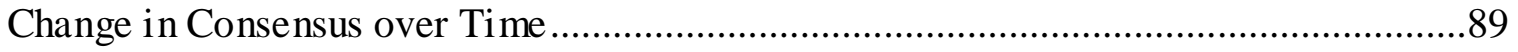

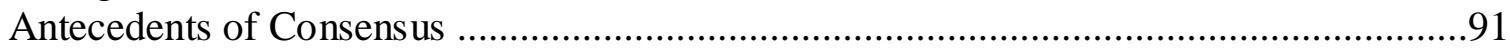

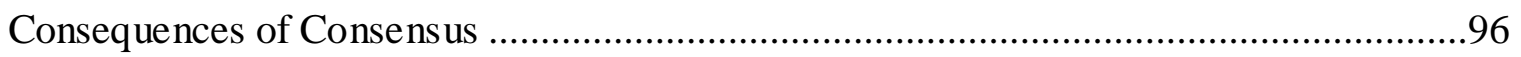

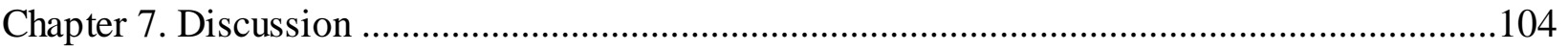

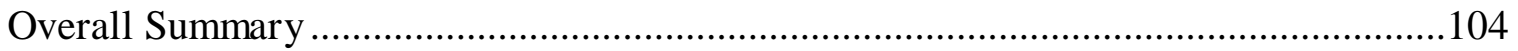

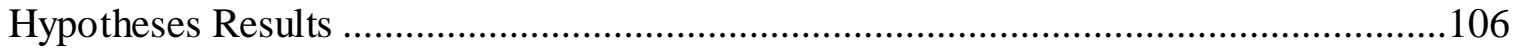

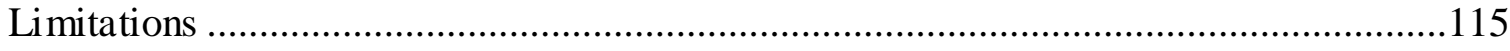

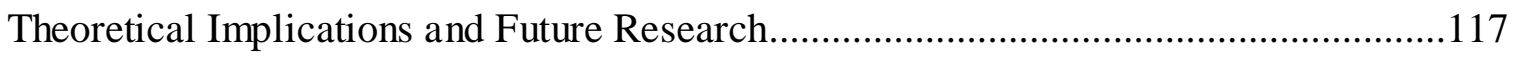

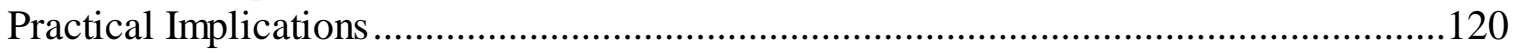

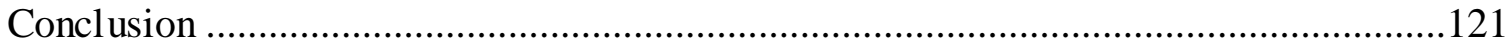

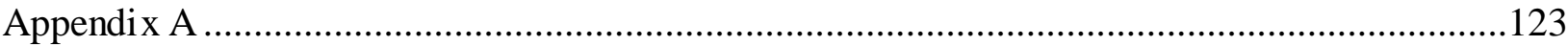

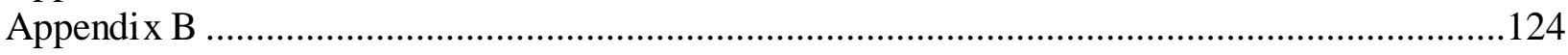

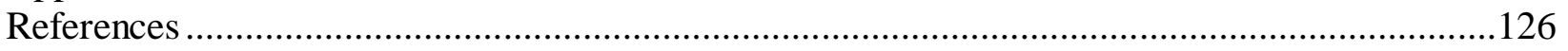




\section{LIST OF TABLES}

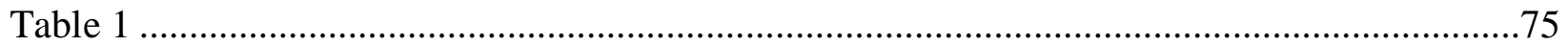

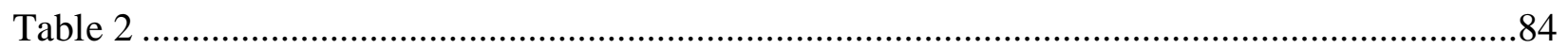

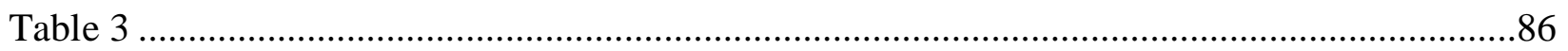

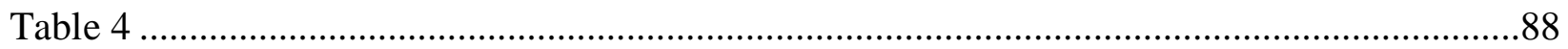

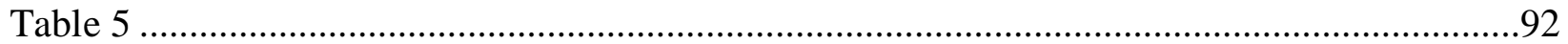

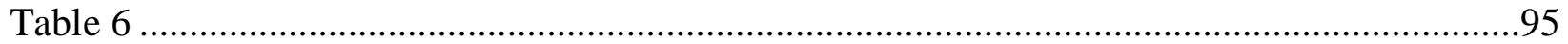

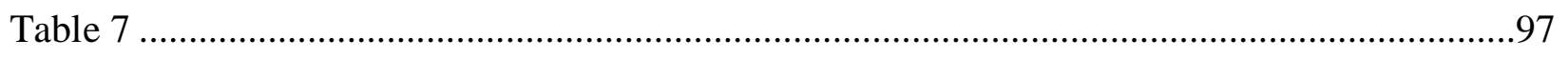

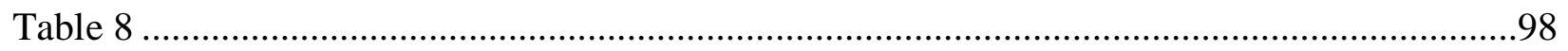




\section{LIST OF FIGURES}

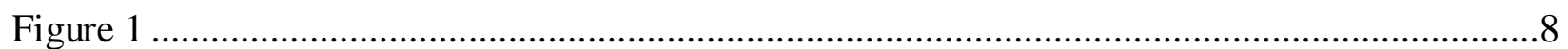

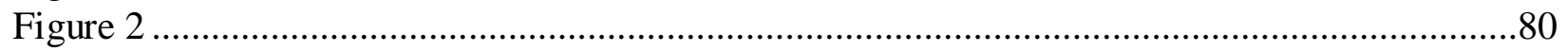

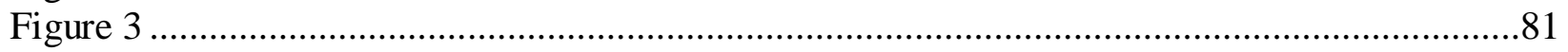

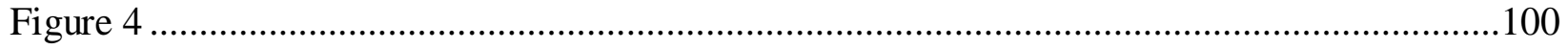

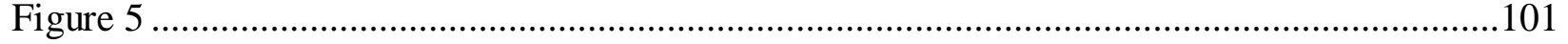




\title{
Chapter 1: Introduction and Research Overview
}

\author{
"In leadership, there are no words more important than trust. In any \\ organization, trust must be developed among every member of the team if \\ success is going to be achieved." \\ -Mike Krzyzewski, Coach of the Duke Blue Devils for four NCAA \\ Championships
}

It has long been recognized that leaders play a critical role in team and organizational functioning as well as in influencing employee attitudes and behaviors (e.g., Burke, Stagl, Klein, Goodwin, Salas, \& Halpin, 2006; Dalton, Daily, Ellstrand, \& Johnson, 1998; Dirks \& Ferrin, 2002; Podsakoff, MacKenzie, \& Bommer, 1996). At the same time, interest in delineating the role of trust in organizations has continued to grow (Fulmer \& Gelfand, 2012). While many styles and behaviors of leadership have been investigated in relation to outcomes in organizations, there has been an increasing emphasis on understanding the importance of trust in leaders, defined as a psychological state of a follower comprising willingness to accept vul nerability based on positive expectations of a leader (Dirks \& Ferrin, 2002; Fulmer \& Gelfand, 2012; Rousseau, Sitkin, Burt, \& Camerer, 1998). Trust in leaders has received attention from researchers and practitioners alike because it is fundamental to the relationships between employees and their leaders, with implications for important employee outcomes. Employee trust in leaders has been shown to relate to a wide range of individual-level outcomes including job satisfaction (Gillespie \& Mann, 2004; Whitener, 2001), organizational commitment 
(Pillai, Schriesheim, \& Williams, 1999), citizenship behavior (Mayer \& Gavin, 2005), and task performance (Aryee, Budhwar, \& Chen, 2002; Colquitt, Scott, \& LePine, 2007).

The research on trust in leaders has, for the most part, focused on the individual level of analysis. Little work has been conducted on collective team-level trust in leaders, defined as a shared psychological state among team members comprising willingness to accept vulnerability based on positive expectations of a team leader (Fulmer \& Gelfand, 2012). Moving research from the individual level to the team level should have important implications because organizations increasingly use teams to structure work activities (Kozlowski \& Ilgen, 2006) in order to stay adaptive in today's dynamic business environment (Hong, 1999). The small number of extant studies on collective team-level trust in leaders points to its important role in influencing team or unit outcomes, such as performance, sales, and profits (Davis, Schoorman, Mayer, \& Tan, 2000; Dirks, 2000; Simons \& McLean-Parks, 2002). However, research to date has largely ignored how collective team trust in leaders emerges and operates. The primary purpose of this research is to investigate factors related to the convergence in trust in the leader among team members after a change in leadership.

An emergent construct is one that resides in the cognitions, perceptions, feelings, or attitudes of individuals, but when individuals within a unit converge or develop consensus in this construct, a higher-level form of the construct emerges (Kozlowski \& Klein, 2000). Dansereau, Yammarino, and Kohles (1999) suggest that emergent constructs can shift their levels of analysis over time. For example, a construct can primarily exist at the individual level until a change in the context or the actors spurs convergence in perceptions, beliefs, or responses among individuals that allow the 
construct to emerge at a higher level. For trust in leaders, when a new team leader is appointed, it is unlikely that team members will share the same degrees of trust in the leader immediately. In other words, the consensus in trust in the leader should be initially low and team members are likely to have idiosyncratic levels of trust in the leader. After the introduction of a new leader, processes will need to occur to allow members to converge in their levels of trust in the new leader. Through interactions and other experiences with the new leader, a common level of trust in the new leader can develop among team members to create a collective construct of team-level trust in the leader.

Emergence of a collective construct thus implies that some degree of consensus among individuals must occur (Kozlowski \& Chao, in press). Studies in other content areas have begun to explore factors contributing to emergence and consensus, particularly with respect to climate perceptions (Ostroff, Kinicki, \& Muhammad, 2012). For example, Zohar and Tenne-Gazit (2008) found that transformational leadership and group network characteristics (density and centralization) were related to the degree of similarity in safety climate perceptions at the unit level. Naumann and Bennett (2000) found that work group cohesion and leader visibility were related to greater consensus in members' perceptions of procedural justice. While there is some research showing that various factors are related to the degree of similarity or consensus among group members for a particular construct, research on emergent processes remains scant (Kozlowski \& Chao, in press). A number of mechanisms have been proposed to facilitate the emergence of collective constructs, including structure, leadership, homogeneity, communication and social interactions, and team processes (Ostroff et al., 2012). However, some mechanisms are likely to be more important for the emergence of a given construct than for other 
constructs (Kozlowski \& Chao, in press). To the extent that collective trust in leaders can facilitate important aspects of team functioning and bottom line outcomes (e.g., Davis et al., 2000; Dirks, 2009), understanding what prompts team members to form consens us and agree on their levels of trust in the leader should be both theoretically and practically important. Theoretically, understanding the relative importance of different processes that contribute to the formation of collective trust in leaders will further our knowledge about how individuals' levels of trust in a leader come to be shared. Practically, insights from such a study may provide leaders with important information about how to foster collective trust and potentially enhance team outcomes through collective trust.

To elucidate which factors are likely to be the key for developing the consens us in trust in leaders, the concept of event cycles (Morgeson \& Hofmann, 1999) and the principle of compatibility (Ajzen, 1988; Fishbein \& Ajzen, 1974) are relevant. An event cycle refers to a sequence of interactions that is "the basic building block upon which all larger collective structures are composed" (Morgeson \& Hofmann, 1999, p. 252). Event cycles are crucial to emergence because repeated interactions give rise to regularized and consistent routines and practices that can be shared collectively (Hofmann \& Jones, 2005). In the trust literature, leadership variables, particularly those related to the trustworthiness dimensions of ability, integrity, and benevolence or concern (Mayer, Davis, \& Schoorman, 1995), have been deemed as important antecedents of trust (Colquitt et al., 2007; Fulmer \& Gelfand, 2012). However, not all of these variables are important for understanding consens us or how team members come to share a similar level of trust in their leader because some of them, such as the leader attributes of ability and integrity, do not directly entail interactions with the leader. For the emergence of 
team trust in leaders, leader behaviors and interactions between the leader and team members are likely to be particularly important because trust has a strong relational component (Nooteboom, Berger, \& Noorderhaven, 1997; Tyler \& DeGoey, 1996). Leader behaviors that involve interactions and shared experiences with the leader are likely to attract the attention of all team members and should afford members opportunities to interact with the leader and coalesce around a common view of the leader. Using the concept of event cycles, I propose that leader behaviors and interactions, such as showing concern, leading by example, and monitoring, will exert a stronger influence on the consensus in team members' trust in the leader than leader attributes, such as ability and integrity.

In addition, the target of the emergent process should likewise be considered. Ajzen's (1988) principle of compatibility posits that the relationship between a predictor and an outcome of the same target, action, time, or context will be stronger than a relationship between a predictor and an outcome that are mismatched on one or more of these dimensions. This suggests that when the "target" of a collective construct is narrow and specific and refers to an individual, such as a leader, the factors that contribute to emergence should also be narrow and specific and have the same target: in this case, the leader. Trust can have multiple targets or referents such as trust in the leader or trust in the team (Fulmer \& Gelfand, 2012). For the development of consens us in trust in leaders, leader behaviors and interactions with leaders should be more critical than processes that are more general or primarily involve team members, such as team open communication and team demographic diversity. Taken together, based on the concept of event cycles and the principle of compatibility, leader behaviors that afford interactions with the 
leader, as opposed to leader attributes or general interactions among team members, should act as the primary vehicles that give rise to the emergence of collective trust in the leader among team members.

Beyond the emergent processes for trust in leaders, research is likewise needed to examine the outcomes of consensus in trust in leaders. The implications of unit-level consensus (or dispersion) has been examined in a growing range of content areas, including climate (Lindell \& Brandt, 2000), conflict (Jehn, Rispens, \& Thatcher, 2010), justice (Colquitt, Noe, \& Jackson, 2002), satisfaction (Dineen, Noe, Shaw, Duffy, \& Wiethoff, 2007), temporal orientations (Mohammed \& Nadkarni, 2011), and leadership perceptions (Wu, Tsui, \& Kinicki, 2010), showing either that the degree of consensus in perceptions or attributes is related to outcomes or that the degree of consensus interacts with the mean, aggregate level of the focal collective construct to influence outcomes. Research on trust has yet to explore the consequences of the degree of consensus in trust in leaders. Festinger's (1950) social infl uence theory suggests that members in a team value consensus with each other and that shared attitudes should lead to positive psychological effects on the team members. Thus, the degree of consensus itself, regardless of whether the level of team trust in the leader is high or low, reflects some coalescence among team members that should impact collective responses such as team performance and team voice behavior.

Moreover, following work in other areas (Cole, Bedeian, \& Bruch, 2011; Lindell \& Brandt, 2000), it is likely that the degree of consensus in trust in leaders and the mean level of trust in leaders interact in their relationship with team outcomes. The degree of consensus reflects only the extent to which members have similar levels of trust in the 
leader, not whether the mean level of trust is high or low. Thus, considering these two effects (the degree of consensus and the level of trust in leaders) jointly should yield more refined results and interpretations. In particular, consensus may serve as a boundary condition for the effect of a team's mean level of trust in leaders on team performance and team voice behavior.

Finally, the extant research on emergence and consensus is largely cross-sectional (Kozlowski, 2012). Given that emergence is an inherently dynamic phenomenon (Kozlowski \& Klein, 2000), research that examines changes in consensus across time is needed. Accordingly, this study focuses on consens us assessed concurrently with emergent factors and outcomes, which provides insight into the factors that relate to higher degrees of consensus. This study also examines consensus assessed shortly after the introduction of a new leader and again several months later, which allows focusing on changes in consens us and the emergence of consensus. A comparison of the relationships that involve these two forms of consensus can potentially afford further understanding about the dynamic nature of the emergence of collective trust in leaders.

The theoretical model of this study is presented in Figure 1, illustrating the antecedent and outcome relationships with consensus in trust in leaders discussed above. Specifically, the leader behaviors of leader showing concern, leading by example, and monitoring are expected to have a stronger influence on the emer gence and consensus in trust in leaders than the leader attributes of ability and integrity and team variables of open communication and demographic diversity. Moreover, the degree of consensus and changes in consensus in trust in leaders are predicted to affect team performance and 
team voice behavior independently and interact with the mean aggregate level of trust in leaders in influencing these outcomes.

Figure 1

Theoretical Model of the Study

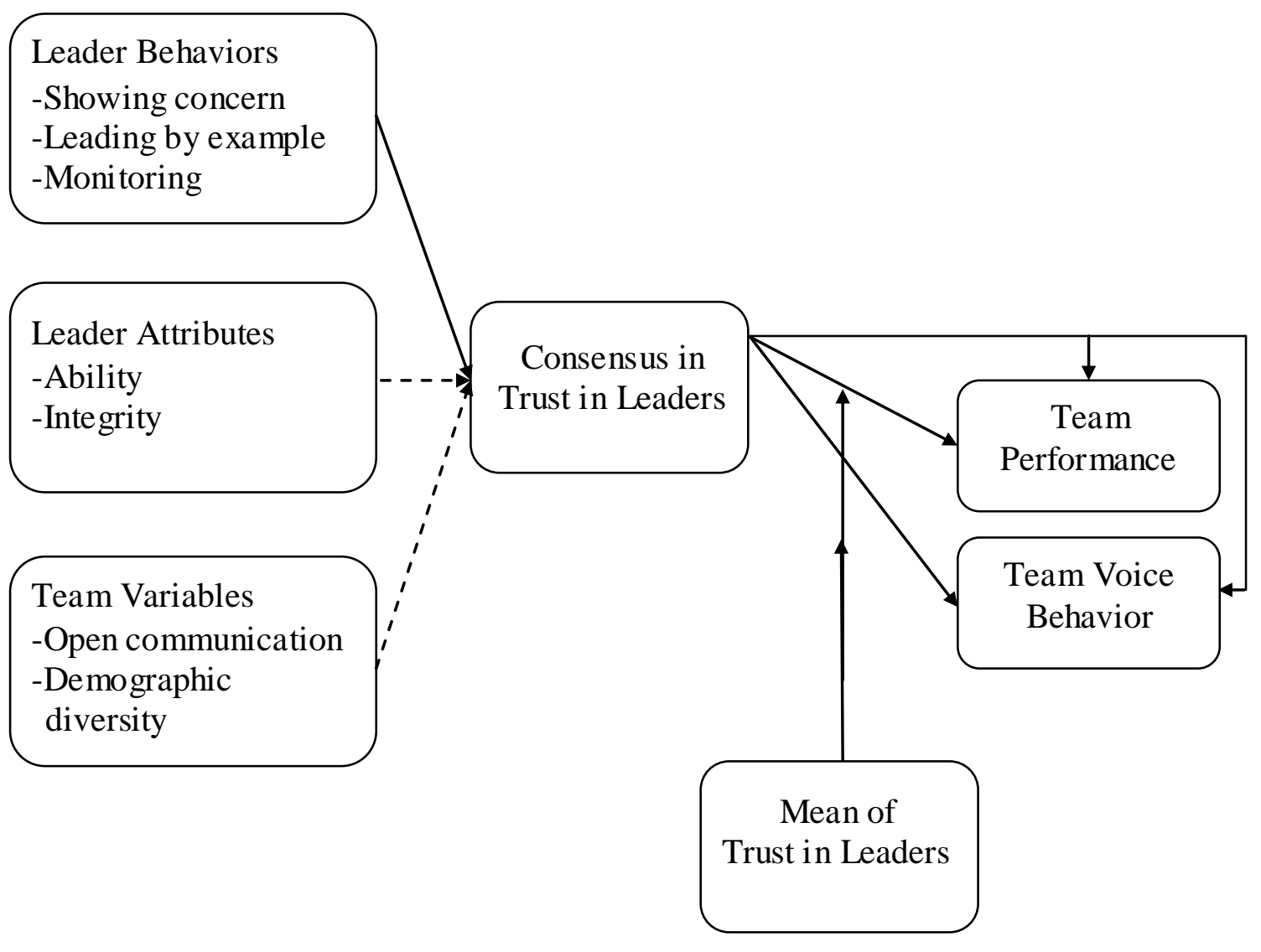

$\longrightarrow$ Expected positive relationship

-... Expected weak relationship

In sum, the overarching goal of this study is to better understand consens us in trust in leaders at the team level and its emergence. This objective is achieved through three distinct but related components. First, I examine how consensus in trust in leaders changes after the introduction of a new leader. Second, I compare and contrast a range of 
emergent processes for the degree of consensus and changes in consensus in trust in leaders with the aim of demonstrating that emergent processes are specific to the collective construct that they influence. Third, the consequences of the degree of consensus and changes in consensus in trust in the leaders are examined. Together, these three research components should afford a greater understanding of how team trust in leaders emerges, which thus far has been neglected in the literature.

This study has the potential to make several contributions to the trust research literature. Understanding why team trust in leaders emerges in some teams but not others can inform theoretical development and future research on collective trust. Unlike the preponderance of research that treats variation in levels of trust among unit members as error, the focus of this research on consensus provides an alternative way to understand trust in leaders at the unit level. Without considering the degree of consensus, researchers ignore a potentially influential team context that may affect team outcomes (Bliese \& Britt, 2001; Bliese \& Halverson, 1998) and that may interact with the effect of the mean level of team trust in leaders.

The present study also contributes to the levels of analysis literature with respect to emergence. The number of studies that have examined emergence of unit-level constructs remains small (Kozlowski \& Chao, in press; Ostroff et al., 2012). Research on the mechanisms responsible for emergent states in teams is therefore at the nascent stage and researchers have yet to explore emergence within the context of trust. While the concept of emergence is applicable to many constructs, the specific processes involved are likely to differ depending on the construct of interest (Kozlowski \& Chao, in press). 
This research focuses on consensus in trust in leaders using a levels of analysis approach to reveal the emergent processes that are specific to team trust in leaders.

The organization of the rest of this dissertation is as follows. In the next chapter (Chapter 2), I review the current research on trust in leaders at the individual level and the team level. This is followed by Chapter 3, in which I discuss the notion of emergence in the levels of analysis literature and review research that has examined various emergent processes. In Chapter 4 I further delineate the theoretical model of the present research (see Figure 1) and explain the rationale behind the proposed relationships among emergent processes, consensus in trust in leaders, and team outcomes. Hypotheses are also presented. I next detail the methodology of the present research in Chapter 5, including the organizational context, procedure, sample, and measures. Results are then presented in Chapter 6, and in Chapter 7, I discuss the findings and address the limitations and implications of the present research, and provide recommendations for future research. 


\section{Chapter 2. Theory and Research on Trust in Leaders}

In this chapter, I first review the literature on trust in leaders at the individual level, followed by a discussion of the extant research on trust in leaders at the team level. Before beginning this review, the definition of trust in leaders at both levels of analysis is provided.

\section{Definition of Trust in Leaders}

Specifying the definition of trust in leaders is particularly important given the diversity in the conceptualizations of trust (cf. Castaldo, Premazzi, \& Zerbini, 2010; Dietz \& Den Hartog, 2006; McKni ght, Choudhury, \& Kacmar, 2002; Romano, 2003; Tschannen-Moran \& Hoy, 2000). While many of the definitions do not explicitly identify who the trustee is, such as a leader, team, and partner, others have included a specific referent in their definitions. When the trust referent is a leader, which is the focal target of present research, a range of definitions have been offered. Appendix A presents a sample of these definitions at both the individual and team levels of analysis.

It can be seen in Appendix A that, while trust is a complex construct, many view it as a psychological state (Hardin, 2001; Lewis \& Weigert, 1985; Luhmann, 1979; Kramer, 1999; Rempel, Holmes, \& Zanna, 1985; Wright \& Ehnert, 2010). For example, one commonly adopted definition in or gani zational sciences is that of Mayer and his colleagues (1995), who define trust as "the willingness of a party to be vulnerable to the actions of another party based on the expectation that the other will perform a particular action important to the trustor, irrespective of the ability to monitor or control that other party" (p. 712). Rousseau and her colleagues (1998) similarly define trust as "a psychological state comprising the intention to accept vulnerability based upon positive 
expectations of the intentions or behavior of another" (p.395). Both of these definitions refer to trust as a psychological state. Other examples include Dirks (2000), Oreg and Sverdlik (2011), and Van Dijke, De Cremer, and Mayer (2010).

In addition to trust being a psychological state, other commonalities can be noted in the existing definitions. Many researchers agree that positive expectations of trustworthiness (which refers to the expectation about the positive intentions of the trustee and that the trustee can be relied upon) and willingness to accept vulnerability (which refers to the trustor's intention to rely on the trustee) are key features in defining the construct of trust (e.g., Dietz \& Den Hartog, 2006; Ferrin, Bligh, \& Kohles, 2008; Huff \& Kelley, 2003). Consistent with these perspectives, I adapt the trust definition provided by Fulmer and Gelfand (2012) in this research. Trust in leaders at the individual level refers to a psychological state of a follower comprising willingness to accept vulnerability based on positive expectations of a leader.

Because trust at higher levels is conceptualized as a shared construct held among unit members (e.g., De Jong \& Elfring, 2010), collective trust in leaders at the team level refers to a shared psychological state among team members comprising willingness to accept vulnerability based on positive expectations of a leader. Trust arises from a dyadic relationship between two parties — a trustor and a trustee — such as a leader and a follower, and reflects the quality and characteristics of the relationship between the two parties (Bower et al., 2000; Hosmer, 1995; Mayer et al., 1995). Trust from dyadic relationships can come to be shared among individuals in a unit when the individuals have similar levels of trust in a focal person, such as when members in a team have comparable levels of trust in their leader. In other words, the construct of trust resides at 
the individual level and becomes "shared" in a team as a collective construct when the team leader develops a similar level of trust with each member in a team.

\section{Trust in Leaders at the Individual Level}

Both the antecedents and outcomes of individuals' level of trust in their leaders have been widely examined (Fulmer \& Gelfand, 2012). Regarding antecedents of individuals' trust in leaders, some research has examined the roles of organizational context and follower characteristics. For example, perceived organizational support has been found to be a strong predictor of trust in leaders (Dirks \& Ferrin, 2002; Whitener, 2001). Individual differences, such as a secure attachment style (Simmons, Gooty, Nelson, \& Little, 2009) and propensity to trust (Dirks \& Ferrin, 2002; Colquitt et al., 2007) have been positively related to a higher level of trust in leaders at the individual level. Followers' identification with leaders has also been positively related to individuals' trust in leaders (Gillespie \& Mann, 2004).

However, the majority of research on individuals' trust in leaders has focused on leadership styles as the antecedents. For example, research has shown that various leadership styles, including transformational leadership (Jung \& Avolio, 2000; Jung, Yammarino, \& Lee, 2009), transactional leadership (Jung \& Avolio, 2000), operant leadership (Rubin, Bommer, \& Bachrach, 2010), charis matic leadership (Conger, Kanungo, \& Menon, 2000), authentic leadership (Avolio, Gardner, Walumbwa, Luthans, \& May, 2004), servant leadership (Van Dierendonck, 2011), empowering leadership (Caldwell \& Dixon, 2010), and ethical leadership (Brown, Treviño, \& Harrison, 2005; Kalshoven, Den Hartog, \& De Hoogh, 2011) have been positively linked to individuals' trust in their leaders. 
The most common framework for delineating leader characteristics as antecedents of individuals' trust in leader is based on Mayer and his colleagues' (1995) three dimensions of trustworthiness - ability, benevolence, and integrity (e.g., Colquitt et al., 2007). To the extent that followers perceive leaders to possess these characteristics, their trust in the leaders should be higher (Dirks \& Ferrin, 2002). For example, leaders' ability to communicate a collective vision has been linked to higher levels of individuals' trust in leaders (Gillespie \& Mann, 2004). Other skills and competencies related to performance have also been posited to influence individuals' trust in leaders (Bower, Schoorman, \& Tan, 2000). Likewise, leaders' benevolence toward followers, as indicated by providing individualized support and showing concern, has been related to individuals' trust in leaders (Hernandez, 2008; Korsgaard, Brodt, \& Whitener, 2002; Podsakoff et al., 1996; Roussin, 2008). Lastly, leader's integrity, signaled by upholding justice principles, using participative decision-making, maintaining word-deed consistency, and providing an appropriate role model, has also been found to be a key factor in individuals' trust in their leaders (Ambrose \& Schminke, 2003; Aryee et al., 2002; Gillespie \& Mann, 2004; Huang, Iun, Liu, \& Gong, 2010; Korsgaard, Schweiger, Sapienza, 1995; Palanski \& Yammarino, 2009; Simons, 2002). Unmet expectations, which signal a breach to integrity, have been found to lower individuals' trust in leaders (Dirks \& Ferrin, 2002). Among the outcomes of individuals' trust in leaders, job attitudes, organizational citizenship behavior (OCB), and performance have received the most research attention (Fulmer \& Gelfand, 2012). Researchers have found that trust in leaders is highly associated with individuals' organizational commitment, job satisfaction, satisfaction with the leader, and ratings of leadership effectiveness (Dirks \& Ferrin, 2002; Gillespie \& 
Mann, 2004; Whitener, 2001). Further, individuals' trust in leaders also increases belief in information from the leader and support for leader decisions (Dirks \& Ferrin, 2002), even in the face of unfavorable outcomes (Brockner, Siegel, Daly, Tyler, \& Martin, 1997). Individuals' trust in leaders has also been consistently related to OCB (Colquitt et al., 2007; Dirks \& Ferrin, 2002). However, the overall results for in-role performance have been weak and inconsistent (cf. Dirks \& Ferrin, 2002; Mayer \& Gavin, 2005;

Palanski \& Yammarino, 2011; Yang \& Mossholder, 2010).

\section{Trust in Leaders at the Team Level}

In their seminal review, Mayer and his colleagues (1995) identified trust at the team level as the next direction for the research on trust. In this study, I adopted the definition of teams by Guzzo and Dickson (1996) to be "a work group [that] is made up of individuals who see themselves and who are seen by others as a social entity, who are interdependent because of the tasks they perform as members of a group, who are embedded in one or more larger social systems (e.g. community, organization), and who perform tasks that affect others (such as customers or coworkers)" (p. 308-309).

As with other research that increasingly views leadership as a team-level construct (e.g., Bass, Avolio, Jung, \& Berson, 2003; Cole et al., 2011), a small number of studies have examined trust in leaders at the team level of analysis, focusing on the mean level of team trust in leaders. Research on factors that foster a team's mean level of trust in leaders is particularly limited (Fulmer \& Gelfand, 2012). One recent study examined the relationships between different styles of leadership and different forms of team trust in leaders (Schaubroeck, Lam, \& Peng, 2011), showing that servant leadership was related to team level affective trust in leaders while transformational leadership was 
related to team level cognitive trust in leaders (Schaubroeck et al., 2011). The authors suggest that because transformational leadership generally focuses on task-related processes, it should be related to members' trust in the leader's performance-relevant cognition, which can include competence and knowledge, whereas because servant leadership focuses on relational processes with and among team members, it should be related to members' trust in the leader's "genuine care and concern for [their] welfare" (McAllister, 1995, p. 26),.

Slightly more research has examined the outcomes of units' mean levels of trust in leaders, focusing primarily on the unit-level bottom-line outcomes (e.g., Davis et al., 2000; Dirks, 2000; Simons \& McLean-Parks, 2002). Dirks (2000) found that team members' trust in their leaders was a stronger predictor of team performance than members' trust in their other team members. The author suggests that team trust in leaders "allows the team to be willing to accept the leader's activities, goals, and decisions and work hard to achieve them" (p.1005). A unit's level of trust in the leader has also been shown to have a positive effect on the unit's sales and profits and a negative effect on turnover because, presumably, the unit members' trust in the leader prompts the members to be committed to the leader and the unit success (Davis et al., 2000). Likewise, collective trust in leaders among unit members has been positively related to customer satisfaction and profitability (Simons \& McLean-Parks, 2002). Research on outcomes of trust at the team level other than effectiveness indicators has been lacking. 


\section{Summary}

The brief review above reveals that the research on trust in leaders at the individual level has flourished, while the research on team trust in leaders remains limited. Burke, Sims, Lazzarra, and Salas (2007) called for research to explicate the relationship among team trust in leaders, leadership, and team performance. A study by Schaubroeck and his colleagues (2011) provides one of the first efforts to examine these relationships, showing that the relationships between servant and transformational leadership and team performance are partially mediated by teams' aggregate level of trust in their leaders.

Research has not considered the role of consensus in trust in leaders on team outcomes. Likewise, the existing research has ignored the processes through which trust in leaders emerges as a team-level construct that becomes shared across team members. Exploring emergent processes and focusing on the leader behaviors that help to de velop consensus should yield important insights into the formation of collective trust in leaders. This is important because when team members do not possess similar levels of trust in their leader, each team member has an idiosyncratic trust level and a collectively shared team trust does not emerge. In this case, the construct only resides at the individual level of analysis (Ostroff \& Bowen, 2000). In contrast, when team members have sufficient consensus in their trust in a leader, the shared construct becomes meaningful at the team level and can exert its impact on team outcomes. By taking consensus in trust in leaders into account in the examination of team outcomes, additional insight into the link between trust in leaders and team outcomes can be gleaned. 
Having briefly reviewed the state of the literature on trust in leaders at the individual and team levels, in the next chapter (Chapter 3), I turn to the research and theory on the emergence of unit-level constructs. An overarching goal of the present research is to show that incorporating concepts from the levels of analysis literature, with a focus on emergence, can help inform and broaden the research on trust in leaders at the team level. 


\section{Chapter 3. Theory and Research on Emergence}

Levels of analysis is a framework for examining organizational phenomena that are inherently nested within hierarchical levels (Klein, Dansereau, \& Hall, 1994). The level of analysis refers to the focal unit for theory, measurement, analyses, and interpretation of results (Morgeson \& Hofmann, 1999; Rousseau, 1985). Incorporating the levels of analysis framework is useful because the focus of this study is on the mechanisms through which individual team members' trust in their leader comes to be shared so that a collective construct of team trust in leaders emerges at the team level. In this review, I discuss two issues from the levels approach: 1) the meaning of collective constructs and their consens us and 2) the emergence of collective constructs.

\section{Collective Constructs and Consensus}

Many constructs in organizational science exhibit emergent group effects, meaning that the construct at the higher level represents more than the sum of its parts at the lower level and can explain variance above and beyond that attributable to the lower level (Kozlowski \& Klein, 2000). Although collective constructs can take a wide range of forms (e.g., Kozlowski \& Klein, 2000; Chan, 1998), Goldstein (1999) noted five characteristics:

1) radical novelty (collective constructs have features that are not observed from their lower components);

2) coherence or correlation (collective constructs are integrated wholes that can maintain themselves);

3) global or macro level (collective constructs reside at a higher level than their components); 
4) dynamical (collective constructs emerge over time as the system involves); and

5) ostensive (collective constructs are observable).

Moreover, some collective constructs have different relationships with other variables than their lower-level counterparts. Collective constructs can have different relationships with outcomes at the higher level than the analogous relationships at the lower-level. For example, Ostroff (1992) found that unit-level satisfaction had a positive relationship with unit-level performance, even though past research consistently indicates that the relationship at the individual level was weak. Even when the constructs at the higher and lower levels have similar functions, their underlying structures, or the way through which they lead to the outcomes, may differ (Morgeson \& Hofmann, 1999). Further, collective constructs have been shown to affect lower-level outcomes above and beyond the effects of the analogous lower-level constructs (Schulte, Ostroff \& Kinicki, 2006; Spell \& Arnold, 2007).

While some constructs exist at higher level and can be assessed at that level through a single measurement at the higher level, many other constructs reside in individuals' cognition, beliefs, behaviors, or attitudes such as perceptions of climate, feelings of commitment, or attributions about a leader. Trust as a psychological state resides within individuals. The level of measurement for such constructs starts with individuals. The individual-level measurements are then aggregated to the higher level to represent that construct at the higher level.

In understanding aggregated, higher level constructs, a distinction between the mean level and consensus has been made (e.g., Lindell \& Brand, 2000; Schneider, 
Salvaggio, \& Subirats, 2002). Lindell and Brandt (2000) explicate that the mean level can be understood as "the proximity of the group mean to the positive endpoint of the response scale" (p.333). That is, the mean reflects how "high" or "low" the aggregate score is. Consensus refers to the dispersion in group members' scores around the mean (Chan, 1998; Lindell \& Brandt, 2000). For purposes in this study, the mean level represents the collective level of members' trust in their leader or how much members collectively trust their leader. Consens us represents the degree of variability or dispersion across members in their levels of trust in the leader, with low variability indicating higher consensus.

Aggregated, higher level constructs can be compositional, meaning that there is a functional relationship between the higher level construct and its lower level counterpart, both of which refer to the same content (Chan, 1998). In this research, team trust in leaders is compositional because its definition specifies that trust in a leader resides in individual team members but it becomes a collective construct when team members agree on the levels of trust in their leader. Here, the agreement or the consens us among team members represents the form of the functional relationship between the individual and team level of trust in leaders, or the type of combinational process "by which the lower level construct is combined to form a higher level construct" (Chan, 1998, p. 235). Other key study variables, such as perceptions of leader attributes and behaviors, are also compositional because the perceptions of the leader originate from individuals and become team-level constructs when the perceptions are shared among team members. Composition models that entail the level of construct (e.g., level of trust) can take several forms - additive, direct consensus, and referent shift (Chan, 1998). In the additive model, 
the mean level of collective constructs is meaningful regardless of the extent to which members share the lower-level construct. In other words, consens us or agreement is not a requirement for aggregated scores to represent a higher level construct in the additive model. Because the definitions of all collective constructs specify consens us in the present research, this model is not applicable in this study.

Direct consens us models are predicated on the assumption that individuals within a unit share similar perceptions, attributes, feelings, or cognitions. That is, the direct consensus model considers the aggregated, collective construct to be meaningful only when there is sufficient consensus among the unit members on the analogous lower level construct (Chan, 1998). In this study, for the level of team trust in leaders, the direct consensus model is the most appropriate because trust in leaders resides at the individual level and, when the levels among members are sufficiently similar, individuals' trust gives rise to team level, collective trust. Likewise, given that team level leader attributes and behaviors involves shared attributions about the leader across team members, a direct consensus model would be the appropriate compositional model for those constructs.

Another compositional model suitable for the examination of the aggregate level of a collective construct is the referent shift consensus model (Chan, 1998). It is similar to the direct consensus model in that it requires similar responses among unit members, but the referent for the items refers to the unit as a whole instead of the individual. In this study, team open communication assumes the referent-shift consens us model because the definition of the construct is directed toward the team itself and focuses on the extent to which team members as a group openly communicates with one another. In other words, 
since team communication only exists at the tea m level a referent shift model is more appropriate than a direct consens us model.

As can be seen in the above discussion, demonstrating consensus is necessary to justify aggregation in both direct consensus and referent-shift consens us models.

Consensus is represented by the within-unit agreement among members. When consensus is too low, the collective construct loses its shared meaning as members have dissimilar levels on the lower level construct (Klein, Cohn, Smith, \& Sorra, 2001). In this case, the collective construct does not exit and only idiosyncratic levels of the lower construct can be related to individual outcomes (Ostroff \& Bowen, 2000). Even when sufficient consensus to justify aggregation is demonstrated, some within-unit variation among members typically exists (Bliese \& Halverson, 1998; Chan, 1998; Zohar \& Luria, 2004). The extent of consensus can represent something meaningful about the unit and should be considered explicitly in organi zational research (Schneider et al., 2002).

While additive, direct consens us, and referent shift composition models pertain to the aggregate level (or the mean level) of collective constructs, dispersion models are concerned with the degree of consensus in the higher level construct. In dispersion models, the variable of interest is the extent to which members share similar levels of a lower level construct, or the degree of agreement on the lower level construct among unit members. Unlike the direct and referent-shift consens us models, a dispersion model focuses on differences in the amount of consens us between units, rather than differences in the mean levels between units. In the context of trust, some prior studies have shown that team members do not always agree on their levels of trust as evidenced by statistics that indicate the degree of agreement (Colquitt, LePine, Zapata, \& Wild, 2011; De Jong 
\& Dirks, 2011; Gillespie, 2005). In the present research where consensus in trust in leaders concerns the similarity and differences in team members' individual levels of trust in leaders, the dispersion model is most appropriate.

The preponderance of studies at higher levels have focused on the level (or the aggregated mean) of the construct, rather than consensus. Only a small number of prior studies have examined both the mean level and consensus, such as in studies of organizational climate or leadership (e.g., Lindell \& Brandt, 2000; Dickson, Resick \& Hanges, 2006; Dawson, González-Romá, Davis, \& West, 2008; Cole et al., 2011). These studies demonstrate the utility of considering consensus as well as the mean level. . In the present research, team level of trust in leaders refers to the collective level of team members' trust in leaders, provided that there is some level of agreement to justify aggregation (a direct consensus model). Consens us in trust in leaders refers to the degree of agreement in team members' trust in leaders (a dispersion model). A key question is what leads to consensus, or how does a collective construct emerge (Kozlowski \& Chao, in press).

\section{Emergent Processes}

The development of a collective construct from the lower level to the higher level is termed emergence. Emergence has been characterized as "the arising of novel and coherent structures, patterns, and properties during the process of self-organization in complex systems" (Goldstein, 1999, p.49). Kozlowski and Klein (2000) similarly describe emergence as "how the dynamics and interactions of lower-level elements unfold over time to yield structure or collective phenomena at higher levels" (p.16). These authors further explain the process: 
...individuals in organizations do not exist in a vacuum. People in groups

and sub-units are exposed to common features, events, and processes.

They interact, sharing interpretations, which over time may converge on consensual views of the group (p. 10).

Both factors in the system and from the actors within the system can trigger the emergence of a collective construct (Dansereau et al., 1999). However, not all individual level constructs emerge to become higher level, collective construct. Individuals do not always experience the same reality or have similar interpretations of the same reality (Bruner, 1957; Carley \& Krackhardt, 1996, Moussavi \& Evans, 1993). Social cognitive and social information processing theories (Bandura, 2001; Salancik \& Pfeffer, 1978) also predict that individuals have unique perceptions stemming from their own cognitions and experiences. It stands to reason that, due to differences in the system and in the actors, some groups or units achieve a higher degree of consens us while in other groups or units, members fail to converge in their perceptions, cognitions, or feelings. Variance within a collective construct, therefore, is a meaningful construct that needs to be examined in its own right to understand factors that are related to more or less variance in a collective construct (Ostroff \& Fulmer, in press)..

In organizational science, research has examined the processes by which a construct that resides within individual members can combine to emerge as a collective phenomenon at the higher level (House, Rousseau, Thomas-Hunt, 1995; Rousseau, 1985). Emergent processes refer to factors that enable convergence so as to "combine and coalesce an individual-level construct to allow the collective construct to manifest" (Kozlowski \& Chao, in press). Broadly defined, emergent processes can be categorized 
into five groups: structure, leadership, homogeneity, communication and social interactions, and team processes. Within each group, research has identified a number of factors through which unit-level constructs can emerge (Ostroff et al., 2012). I review these accordingly.

Structure. In terms of structure, factors such as team size, HR practices, work interdependence, job routinization, and job formalization have been related to the emergence of unit-level constructs (Bowen \& Ostroff, 2004; Colquitt et al., 2002; Klein et al., 2001; Zohar \& Luria, 2005). These factors can influence and constrain the effects of other emergent processes and how the emergence takes shape (Kozlowski \& Chao, in press; Morgeson \& Hofmann, 1999). This notion is akin to Lewin’s (1951) field theory, which posits that individuals' behaviors are products of their personal characteristics and their environment. Emergence of a collective construct among lower-level units, in addition to being influenced by factors related to the construct, can be affected by broad, higher-level contextual and structural factors. However, research on structural variables as they relate to emergence has been limited and many studies have found weak effects (Ostroff et al., 2012).

Leadership. In contrast, both theory and research have shown that that leadership plays a key role in emergence. Researchers have long suggested that unit leaders help in instilling shared meanings among unit members (Likert, 1967; McGregor, 1960; Naumann \& Bennett, 2000; Smircich \& Morgan, 1982) and leaders help transform independent individuals into a unit of interdependent members (Dansereau et al., 1999). As such, leaders have been called engineers of unit perceptions (Naumann \& Bennett, 2000) or meaning managers (Rentsch, 1990) because they can facilitate shared mental 
models among team members (Marks, Zaccaro, \& Mathieu, 2000). Despite the recognition of the role of leadership in emergence, the specific mechanisms are not well understood (Ostroff et al., 2012). Leadership is fundamentally a social influence process (Uhl-Bien, 2006) that involves persuasion (Hogan, Curphy, \& Hogan, 1994) and communication of collective goals (Zaccaro, 2001). Indeed, leader informing behavior has been found to be related to team consensus in climate perceptions (González-Romá, Peiró, \& Tordera, 2002). Further, leaders often have the power to reward desired behaviors (Yukl, Wall, \& Lepsinger, 1990), which can be used to encourage members to develop collective goals, perceptions, and attitudes. Even when not actively promoting shared perceptions, leaders are constantly observed by team members. The visibility of the leader actions has been found to influence consens us in climate perceptions (Naumann \& Bennett, 2000). To the extent that leaders behave consistently across situations and people, team members are more likely to share their perceptions of the organizational climate (Zohar \& Luria, 2004).

Homogeneity. Homogeneity refers to similarity in attributes, either at a surface or deep level (Harrison, Price, \& Bell, 1998), among unit members. Surface level attributes refers to "overt, biological characteristics that are typically reflected in physical features" (p. 97); while deep level attributes refer to cognitions and emotions such as attitudes, values, and beliefs. Homogeneity is posited to influence consensus directly because people with similar attributes will be more likely to perceive the context in a similar manner, and indirectly because similarity enhances social interactions that can facilitate development of common views. These notions are founded in social categorization and identity theories (Tajfel \& Turner, 1979; Turner et al., 1987) and research on homophily 
and unit demography (Tsui, Egan, \& O’Reilly, 1992). In addition, Schneider and Reichers (1983) attribute the emergence of collective constructs largely to the attractionselection-attrition (ASA) process, which predicts that individuals gravitate toward, are selected by, and remain in organizations composed of similar others. Despite these theoretical propositions, studies examining the impact of homogeneity on consensus have yielded mixed results (e.g., Klein et al., 2001; Naumann \& Bennett, 2000; Roberson \& Colquitt, 2005).

Communication and social interactions. Communication and social interaction is another group of factor that has been posited to promote uniform perceptions and attitudes (Ashforth, 1985). Schneider and Reichers (1983) propose that climate consensus forms in a manner similar to the process through which newcomers learn the organizational meanings of a workplace. The process can be understood through the social information processing (SIP) theory (Salancik \& Pfeffer, 1978), which predicts that people rely on attitudes held by others to develop attitudes of their own, particularly when situations are novel or ambiguous. Communication and interactions among unit members thus provides opportunities for employees to check with one another about their attitudes and perceptions, which facilitates shared perceptions and attitudes as well as the emergence of collective constructs. Morgeson and Hofmann (1999) term the contacts, encounters, and interactions that ensue as "event cycles" and credit them to be the foundation for the emergence of collective constructs. Repeated over time, event cycles form a system of social structure that can enable the emergence of collective constructs.

Some empirical support lends credence to the importance of social interaction and communication. For example, using a social network perspective, Zohar and Tenne-Gazit 
(2008) supported the notion that network density (number of ties between people) and centralization influenced emergence of shared climate perceptions. Klein and her colleagues (2001) found that social interactions are positively related to group consensus. Using a network model, Newman, Hanges, Duan, and Ramesh (2008) showed that employee formal and informal communication networks influenced their consensus in organizational climate perceptions. Team interaction skills were also found to promote team consensus in the form of shared mental models about processes related to effective performance (Marks et al., 2000).

Team processes. Related to homogeneity and communication, team processes are another category that influences emergence. Units such as teams represent a social system (Katz \& Kahn, 1978) in which each member's perception is influenced heavily by the attitudes and behaviors of other members. Members in a team that experience the same environment should develop attitudes and perceptions that are more similar to one another than to those of individuals who belong to different teams. Supporting this notion, research has demonstrated that members of a work team share similar interpretations of organizational climate, events, and perceptions of organizational values (González-Romá et al., 2002; Rentsch, 1990). Moreover, as team members tend to share mental models (Marks et al., 2000) and action synchronization (Kozlowski \& Bell, 2003), collective perceptions, attitudes, and beliefs should be more likely to develop. Some empirical research has also examined the relationships between various team processes and emergence. For example, group cohesion has been found to be related to shared climate perceptions and shared justice perceptions (Luria, 2008; Naumann \& Bennett, 2000). 


\section{Summary}

The brief review above on emergence reveals that it is a complex process that transforms an individual-level construct to a collective construct. Five groups of factors have been identified to facilitate emergence of unit level constructs and the degree of consensus among unit members, including structure, leadership, homogeneity, communication and social interactions, and team processes. Despite the theory and research on these emergent processes, few studies have compared the effects of multiple processes on a given collective construct. Zohar and Tenne-Gazit (2008) showed that both transformational leadership and team member network independently influence the emergence of safety climate at the team level. González-Romá and his colleagues (2002) found that leader informing behavior was positively related to agreement on work unit innovation, support, and goal orientation climates, while member social interaction was positively related to agreement on goal orientation and climates. Both leadership and team dynamics have been deemed particularly important in facilitating emergence within teams (Cole \& Bedeian, 2007).

While a small number of studies have included multiple factors in examining emergence of a collective construct, research is lacking in the context of trust. For a given construct, some of the factors may be more important than the others (Kozlowski \& Chao, 2012), such that the set of factors differs across collective constructs. For example, the emergent processes important for a collective construct about a specific focal person, such as a leader, may be different from those important for a collective construct about a board context, such as organi zational climate. There have been calls for examining the relative importance of different factors of emergence (Ostroff et al., 2012). Below, I use 
the notions of event cycles (Morgeson \& Hoffman, 1999) and target compatibility (Ajzen, 1988) to propose the factors that should be more important for the consens us in trust in leaders. I focus on the effects of leader behaviors and interactions with team members, team demographic diversity, and team open communication on the emergence of team trust in leaders. Building on the literature reviewed on levels of analysis in this Chapter and trust in leaders in Chapter 2, in the next chapter (Chapter 4) I turn to the theoretical model of the present research and present the hypotheses of this research. 


\section{Chapter 4. Building Team Trust in Leaders: Theoretical Model and Hypotheses}

Organizations are inherently multilevel systems with dynamic interplay among different hierarchical levels, and organi zational science strives to grasp the complexities within organizations. Many constructs in organizational science reside at the individual level but can emerge to become a collective construct at higher levels. Despite the prevalence of these collective constructs, little is understood about how collective constructs emerge, when they emerge, and why they emerge. The lack of knowledge in this regard represents a major gap in understanding how organizations operate and function. Further, the majority of the extant research on emergence is cross-sectional (Kozlowski, 2012). Such research, while assuming emergence is fundamentally processoriented, nevertheless treats it as a static phenomenon (Kozlowski \& Chao, in press). To examine the dynamics of emergence, or how the emergence of a collective construct develops over time, research that examines both the degree of and changes in consens us would be helpful in shedding light on the dynamic nature of emergence. The present research aims to provide insight into these questions by focusing on the topic of trust in leaders.

Among the multitude of potential emergent factors, I focus on the factors related to leadership (leader behaviors and attributes) and social interactions (team communication and diversity) as both have been consistently posited to be key factors for emergence. Because interactions are considered critical for emergence (Kozlowski \& Klein, 2000; Morgeson \& Hoffman, 1999), emergent processes that involve behaviors and interactions should exert more influence on the emergence than other emergent factors, such as personal characteristics. At the same time, due to their hierarchical 
position and role, leaders are responsible for facilitating a wide range of group processes and play a key role in helping unit members make sense of their organizational context (Schein, 2010). Further, based on the principle of compatibility (Ajzen, 1988) as explained below, an emergent process that is matched to the target of the emergent construct should be more important than an emergent process with a mismatched target. For example, leader behaviors as emergent processes match the target of the collective construct of trust in leaders, while other factors such as team communication and team diversity do not. Together, this suggests that leader behaviors that entail interactions between the leader and team members should be most critical.

In this chapter, I provide the rationales for three sets of hypotheses. First, I focus on changes in consensus in trust in leaders over time (Hypotheses 1 and 2). Second, I delineate the effects for emergent processes of different content (leader attributes vs. leader behaviors and interactions) and different targets (leader vs. team) on the degree of consensus concurrent to the emergent factors and changes in consensus in trust in leaders (Hypotheses 2 and 3). Third, I explore the main effect of consensus in trust in leaders on team performance and team voice behavior, after taking into account the mean level, as well as the interactive effect between consensus and mean level of trust in leaders (Hypotheses 4, 5, 6, and 7).

\section{Changes in Consens us over Time}

After the introduction of a new leader and changes in some of the members of the team, team members likely have idiosyncratic levels of trust in their leader and the process of emergence will need to take place to produce consens us in trust in the new leader among team members. Emergence has been described as a dynamic process 
(Goldstein, 2001; Kozlowski \& Chao, in press) whereby the level of analysis for a collective construct can shift over time (Dansereau et al., 1999). In its developing stage, an emergent construct takes shape from interdependent lower-level constructs that gradually become an organized collective to emerge as a higher-level construct. Emergence can be caused by factors that are endogenous, related to the actors, and exogenous, related to the environment (Dansereau et al., 1999). For trust, endogenous factors should be more important because of its focus on the dyadic relationship and the actors within a team (Hosmer, 1995; Mayer et al., 1995).

A change of leadership and membership of the team are thus major endogenous factors that can influence the emergence of the collective trust in leaders. Members generally know little about their new leader's behaviors and attributes when the leader is first assigned to the team, and because there have been few opportunities to observe, engage, and interact with the leader. In the absence of shared, common perceptions, individuals tend to rely on their personal attitudes and experience in forming perceptions and attitudes (Ostroff \& Bowen, 2000). When team members have limited information about the leader's style and behaviors, idiosyncratic perceptions of the leader are likely to dominate and the team should have low consensus in trust in their leader. Over time, team members go through a sense-making process (Weick, 2001) as they attempt to develop further understanding of the leader.

For trust in leaders, the sense-making process should be primarily driven by interactions with leaders because the psychological state of trust arises from the dyadic relationships between leaders and followers (Bower et al., 2000). On an individual basis, team members develop their perceptions of the leader from their individual interactions 
with the leader (Klein \& House, 1995). When leaders interact with all team members consistently, they fulfill a unique role in instilling shared perceptions among members (McGregor, 1960; Naumann \& Bennett, 2000; Smircich \& Morgan, 1982) that can facilitate the development of consensus among team members. Over time, as leaders have more opportunities to interact with each member, team members should develop increasingly similar levels of trust through repeated interaction cycles with the leader. In short, consensus in trust in leaders may not occur immediately after changes in leadership and membership. However, collective trust in leaders among team members could emerge when the new team leader has sufficient time to interact with the members. Hypothesis 1a: On average, consensus in trust in leaders will increase from shortly after leaders assume responsibility to several months later.

Teams represent a social system (Katz \& Kahn, 1978) in which members are under similar structural influences and have similar experiences (Edmondson, 1999). A large body of work has shown that group membership influences individuals' perceptions, values, and attitudes (e.g., Festinger, 1954; Hofstede, 1998; Tajfel \& Turner, 1979; Turner, 1987). As noted above, for consensus in trust in leaders, team leaders are influential on the variation or agreement of members' trust in the leader. Teams may develop different degrees of consens us depending on how their leaders provide, interpret, and explain organizational information and events for the team members (Naumann \& Bennett, 2000; Schein, 2010). Zohar and Luria (2005) found variation in consensus in safety climate between groups within a single organization, due to team leader discretion under the same context of organizational policies and procedures. In a similar vein, I argue that the effects of team leader and factors related to the leaders such as leader- 
member exchanges (LMX), communication with leaders, and behavior expectations can affect the degree of consensus in trust in leaders. As the tenure of leaders increases, teams may increasingly vary in the extent to which they coalesce in their trust in leaders. Hence, differences in the degree of consensus between teams should become larger over time.

Hypothesis 1b: Variance between teams in consensus in trust in leaders will increase from shortly after leaders assume responsibility to several months later.

\section{Leader Behaviors vs. Attributes}

As noted in Chapter 3, several groups of processes have been identified to facilitate emergence of collective constructs. However, few studies have compared the effects of different emergent processes (see González-Romá, Peiró, \& Tordera, 2002; Zohar \& Tenne-Gazit, 2008 for exceptions) and theory is lacking on why some processes might be more important than others for a given collective construct. Research has also yet to be conducted with regard to emergent processes specific to the consens us in trust in leaders. When considering the relations of variables across levels of analysis, Kozlowski and Klein (2000) suggest that "the content underlying constructs at different levels has to have some meaningful connection" (p. 21). In this case, with the focus on consensus in trust in leaders, a meaningful commensurate connection would entail a focus on leaders as the key emergent factor. Leadership has also been consistently regarded as a critical factor in developing shared perceptions (Ostroff et al., 2012).

Within the leadership literature, a distinction has been made between the trait and behavioral approaches to leadership. The proponents of the "great man" perspective argue that leadership is largely based on leader characteristics (Bennis \& Nanus, 1997). In contrast, the behavioral approach focuses on how leaders act and treat followers. For 
example, McGrath (1964) and Blake and Mouton (1964) posited that the purpose of leadership research is to understand what leaders do. Research that compares the two approaches has concluded that both have yielded significant insights for understanding effective leadership (Yukl, 1989; Antonakis, Cianciolo, \& Sternberg, 2004; DeRue, Nahrgang, Wellman, \& Humphrey, 2011).

In considering the emergence and consensus in trust in leaders, I argue that the behavioral approach is more influential than the trait approach. Because trust has a relational component (Nooteboom et al., 1997; Tyler \& DeGoey, 1996), leader behaviors that afford interactions between the leader and members should be particularly important for the formation of members' trust in leaders. Compared to leader attributes, leader behaviors and interactions with leaders should be a more observable and salient factor in members' perceptions of the trustworthiness of the leader, which in turn facilitates members' coalescence around a common attitude about the leader.

Moreover, in the levels of analysis literature, interactions have long been credited to be a key to emergence (e.g., Kozlowski \& Klein, 2000; Kozlowski, 2012; Morgeson \& Hofmann, 1999). In explaining the process of emergence, Kozlowski and Klein (2000) state: "A phenomenon is emergent when it originates in the cognition, affect, behaviors or other characteristics of individuals, is amplified by their interactions, and manifests as a higher-level, collective phenomenon" (p. 55, emphasis added). Likewise, Morgeson and Hofmann (1999) posit that event cycles, or ongoing contacts, encounters, and interactions among members, lead to the emergence of collective constructs. Therefore, consensus in trust in leaders should be influenced by leader attributes less so than by leader behaviors that afford interactions between the leader and team members, as such variables should 
help promote consensus in perceptions, beliefs, feelings, and attitudes among team members. Indeed, leader behaviors, especially those that involve interactions with followers, have been found to be important for consensus in other areas, such as climate perceptions (Zohar \& Luria, 2004). Below I describe the leader attributes and behaviors that will be examined.

Leadership attributes. Since the typology of trustworthiness dimensions was offered by Mayer and his colleagues (1995), ability, integrity, and benevolence have been viewed as key to trust and widely examined (see Fulmer \& Gelfand, 2012, for a summary). Leader ability and integrity can be construed as traits or general attributes in that a leader either possesses the attribute or does not. Leader benevolence can be inferred from leader showing concern, which entails interactive behavior on the part of the leader when the leader demonstrates concern for the welfare of a follower (McAllister, 1995; Mishra, 1996).

Leader ability and integrity have been considered as keys to leader credibility (Hackman \& Johnson, 1996; Yukl, 1998). Leader ability refers to the domain-specific competence of a leader (Mayer et al., 1995). Leader inte grity refers to the extent to which leaders possesses principles of fairness and honesty (Mayer et al., 1995) and has been identified as an important feature of leadership (Kouzes \& Posner, 1993). Leader ability and integrity have both been shown to be positively related to the level of trust in leaders at the individual level (Colquitt et al., 2007). These two leader attributes allow leaders "to engender trust and commitment of those who take their direction" (Ulrich, 1996, p. 215). However, I argue that these two leader attribute variables will be of relatively lesser importance for consensus because they do not directly entail interacting with followers. 
In order for consensus in trust in leaders to emerge, leaders need to actively demonstrate key behaviors, role model, and interact with their team members.

Leader behaviors. For leader behaviors that involve interactions between the leader and team members, I draw from those identified in recent work on servant leadership (Liden et al., 2008; Neubert, Kacmar, Carlson, Chonko, \& Roberts, 2008; Walumbwa, Hartnell, \& Oke, 2010), empowering leadership (Arnold, Arad, Rhoades, \& Drasgow, 2000; Srivastava, Bartol, \& Locke, 2006), and the trust literature (Ferrin, Bligh, \& Kohles, 2007; Langfred, 2004). Servant leadership and empowering leadership were selected for their suitability for research in the team context because they foc us on both interactions with individual members and the team as a whole (Schaubroeck et al., 2011; Stewart, 2006). Both styles of leadership have been shown to influence trust in leaders at the individual level (e.g., Caldwell \& Dixon, 2010; Van Dierendonck, 2011) and servant leadership has been linked to trust in leaders at the team level (Schaubroeck et al., 2011). With regard to the specific behaviors, showing concern has been positively linked to the level of trust in leaders (Korsgaard et al., 2002), leading by example has yet to be examined explicitly in relation to trust in leaders, and monitoring has been proposed to be either positively or negatively related to trust in leaders depending on contextual factors (Ferrin et al., 2007). This study focuses on their effects on the consensus in trust in leaders at the team level.

Before turning to each leader behavior, it should be noted that the process through which these behaviors influence consensus in team trust in leaders among team members is largely due to attribution. Attribution refers to making sense of an event or a behavior, determining its causes, and forming perceptions (Hamilton, 1980; Heider, 1958). 
Research has highlighted the role attribution plays in forming interpersonal trust (Ferrin \& Dirks, 2003; Fulmer \& Gelfand, in press). The three leader behaviors examined in this study involve interactions between the leader and the team members and observations of the leader from the team members. As team members observe consistent leader actions across situations and people, they should make similar attributions of the leader and hence develop similar levels of trust in the leader. Kelley's (1967) covariation model proposes that individuals make attributions of others' behavior based on three featuresdistinctiveness, consistency, and consensus. Consistency is particularly relevant for the process through which the proposed leader behaviors influence consensus in trust in leaders. Consistency refers to reoccurrence of an event with a target person or a behavior of a target person. Naumann and Bennett (2000) found that, when team members had opportunities to observe leader behaviors reliably, it facilitated formation of uniform perceptions. Likewise, Zohar \& Luria (2004) found that leader consistent demonstration of key behaviors was positively related to the degree of perception agreement. The impression of consistency in leader behaviors can further be bolstered through vicarious learning (Bandura, 1962), when team members observe the leader interact with other team members instead of interacting directly with the leader. To the extent that team members observe leader behaviors consistently across people and situations, they should be more likely to develop consensus in trust in the leader - a notion that is discussed with each of leader behaviors below.

Leader showing concern. The leader behavior of showing concern is defined as "the act of showing sensitivity to others' personal concerns" (Liden et al., 2008, p.162). Individual members can be direct recipients of leader concern, meaning that the leader 
shows that he or she actively keeps the member's interests in mind. As noted earlier, trust in a leader arises from the dyadic relationship between a leader and a follower, which is related to the notion of LMX (Bower et al., 2000). Recent studies indicate that the degree of differentiation in LMX can vary across leaders such that some leaders establish similar relationships among their followers while others can differ substantially in their relationships with their followers (e.g., Boies \& Howell, 2006; Liden, Erdogan, Wayne, \& Sparrowe, 2006; Hooper \& Martin, 2008). To the extent that leaders are high on average LMX and concern for the team members, they should treat team members similarly and facilitate the development of the consens us in trust in leaders among members. When members are not the direct recipients of leader concern, they can observe a leader's concern for fellow members. This vicarious learning (Bandura, 1962) should also help team members develop consensus with their follow members on trust in the leader. As members' observations indicate that a leader shows concern consistently over time and over people, leaders showing concern should facilitate the emergence of a collective attribute about the trustworthiness of the leader, and members' agreement on the leader's trustworthiness should increase over time.

Further, when leaders demonstrate concern, they are able to foster positive relationships with the team members (Klauss \& Bass, 1982). High quality leader-member relationships have been linked to greater consensus among followers in climate perceptions as "there should be more opportunities for sharing and explaining perceptions across a broad array of relevant contextual stimuli” (Kozlowski \& Doherty, 1989, p. 548). The link between leader showing concern and team consens us is further indicated by research demonstrating that supportive leadership is related to group cohesion at the 
team level (Greene \& Schriesheim, 1980) and that high average LMX in a team is related to member agreement on their perceptions of the organizational policies and procedures (Ford \& Seer, 2006). House (1971) posits that leader demons trating consideration can result in social support among team members. When a team has positive team dynamics such as cohesion and support, team members should be more likely to agree with one another on their levels of trust in the leader.

In contrast, when a leader has a low average level of concern in team members, the concern team members receive from the leader may not be consistent across situations and individuals. This should hinder team members from developing a high consensus in the trust in their leader. Related to this idea, LMX differentiation has been shown to be positively linked to conflicts among team members (Boies \& Howell, 2006). Further, the lack of consideration also lowers the quality of interactions that team members have with their leader, which decreases opportunities for explanations and interpretation of organizational information and events from the leader (Kozlowski \& Doherty, 1989) and lowers positive team dynamics (Greene \& Schriesheim, 1980). Therefore, the attitudes of the team members should be less likely to converge with each other over time when the leader shows little concern for team members and, hence, the degree of consensus in their levels of trust in the leader should be lower. To the extent that people are either directly or vicariously experiencing a leader's demonstration of concern, team members should have increasingly similar attributions about the leader over time. Leader showing concern is thus predicted to positively relate to the degree of consensus in trust in leaders and to the emergence of consens us in trust in leaders over time. 
Leading by example. Arnold, Arad, Rhodes, and Drasgow (2000) define leading by example as "a set of behaviors that show the leader's commitment to his or her own work as well as the work of his/her team members" (p. 254). Theory and research suggest that employees tend to perceive leaders as role models (e.g., Dickson et al., 2001; Schein, 1990). While leading by example does not entail direct interaction in the forms of conversations and activities between leaders and followers, it has an interactional component as leaders demonstrate to their team members how to behave and what is expected through actions rather than words.

In the theory of causal attribution, response consistency across situations is deemed a key in forming internal attributions (Kelley, 1967). These stable perceptions of the leader should in turn facilitate team members' agreement on the attitudes, including trust, toward the leader. As team members constantly observe their leaders, one of the ways through which leaders can "engineer" similar perceptions among team members (Naumann \& Bennett, 2000) is by enactment of exemplary behaviors. Research has indicated that when leader behaviors are consistent with the organizational priority such that the leader is enacting the espoused values, their team members have a higher agreement in their climate perceptions (Zohar \& Luria, 2004). Further, the effect of consistency should be stronger over time as team members have increased opportunities to observe the leader's modeling behaviors, as consistency is inferred when responses are consistent over time (Kelley, 1967). Thus, I expect that the leader behavior of leading by example should facilitate consensus and changes in consensus in trust in leaders.

Leader monitoring. Adapting from Langfred (2004), leader monitoring in this study refers to a leader's surveillance and awareness of team members' activities. The 
relationship between trust and monitoring has proven to be complex. While some research has connected it negatively to trust at the individual level (Bromiley \& Cummings, 1995; Creed \& Miles, 1996; McAllister, 1995), other research has suggested its effect depends on the context such that a positive link to trust at the individual level can be expected when monitoring is deemed appropriate (Ferrin et al., 2007). Regardless of its effect on the level of trust, I propose that leader monitoring is likely to increase consensus in trust in leaders among team members.

The effect of monitoring on consensus in trust in leaders can occur via two mechanisms. First, when a leader monitors team members' progress of team tasks, the behavior serves to coordinate team members and direct their attention toward the collective goals (Zaccaro, 2001). Leaders are in the position to encourage desired behaviors, such as those contributing to the collective goals, and discourage undesired ones that are distracting from the collective goals (Yukl et al., 1990). As team members jointly focus on their team's goals, the shared sense of being part of a collective should help them develop consensus in their perceptions and attitudes toward the leader, including their levels of trust in the leader.

Second, because leaders who monitor seek to ensure that everyone in the team fulfills their duties and meets their deadlines, the team as a whole is treated similarly. Leader monitoring thus signals consistency across people, which in turn engenders uniform team perceptions (Kelley, 1967). In the team-level justice literature, research has suggested the link between Leventhal's consistency rule of justice (1980) whereby procedural justice is doled out similarly for each individual and the agreement of unit members' justice climate perceptions (Colquitt et al., 2002). Further, when team 
members observe the leader monitoring other team members, the vicarious learning should also contribute to similar perceptions of the leader. The effect of similar treatment of all team members should promote a high degree of consensus in trust in leaders and, as team members have more opportunities to observe their leader engaging in monitoring, lead to an increase in consensus over time. Therefore, leader monitoring should be positively related to the degree of consensus and changes in consensus in members' trust in leaders.

Hypothesis 2a: The leader behaviors of leading by example, showing concern, and monitoring will be related to consensus in trust in leaders and will show stronger relationships with consensus than the leader attributes of ability and integrity.

Hypothesis 2b: The leader behaviors of leading by example, showing concern, and monitoring, will be related to a change in consensus in trust in leaders and will show a greater change in consensus than the leader attributes of ability and integrity.

\section{Emergent Process and Consensus Target Match}

In addition to differentiating between leader attributes and leader behaviors, another distinction that may determine whether an emergent process is more or less relevant is whether it matches the target of the collective construct. Within the levels of analysis theory, Kozlowski and Klein (2000) suggest that the content underlying constructs at the lower and higher levels should be meaningfully related to exhibit a strong relationship. Extending their rationale, I argue that the emergent processes between the lower level and higher level constructs should also be meaningfully related 
to the constructs. One implication is that the processes that facilitate emergence should also refer to the same target of the emergent construct.

For collective constructs targeted to a broad context, such as organizational climate, both factors related to leaders' and members' behaviors and interactions can influence the emergence of shared perceptions, as they convey information about what is valued, rewarded, and expected in the organization (Ostroff et al., 2012). For example, Newman and his colleagues (2008) have shown that employee social processes influence the agreement in their organizational climate perceptions, and Zohar and Luria (2004) have found that leader behavior consistency is related to the agreement in employee safety climate perceptions. However, the matching of the target between emergent processes and collective constructs should become more specific and critical when the target is a focal person. In other words, when considering a collective construct that is related to a single narrow target like a person, target match should be important such that behaviors of the target and interactions with the target should play a particularly relevant role in influencing consensus. The theory and research on person perceptions have highlighted that factors related to the target person are key to impression formation (e.g., Gilbert, 1989; Trope, 1986). Therefore, for the consensus in trust in leaders, behaviors and interactions that are directed toward the target of trust-in this case the leadershould be more important than general behaviors and interactions.

To support this notion, I draw on the principle of compatibility (Ajzen, 1988), in which a relationship between two variables of the same target will be stronger than that between two variables of different targets. The relationship between two variables of a matched target is expected to be strong due to belief congruence (Rokeach, Smith, \& 
Evans, 1960), in that the beliefs and considerations activated in two contexts are similar (Ajzen \& Sexton, 1999; Ajzen, 2012). A change in context may elicit different beliefs and considerations, and it is difficult for people to attend to and elaborate on conflicting thoughts (Hovland \& Weiss, 1953). Thus, I predict that the emergent processes that are related to leadership should be relatively more important for consensus in trust in leaders than the emergent processes that are related to team process. I selected two team process factors - team open communication and team demographic diversity - to examine their effects on the consensus in trust in leaders. Again, the proposition will be examined with the degree of consensus and changes in consens us in trust in leaders over time.

Team open communication. Team open communication refers to the extent to which team members feel that the team as a whole encourages and listens to members' input (Barry \& Stewart, 1997). Open communication affords opportunities for team members to gain personal knowledge about each other, remove uncertainty and concern, and develop positive experience and expectations about fellow team members. However, because team open communication pertains to interactions among team members rather than with the leader, it should be less influential in engendering consensus in trust in the leader than specific leader behaviors. Based on the principle of compatibility (Ajzen, 1988), the relationship between emergent factors and consens us of a collective construct should be stronger when they refer to a common target. Further, as noted earlier, trust in the leader is based on a dyadic relationship between a leader and a follower (Bower et al., 2000). In their description of team members' perceptions of the leader, Klein and House (1995) contend that members should individually perceive the leader's behavior depending on the relationships between the leader and each of the team members. 
Consensus forms when team members develop similar levels of trust in the leader based on their individual exchange and relationship with the leader. Communication among team members about the leader and knowledge about the level of trust other members have in the leader might prompt an individual member to attend more to leader behaviors and their own interactions with the leader in order to gauge their own level of trust. Consensus in trust in leaders should be directly influenced by leader behaviors, the interactions between the leader and team members, rather than communication among team members.

Team de mographic diversity. As discussed in Chapter 3, homogeneity of the unit members has been proposed to facilitate unit consensus directly through similar perceptions arising from common attributes and characteristics, and indirectly through positive interactions, as individuals tend to prefer similar others (Roberson \& Colquitt, 2005; Schneider \& Reichers, 1983; Tajfel \& Turner, 1979; Tsui et al., 1992). Research has indeed shown that demographic diversity is negatively related to communication among members (Brass, 1995; Williams \& O'Reilly, 1998) and is positively related to unit conflict (Jackson et al., 1991; Pelled, Eisenhardt, \& Xin, 1999). Research has further demonstrated the link between demographic diversity and attitude diversity (Harrison et al., 1998). Despite this rationale, empirical evidence for the link between diversity and consensus has been inconsistent and often weak (e.g., Klein et al., 2001; Naumann \& Bennett, 2000).

With regard to the consensus in trust in leaders, I again draw on the principle of compatibility (Ajzen, 1988) and predict that the demographic diversity of team members would exert little influence on the emergence and degree of consensus in trust in leaders 
because the two variables refer to different targets (team members vs. leader). Diversity in teams is more likely to affect affiliation and group dynamics (Kanter, 1977), in part because of the matched target. It is possible that diversity in teams could influence dyadic relationships with the leader and team members and, hence, trust in the leader. However, the leader who shows concern, monitors, and leads by example with individuals and towards the team as a whole (where members can either experience it themselves or vicariously) should be more influential in consensus in trust in the leader than diversity in team members. Therefore, I propose that team demographic diversity should be a less relevant predictor of consensus in trust in leaders.

Hypothesis 3a: Leader leading by example, showing concern, and monitoring will be related to consensus in trust in leaders and will show stronger relationships with consensus than team demographic diversity and open communication. Hypothesis 3b: Leader leading by example, showing concern, and monitoring will be related to a change in consensus in trust in leaders and will show a greater change in consensus than team demographic diversity and open communication.

\section{Outcomes of Team Consensus}

Two team outcomes, team performance and team voice behaviors, were examined in relation to the degree of consens us and changes in consens us in trust in leaders over time. As reviewed in Chapter 2, team performance and other related bottom-line measures have been consistently examined as a key outcome of the mean level of trust in leaders at the unit level (Davis et al., 2000; Dirks, 2000; Simons \& McLean-Parks, 2002). Given these findings, it is important to extend past research to examine whether consensus in trust in leaders also influences team performance. Team voice behavior was 
selected because trust is a relational construct (Nooteboom et al., 1997; Tyler \& DeGoey, 1996), and the willingness to speak up has been described as a form of interpersonal risk people take in their social relationships (Burks, Sims, Lazzara, \& Salas, 2007;

Edmondson, 1999). Voice has been examined at the team level and shown to drive how teams operate and function (Edmondson, 2003; Morrison, Wheeler-Smith, \& Kamdar, 2011). However, research on trust in leaders and voice has been limited to the individual level (Premeaux \& Bedeian, 2003), as the existing research on team trust in leaders has

yet to explore outcomes other than performance and turnover (Fulmer \& Gelfand, 2012). The present research explores their relationship at the team level of analysis and in relation to consensus.

\section{Main Effects}

The main effects of consensus in trust in leaders on team performance and team voice behavior are discussed first. Consens us by itself represents factors related to member agreement and the extent of similar experiences, in addition to factors related to the collective construct (Lindell \& Brant, 2000; Schneider et al., 2002). The effects of consensus may be positive or negative depending on the outcomes (Harrison \& Klein, 2007). In this study, I propose that consensus in trust in leaders is positively related to team performance and negatively related to team voice behavior.

Main effect on team performance. The mean level of trust at the unit has been linked to unit performance (Davis et al., 2000; Dirks, 2000; Simons \& McLean-Parks, 2002). I propose that consens us in trust in leaders will have an independent effect on team performance beyond the effect of the mean level of trust in leaders. Consensus in trust in leaders itself, regardless of the level of trust being high or low, is a meaningful 
construct in that it indicates team dynamics and dynamics with leader, in addition to the factors related to trust in leaders. Consensus can therefore be viewed as an indication of the social context of a team (Bliese \& Britt, 2001; Bliese \& Halverson, 1998). For example, team members are in a very different social environment when everyone agrees that they trust their leader a moderate amount compared to when half trust the leader completely while the other half do not trust the leader at all. In these two scenarios, the mean level of team trust in the leader is the same, but the former has higher consensus than the latter. The social context of these two teams should be very different.

Social influence theory (Festinger, 1950) posits that members in a team rely on one another for information to make sense of their environment and that members are motivated to achieve consensus in their attitudes and perceptions. Whether the mean level of team trust in leaders is high or low, consensus constitutes a type of social context that exerts normative and informational influences on team members that convey an expectation of the leader and team members (Deutsch \& Gerard, 1955; Firebaugh, 1979). Consensus and its normative influences are expected to facilitate the team's coordination and cooperation. Interpersonal liking arising from similar attitudes shared by team members should further facilitate cooperation (Byrne, 1971). Indeed, research has found that teams who share similar attitudes are more likely to be cooperative and to sustain a norm of cooperation than teams who do not share similar attitudes (Gächter \& Thöni, 2005). Further, research has linked team member schema agreement to team effectiveness (Rentsch \& Klimoski, 2001). Together, these findings suggest that when the degree of consensus in trust in leaders is high, the team should have higher performance. Similar positive benefits should likewise occur when team members increasingly agree 
with one another's perceptions and attitudes about their leader over time. Therefore, teams with high consensus and teams with a large increase in consensus in trust in leaders should exhibit better performance than teams with low consensus or a small increase in consensus in trust in leaders, even after taking into account the effect of the level of team trust in leaders.

Hypothesis 4a: Consensus in trust in leaders will be positively related to team performance above and beyond the effect of the mean level of team trust in leaders.

Hypothesis 4b: Increased consensus in trust in leaders will be related to team performance above and beyond the effect of the mean level of team trust in leaders.

Main effect on voice behavior. Voice has been described as "the discretionary communication of ideas, suggestions, or opinions intended to improve organizational or unit functioning" (Morrison, Wheeler-Smith, \& Kamdar, 2011, p. 183). Among the various predictors of employee voice behavior, leaders play a particularly influential role because of their ability to effect employee outcomes (Edmondson, 2003; Walumbwa et al., 2009). Recent work has examined voice at the unit level of analysis, focusing on the notion of voice climate, or the extent to which unit members share their perceptions about voice behavior (e.g., whether it is encouraged or efficacious; Frazier \& Bowler, 2012; Morrison et al., 2011). In this research, I focus on team voice behavior, which refers to the extent to which members in a team collectively engage in the discretionary communication of speaking up and offering opinions and suggestions. 
I propose that consensus in trust in leaders will be negatively related to team voice behavior above and beyond the effect of the level of team trust in leaders. As noted above, consensus forms a social context in teams (Bliese \& Britt, 2001; Bliese \& Halverson, 1998). While consensus can be beneficial and may reflect a positive team dynamic, a high level of consensus can also be perceived as a strong situation (Mischel, 1973) that produces uniform perceptions, attitudes, and behaviors. The notion of groupthink (Janis, 1972) describes the situation in which team members are reluctant to raise issues that may be construed as dissent. Groupthink is less likely to occur when a team is less cohesive and in the absence of a strong psychological drive for consensus (Janis, 1972; Esser, 1998). Therefore, when team members do not agree on their levels of trust in the leader, the low consensus may make it more likely for team members to voice their opinions and suggestions without the concern that they would appear to challenge the status-quo. In contrast, in a strong situation when the consensus in trust in leaders is high, team members are likely to avoid instigating changes because of the sense of sharedness and the motivation to maintain cohesiveness, regardless of the mean level of trust in the leader.

Hypothesis 5a: Consensus in trust in leaders will be negatively related to team voice behavior above and beyond the effect of the mean level of team trust in leaders.

Hypothesis 5b: Increased consensus in trust in leaders will be negatively related to team voice behavior above and beyond the effect of the mean level of team trust in leaders. 


\section{Interaction between Mean Level and Consensus}

The constructs of mean level and consensus each tap different mechanisms. The mean level concerns the amount of trust, on average, team members place on the leader, while consensus concerns factors inherent in the dynamics of the team. Because the mean level and consensus are distinct but related to each other, it is important to take both factors and their interaction into account when considering outcomes. The majority of research and theory to date proposes that consensus coupled with a higher mean level is generally better than consens us coupled with a low mean (i.e., relationship between mean and outcome is stronger with higher consensus) because not only is the mean level high but the group dynamic, evidenced through consensus, is also strong (Dickson et al., 2006; Lindell \& Brandt, 2000). The relationship between mean and outcomes with lower consensus should be weaker because the group dynamic is low and a higher level variable does not strongly exist. However, theory and research to date have focused on climate (Dickson et al., 2006; Lindell \& Brandt, 2000; Naumann \& Bennett, 2000), and the nature of interaction for trust may differ because it focuses on a focal individual and, more specifically, the role of a leader in a team, rather than the broader context in which individuals function and perform. Further, the nature of interaction can also depend on the types of outcomes, as not all outcomes are related to group dynamics similarly. As types of emergent processes can differ for different types of collective constructs, the nature of interaction may also differ for different types of collective constructs and outcomes.

Interactive effect on team performance. In addition to exerting a main effect, consensus in trust in leaders and changes in consensus may interact with the mean level 
in influencing team performance. The relationship between the level of team trust in leaders and team performance may depend on the degree of consens us in trust in leaders. As discussed in the review in Chapter 2, the number of studies that have examined the relationship between the level of team trust in leaders and team performance remains small. Further, consensus and its potential interaction with the mean level of trust have not been explored.

I hypothesize that higher consensus in trust in leaders and an increase in consensus will be related to higher team performance regardless of the level of team trust in leaders. As noted above, when team members have similar attitudes, they are more likely to experience positive affect, cooperate with each other, and the team effectiveness and performance should be higher (e.g., Byrne, 1971; Festinger, 1950; Gächter \& Thöni, 2005; Rentsch \& Klimoski, 2001; Marks et al., 2000). Even when members share similar levels of low trust, their convergence in low trust in their leader likely reflects some coalescence among group members that can foster higher team performance.

However, the relationship between the mean level of trust in the leader and team performance may be more strongly affected by low consens us. The paradigm of attraction-selection-attribution (ASA; Schneider, 1987) suggests that, while high interpersonal congruence among organi zational members increases employee attitudinal outcomes, it may undermine the long-term fitness of an organization. Indeed, some disagreement among individuals has been found to be related to higher creativity and team performance (Carnevale \& Probst, 1998; Jehn, 1995; Van Dyne \& Saavedra, 1996). At the same time, disagreement and low consensus can also lead to negative consequences and lower performance (e.g., De Dreu \& Weingart, 2003). The potentially 
positive and negative consequences of disagreement for group functioning and, ultimately, performance may depend on the level of trust in leaders. For a team to function well, a basis for coordination is needed (Zaccaro, Rittman, \& Marks, 2001). One of the main purposes of leadership is to coordinate members to ensure the team accomplishes its collective goals (Zaccaro, 2001). When team members collectively trust the leader, the shared trust should serve to direct members' effort toward collective goals (Dirks \& Skarlicki, 2004). When a leader cannot fulfill this function due to the members' low trust in the leader and when members do not agree on their levels of trust in leaders, it would be difficult for team members to coordinate and work toward collective goals. In contrast, relatively higher levels of trust in the leader would allow for the benefits of some disagreement to be realized as the leader can help coordinate some divergence among members in a way that enhances performance.

Hypothesis 6a: Consensus in trust in leaders will interact with the mean level of team trust in leaders in the relationship to team performance. The relationship between the mean level of trust and team performance will be stronger when consensus is low than when consensus is high.

Hypothesis 6b: Increased consensus in trust in leaders will interact with the mean level of team trust in leaders in the relationship to team performance. The relationship between the mean level of trust and team performance and will be stronger with positive changes in consensus.

Interactive effect on team voice behavior. Moreover, as with team performance, I predict an interactive effect between the mean level and consensus in trust in leaders on team voice behavior. As discussed earlier, when the consensus in trust in leaders is low, 
regardless of the level of team trust in leaders, team members should be more likely to engage in voice behavior. Low consensus indicates a weaker situation with a lower sense of cohesiveness and less pressure for groupthink, increasing the likelihood that team members will engage in voice behavior collectively.

However, the relationship between the mean level of trust in leaders and voice should be affected more strongly when consensus is high. When a team's level of trust in the leader is high, team members should experience a sense of psychological safety within the team context and be more willing to take interpersonal risk (Burks et al., 2007; Edmondson, 1999). Engaging in voice behavior, such as raising sensitive issues and challenging status-quo, is one type of such risk (LePine \& Van Dyne, 1998). To the extent that team members share high trust in their leader, thereby feeling safe and believing their leader would not punish them for speaking up (LePine \& Van Dyne, 1998; Milliken, Morrison, \& Hewlin, 2003), they should be more likely to engage in voice behavior than when they collectively share low trust in their leader. A collective state of low trust in the leader should create particularly low psychological safety (Burks et al., 2007) and high uncertainty (Colquitt et al., 2007) about how the leader will react to ideas and opinions, whereby decreasing the likelihood that team members engage in voice behavior collectively. Therefore, higher consensus will have a stronger impact on the relationship between the mean level of trust and voice.

Hypothesis 7a: Consensus in trust in leaders will interact with the mean level of team trust in leaders in the relationship to team voice behavior. The relationship between the mean level of trust and team performance will be stronger when consensus is higher. 
Hypothesis 7b: Increased consensus in trust in leaders will interact with the mean level of team trust in leaders in the relationship to team voice behavior. The relationship between the mean level of trust and team performance will be stronger with positive changes in consensus. 


\section{Chapter 5. Method}

In this section, I discuss the methodology used for this research. I first describe the organizational context and the procedure for data collection, followed by a description of the study sample and measures. Aggregation statistics and the analysis plan are also discussed.

\section{Organizational Context}

The research was conducted at a large military academy in the United States. Participants were officers-in-training in preparation for a career in military service while pursuing an academic degree at the same time. The participants are organized into teams, called squads, which in turn are nested within platoons and companies. Each squad consists of 10-12 members and a squad leader. At the beginning of each semester, a new squad leader is assigned to each squad. In addition, approximately one-quarter of a squad's membership changes, with senior squad members moving to positions elsewhere in the military organization while new, inexperienced individuals joining the squad.

Squad members and leaders receive regular active-duty benefits and pay that are commensurate with their rank. Upon graduation, they are appointed to officer positions in the military. Because of this, their experience at the academy is structured as an immersion program that involves duties and activities on campus that are similar to those of full-time officers in the military. They also spend time engaging in active military units during their tenure at the institution.

\section{Procedure}

Three waves of survey data were collected between September and December, 2011. In addition, archival data collected by the institution, including demographic 
information and objective individual performance indicators, were matched to respondents. For each wave of data collection, squad members and squad leaders were invited to participate through an organization-wide email sent by a higher ranking activeduty military officer at the institution. The surveys were administered by the research office on the institutional intranet. Participants accessed the survey at a time and place of their choice and were given 7 to 10 days to complete the survey, with two reminders sent during that period. Each survey took approximately 10-15 minutes to complete. Surveys included measures of trust in leaders, trust in teams, perceptions of leader's attributes and behaviors, team processes, and team outcomes. Data for other purposes, including understanding squad member attitudes and experiences, were also collected during these surveys.

Participation in the research was voluntary and confidential. It was, however, not anonymous in that participants were asked to provide their military identification number so that the research office could match survey responses across time and to the archival data. At that point, the research office generated random participant identification numbers, removing personal identifying information before providing the researchers access to the data. The archival objective performance and demographic data was obtained for each responding squad member and squad leader. Time 1 (T1), the first data collection, began four weeks after the introduction of new leadership and changes in some membership in squads. Therefore, squad members had limited time to interact with their squad leader and with the newly added squad members. T1 data provided the initial baseline measure of squad members' trust in their squad leaders, consensus in trust, 
squad members' history with the squad leaders, and their perceptions of the squad leaders' reputation.

Time 2 (T2), the second data collection, occurred two months later. At this time, squad members had interacted with their new squad members and new squad leaders for approximately three months. Squad members assessed leadership attributes, leadership behaviors, and team processes in the T2 surveys. They also provided measures of trust in squad leaders and trust in their other team members.

Time 3 (T3), the third data collection, began about two weeks after the completion of the T2 surveys when squad members and their leaders had interacted for more than three months. Both squad members and squad leaders participated in T3. The survey for squad members measured their trust in squad leaders and their perception of squad outcomes. Squad leaders assessed squad performance. T3 data collection was designed to occur two weeks after $\mathrm{T} 2$ to reduce the response bias problem between the final assessment of trust in leaders at T3 and the leader attributes and behaviors and team measures that were collected at T2. Research has indicated that a short time delay can help miti gate response bias (e.g. Ostroff, Kinicki, \& Clark, 2002).

Following the three waves of data collection, squad members and squad leaders were asked to report the demographic composition of their squads in terms of gender and ethnicity. This follow-up data collection was conducted because the institution was not able to provide demographic data at the level of squads. The multiple waves of data collection provided a unique opportunity to examine the leadership and team variables that contributed to the emergence of trust in leaders. The design of temporal separation among different measures also reduced the threat of common method bias, which is 
exacerbated when using aggregated data (Ostroff et al., 2002; Podsakoff, MacKenzie, Lee, \& Podsakoff, 2003). Despite these advantages, the multiple waves of data collection also posed unique challenges. The most substantial obstacle was an unscheduled shutdown of the institutional intranet four days after the T3 survey had been announced. The survey files could not be recovered promptly which forced the T3 survey to close earlier than scheduled and limited the number of responses during T3 data collection.

\section{Sample}

All three waves of surveys were sent to 2,960 squad members and T3 surveys were also sent to 360 squad leaders. Across the three waves, complete data were collected from 1596 squad members from 360 squads, with a response rate of 54\%. In addition, T3 data also included responses from 146 squad leaders, with a response rate of $40.6 \%$. However, due to aggregation issues discussed below, the final, usable sample is considerably smaller.

The unit of analysis in this research is squads. The squad level was chosen after consultation with officers at the institution who indicated that the squad level is most salient and meaningful for squad member identity and relations with the leader and team. Bliese and Halverson (1998) found that with a minimum of five members per team, reliability of aggre gate scores as indexed by ICC2 begins to stabilize. However, due to the changing response rates and respondents across surveys, there were few squads with at least five respondents across all time periods. The sample size for the number of teams became acceptable with the cutoff of a minimum of three or four members. The number of squads with a mi nimum of three members is 105 ; whereas the number of squads with a minimum of four members is 46 . The aggregation statistics across the two cutoffs 
(minimum of three vs. minimum of four) were highly comparable. Therefore, the cutoff of a minimum of three was chosen as it yielded a higher number of teams and more statistical power. Results reported in Chapter 6 were derived from squads with three or more members. Identical data analyses were also conducted using the cutoff of a minimum of four and the pattern of results was highly similar.

Using the cutoff of a minimum of three per squad, the respondents included in the final sample were 719 squad members from 105 squads from 3 waves of data collection. Across waves, the average number of responding squad members was 4.36 . The final sample for each wave varied, as not all squad members participated in all waves of surveys. From the 105 squads, 554 squad members completed T1 (M=5.28 members per squad), 476 squad members completed T2 (M=3.58 members per squad), and 443 squad members completed T3 (M=4.22 members per squad). ${ }^{1}$ The final sample also includes data from a total of 45 squad leaders across 3 waves whose responses could be matched with the squads with at least 3 responding members.

Sample characteristics. Of the 719 squad members from the final sample, $20 \%$ were female, 4\% were African American, 4\% were Asian American or Pacific Islander, $13 \%$ were Hispanic, $70 \%$ were Caucasians, and $9 \%$ belonged to other ethnic categories, selected multiple categories, or did not report. The age range of the final sample was between 18 and 26 with a mean of $20.81(\mathrm{SD}=1.32)$. In terms of organizational tenure, as indicated by the squad members' class year, $10 \%$ of the respondents had been at the institution for 3 years, $20 \%$ for 2 years, $37 \%$ for 1 year, and $33 \%$ were newcomers with

\footnotetext{
${ }^{1}$ A separate analysis was conducted using the data from the respondents who completed all three waves of surveys $(n=341)$. The results from squads with three or more members $(n=28, M=3.39$ members) were consistent with those presented in Chapter 6, with the exception that team ethnic diversity and the interaction between consensus and mean level on team performance were not significant at the $p=.05$ level.
} 
less than 6 months tenure. For performance, the average cumulative academic grade point average was 3.14 and the average cumulative military grade point average was 3.38.

Sample representativeness. The characteristics of the final sample $(n=719)$ were compared with the respondents who were not included in the final analyses $(n=877)$. This was done to examine whether the 719 squad members from teams with three or more respondents were significantly different in demographic and other characteristics from the squad members who were not included in the final sample. The $\chi^{2}$ tests for gender $\left(\chi^{2}\right.$ $=.50$, n.s. $)$, ethnicity $\left(\chi^{2}=5.82\right.$, n.s. $)$, and class year $\left(\chi^{2}=.58\right.$, n.s. $)$ showed no significant differences between the final sample and the original sample. The t-tests for the two performance measures, the cumulative academic grade point average $(t=.08$, n.s. $)$ and the cumulative military grade point average $(t=.01$, n.s. $)$, showed no significant differences between the two samples.

Likewise, the characteristics of the final sample ( $\mathrm{n}=719)$ were compared with all squad members at the institution ( $\mathrm{n}=2960)$ to test whether the final sample was different from population at the institution. The $\chi^{2}$ tests for gender $\left(\chi^{2}=2.50\right.$, n.s. $)$ showed no significant difference between the final sample and the overall squad members at the institution. However, ethnicity $\left(\chi^{2}=105.13, \mathrm{p}<.05\right)$ and class year $\left(\chi^{2}=151.44, \mathrm{p}<.05\right)$ showed significant differences. A closer examination revealed that, compared to squad members in general, a smaller proportion of African Americans (7\% in general vs. $4 \%$ in the final sample) and a larger proportion of Caucasians (64\% vs. $70 \%)$ were included in the final sample, consistent with prior research on response rates and diversity (Sax, Gilmartin, \& Bryant, 2003). For class year, compared to all squad members at the institution, a smaller proportion of the newly entered squad members (3\% in general vs. 
$10 \%)$ and a larger proportion of squad members with three years of tenure $(38.1 \% \mathrm{vs}$. $33 \%$ ) were included in the final sample. For performance, t-test results showed no significant differences between the final sample and all squad members at the institution in the cumulative academic grade point average $(\mathrm{t}=.14, \mathrm{n} . \mathrm{s}$. $)$ and the cumulative military grade point average $(t=.19$, n.s.). Together, these results indicated that the final sample was fairly similar to the overall population from which they were drawn.

\section{Measures}

Squad members completed a survey at each wave of data collection, assessing their trust in leaders, trust in teams, leader attributes and behaviors, team processes, and team outcomes. Squad leaders provided assessments of team performance during the T3 data collection period. Appendix B contains all the measures. Item language was adapted to be specific to the organization. Unless otherwise specified, all responses were made using a Likert-type 5-point scale ( $1=$ strongly disagree, $5=$ strongly agree $)$.

Trust in leaders. The trust in leader measure used in the present study is newly developed and consists of four items. A new measure of trust was needed because existing scales 1) do not follow closely the construct definition discussed in Chapter $2 ; 2$ ) assess behaviors rather than a psychological state; 3 ) include the antecedents and consequences of trust (e.g., relationship closeness, reputation, voice, and monitoring); and/or 4) include multiple trustors and trust referents. The procedure for scale development is described briefly below. Detailed information regarding scale development and psychometric properties is beyond the scope of the present proposal and is reported in a separate paper in progress (Fulmer \& Ostroff, in preparation). 
I used the deductive approach whereby a scale is developed based on the existing theoretical definition of a construct to ensure content validity (Hinkin, 1998). Following the recommendations set forth by DeVellis (2003) and Hinkin (1998), the procedure involved four steps-item generation, item reduction, confirmatory factor analysis, and convergent and divergent validity. First, I reviewed the current literature on trust and collected existing trust measures which resulted in a pool of 120 items. In addition, a small number of items were written based on the construct definition discussed in Chapter 2, in accordance with Hinkin's (1998) guidelines. Next, all items were administered for content validity assessment to a group of 15 judges who rated the extent to which each item corresponded to the definition of trust in a leader. Note that the use of a small sample of non-subject-matter experts is suitable in this step as expert understanding of the construct is not required (Anderson \& Gerbing, 1991; Schriesheim, Powers, Scandura, Gardiner, \& Lankau, 1993). In keeping with the recommendation of four to six items per scale (Schriesheim et al., 1993), 11 items that demonstrated content adequacy were initially retained.

Multiple pilot studies across multiple working adult samples of 326 were then conducted to examine the measure's psychometric properties and its relationship with other related variables. First, an exploratory factor analysis was conducted without constraining the number of factors. The results from the first eigenvalue and the scree plot indicated a single factor structure. However, items that did not meet the Kaiser criterion (Cattell, 1966) or had a substantially lower loading on the factor were eliminated. Complementing the factor analysis, internal consistency was assessed using Cronbach's alpha (Cortina, 1993). Because the results indicated strong item covariance, 
items that demonstrated smaller variance and did not adversely affect the reliability were further eliminated (Hinkin, 1998). Four items were retained in the final scale (see Appendix B).

A confirmatory factor analysis was then conducted, using Mplus (Muthén \& Muthén, 2011) to assess the viability of a one-factor structure. The result of the $\chi^{2}$ test was significant $\left(\chi^{2}=153.98, d f=2, p<.001\right)$ which indicated less than optimal model fit. However, as Kenny (2012) suggests, sample sizes that are larger than 400 tend to yield significant $\chi^{2}$ results and the sample size here was 326 . In addition to the $\chi^{2}$ test, three fit indices are commonly considered. The comparative fit index (CFI) compares the proposed model with the null model. Values that are greater than 0.90 have been proposed to indicate a good fit (Medsker, Williams, \& Holahan, 1994). The CFI value of the present model was 0.91. The standardized root mean square residual (SRMR) compares the observed and predicted covariance matrix. Values that are less than .08 are considered to indicate a good fit (Brown \& Chudeck, 1993). The SRMR value of the present model was 0.06 . The root mean square error of approximation (RMSEA) shows the distance between the proposed model and the perfect-fit model. Brown and Chudeck (1993) suggest that values greater than 0.10 indicate a poor fit. The RMSEA value of the present model was 0.31 which may indicate a subpar model fit. However, Kenny, Kanishkan, and McCoach (2011) have argued that RMSEA is an unsuitable fit index for models with a low degree of freedom as the RMSEA values tend to be artificially inflated in such a case. The present model has only 2 degrees of freedom. This may be related to the high RMSEA value, especially given that the other fit indices suggest a good fit. The 
confirmatory factor analysis also revealed that all items loaded well on the single factor, with the standardized loadings for all items greater than $0.70(p<.001)$.

Results from the subsequent pilot studies suggested that the four-item scale demonstrated superior convergent validity with leader member exchange (Graen \& UhlBien, 1995) and perceived organi zational support (Eisenberger, Huntington, Hutchison, \& Sowa, 1986), and divergent validity with intrinsic motivation (Grant, 2008) and individual hurriedness (Jansen \& Kritof-Brown, 2005) compared to existing trust measures, including those of Mayer and Davis (1999) and McAllister (1995). The new four-item scale also showed superior criterion-related validity with cynicism (Reichers, Wanous, \& Austin, 1997) and satisfaction with leader (Smith, Kendall, \& Hulin, 1969). Across multiple samples, the alpha of the scale ranged between 0.86 and 0.91 .

For the present sample, the four items were used to measure the extent to which each team member trusts their team leader during each of the three waves of data collection in Fall 2011. Sample items included "I believe my leader will look out for my welfare," and "I am willing to let my leader have influence over matters that are critical to me." As discussed previously, the number of responses from T3 was lower than expected due to an unscheduled network shutdown. Since trust in leaders is a primary variable in this research, maximizing the number of respondents is important. Among the 379 squad members who responded to the trust in leader measure at both T2 and T3, the correlation between the two time points was $0.71(p<.001)$. Therefore, in order to obtain a sufficient sample size, I utilized the trust in leader score assessed at T2 for $41 \%$ of squad members who had responded in T2 but not in T3. The T3 data (or T2 when T3 data was missing) was used to examine the concurrent relationship between the degree of 
consensus and its antecedents and outcomes. The data from T1 was compared to the T3 data (or T2 when T3 data was missing) to study these same relationships with changes in consensus over time. The alpha for this scale was 0.89 at $\mathrm{T} 1$ and 0.94 for combining T2 and T3.

Consensus in trust in leaders. Trust consensus in leaders is specified as a dispersion model (Chan, 1998). Following the strategy used in prior research on climate consensus (Lindell \& Brandt, 2000; Schneider et al., 2002; Zohar \& Luria, 2005), consensus in trust in leader is operationalized as the standard deviation (SD) of members' trust in the leader within a team. Therefore, higher scores indicate lower consensus and lower scores indicate higher consens us. SD has been preferred over $r_{w g}$ and other measures of dispersion (Bliese, 2000; Roberson, Sturman, \& Simons, 2007) when the goal of the research is to examine the degree of consensus as a primary variable, rather than as a statistical hurdle to justify aggregation.

Trust in teams. The trust in teams scale was adapted from the trust in leaders scale, using team members as the referent instead of the team leader. This measure was collected during T2. Four items were used to assess the extent to which each team member trusts their team members, such as: "I feel I can count on my team members to act in my best interest," and "I am willing to let my team members have influence over matters that are critical to me." The alpha for this scale was 0.90 .

To assess the psychometric properties of this scale, an exploratory factor analysis was first conducted without constraining the number of factors. The results from the first eigenvalue and the scree plot indicated a single factor structure. A confirmatory factor analysis was then conducted to assess the model fit, which revealed similar results to the 
trust in leaders scale. The fit indices suggest an acceptable fit $\left(\chi^{2}=210.08, d f=2, p<\right.$ $.001 ; \mathrm{CFI}=.89 ; \mathrm{RMSEA}=.36 ; \mathrm{SRMR}=.06)$. The standardized loadings for all items were greater than $0.70(p<.001)$. I also conducted a combined confirmatory factor analysis with the two trust measures with different referents (leaders and teams). The fit statistics indicated a reasonable fit of the overall model $\left(\chi^{2}=516.15, d f=19, p<.001 ; \mathrm{CFI}=.90\right.$; RMSEA=.18; SRMR=.05). Further, to demonstrate criterion validity, the measure of trust in teams should be related to relevant team outcomes. At the team level, the scale was related to team potency (Kirkman, Rosen, Tesluk, \& Gibson, 2004; r = .38, p <.05).

Consensus in trust in teams. As with trust in leaders, consens us in trust in teams is based on a dispersion model (Chan, 1998). Thus, it was operationalized through the SD of member scores (i.e., the SD of members' trust in team members within a team). Higher scores indicate lower consens us, and vice versa.

Member perceptions of the leader. At T2, team members assessed their leaders' attributes and behaviors, including leader ability, integrity, showing concern, leading by example, and monitoring. As with prior research on leader attributes and behaviors (e.g., Cole et al., 2011; Walumbwa, Hartnell, \& Oke, 2010), the leadership variables were assessed by followers and then aggregated. The aggregation statistics for these measures are discussed later in this chapter.

Leader ability. The leader ability scale was adapted from the servant leadership scale (Liden, Wayne, Zhao, \& Henderson, 2008). Specifically, four items from the conceptual skills sub-dimension were used, which assess the extent to which a leader possesses "the knowledge of the organization and tasks at hand so as to be in a position to effectively support and assist others, especially immediate followers" (p. 162). Sample 
items included "my squad leader is able to effectively think through complex problems," and "my squad leader has a thorough understanding of the institution and its goals." Alpha for this scale was 0.88 .

Leader integrity. Four items from the ethics sub-dimension of the servant leadership scale (Liden et al., 2008) were used to measure squad members' perception of their leader's integrity, which refers to the extent to which the leader "adheres to a set of principles that the trustor finds acceptable" (Mayer et al., 1995, p.719). Sample items included: "my squad leader holds high ethical standards," and "my squad leader would not compromise ethical principles in order to achieve success." Alpha was 0.91 .

Leader showing concern. Four items from the leader emotional healing scale in the servant leadership scale (Liden et al., 2008) were used. The scale includes items such as: "my squad leader can recognize when I'm down without asking me," and "my squad leader takes time to talk to me on a personal level." ${ }^{, 2}$ Alpha for this scale was 0.90 .

Leading by example. Three items from the leading by example scale of the Empowering Leadership Questionnaire (Arnold, Arad, Rhoades, \& Drasgow, 2000) were included. Sample items were "my squad leader works as hard as anyone in my squad," and "my squad leader sets high standards for performance by his/her own behavior." Alpha for this scale was 0.92 .

Leader monitoring. The measure by Langfred (2004) was used to examine team members' perceptions of the monitoring behavior of their leader. The scale consists of four items, including "my squad leader monitors our progress on unit projects," and "my

\footnotetext{
${ }^{2}$ A confirmatory factor analysis was conducted to examine whether leader showing concern and trust in leaders were two distinct factors. The fit statistics indicated a good fit for the two-factor model $\left(\chi^{2}=\right.$ 253.91, $\mathrm{df}=19, \mathrm{p}<.001 ; \mathrm{CFI}=.94 ; \mathrm{RMSEA}=.10 ; \mathrm{SRMR}=.04)$. The standardized loadings for all items were greater than $0.70(\mathrm{p}<.001)$.
} 
squad leader checks whether everybody is meeting their obligation to the squad." Alpha for this scale was 0.90 .

Team open communication. Three items from the measure used by Meglino, Lester, and Kors gaard (2002) and adapted from O'Reilly and Roberts (1976) were used to assess the degree of open communication within the team. The three items were: "my squad members are very willing to share information with other me mbers about our duties," "there is a great deal of understanding when my squad members talk to each other," and "my squad members are comfortable talking to each other about what needs to be done." Team communication was assessed during T2. Alpha for this scale was 0.86 .

Team de mographic diversity. After collection of the three waves of data, squad leaders and squad members reported the demographic characteristics of gender and ethnicity for their squad members. The data obtained from squad leaders were used and, when they were unavailable, the responses from the squad members were used. Because of the small n of each mi nority ethnicity group (i.e., African American, Hispanic American, Asian American, and Native American) within a squad, ethnicity was categorized into Caucasian and Non-Caucasian and their percentages were obtained. Likewise, the percentages of male and female members were obtained. The Blau (1977) index was calculated as a measure of diversity for gender and ethnicity (cf. Bantel \& Jackson, 1989; Jackson, Brett, Cessa, Cooper, Julin, \& Peyronnin, 1991). The Blau index was calculated using the following expression,

$$
1-\sum_{i=1}^{n} p_{i}^{2}
$$

where $p_{i}$ is the percentage of team members in the $i$ th category, and $n$ represents the total number of categories. There were two categories each for ethnicity and for 
gender. The index can take on values ranging from 0 to 1 , with a higher number indicating greater diversity (Teachman, 1980).

Team performance. Five active-duty Company Officers at the institution were interviewed to determine the most appropriate indicators of performance ratings for a squad. Performance of the squad was rated on three criteria, performance, competence, and professionalism, using a five-point scale $(1=$ among the worst, $5=$ among the best $)$. These items were selected based on feedback from the interviews, as they represent the most meaningful and relevant aspects of squad performance. At T3, squad leaders and squad members rated team performance. However, there were only 15 teams for which the corresponding squad leaders responded while performance as rated by squad members was available for 65 teams. Thus, me mber-rated performance was used in subsequent analyses. Alpha for the member-rated measure was 0.85 .

Team voice behavior. Four items from Van Dyne and LePine's (1998) instrument were adapted. Sample items were "I have developed and made recommendations concerning issues that affect this squad," and "I have communicated my opinions about issues to other squad members even if my opinion is different and others disagree with me." Each squad member rated their own voice behavior at T3. Alpha for this scale was .95.

Team leader history and reputation. Adapted from Ballinger, Schoorman, and Lehman (2009), the four items assessed the quality of prior relationship, if any, between a squad member and a squad leader. In addition, squad members rated the leader's reputation: "Before he/she took the current billet, I heard that my squad leader had a good reputation." This measure was assessed at T1 and included as a control variable in the 
analyses of consensus in trust in leaders, because it could influence how team members perceive the leader (Ballinger et al., 2009) and how their consensus in trust in leaders developed. The purpose of this scale was to assess the extent to which team members had knowledge about their leader prior to the leader assuming the position in the team. Therefore, the items for history and reputation were combined. An exploratory factor analysis was conducted, and the results from the first eigenvalue and the scree plot supported a single factor structure, with the factor loadings for all items above .40 . Cronbach's alpha for this scale was 0.84 .

Leader de mographics. The demographic variables of team leaders were collected as potential control variables. Forty-five leaders provided their demographic information. Team leaders' age, gender, and ethnicity did not significantly correlate with any study variables. For example, their correlations with the consens us in trust in leaders ranged from -.04 to .11 (n.s.). Based on these results, leader demographic variables were not included in subsequent analyses.

Team size. Biemann and Kearney (2010) demonstrated how group diversity measures could be systematically biased due to varying sizes across teams. Therefore, the trust consensus measures were corrected for the number of respondents per team to avoid bias and erroneous interpretations of the relationships that involve the consensus measures. The process of the correction is described in Chapter 6. Because team size was not significantly related to other key study variables except team voice behavior, the consensus measures were corrected for team size, but team size was not included as a control variable in the analyses. 


\section{Aggregation of Variables}

Because the level of analysis in this research is at the team (squad) level, aggregation statistics including $\mathrm{r}_{\mathrm{wg}}$, one-way ANOVA, ICC1, and ICC2 were calculated to justify aggregation of individual squad members' scores to the team level. The following variables were included because their higher-level definitions assume the perceptions and beliefs are collectively shared among members: trust in leader (mean), trust in teams (mean), leader ability, leader integrity, leader showing concern, leading by example, leader monitoring, team communication, team performance, and team voice behavior. Table 1 displays the aggregation statistics for each variable from teams with 3 or more members.

Table 1

Aggregation Statists of Key Study Variables from Teams with Three or More Members

\begin{tabular}{lcccc}
\hline \multicolumn{1}{c}{ Variable } & ICC1 & ICC2 & $\mathrm{r}_{\mathrm{wg}(\mathrm{j})}$ & $\mathrm{r}_{\mathrm{wg}(\mathrm{j})}$ Range \\
\hline T1 Trust in leaders & 0.06 & 0.25 & 0.75 & $0.00-1.00$ \\
T2 Leader ability & 0.08 & 0.24 & 0.76 & $0.00-1.00$ \\
T2 Leader integrity & 0.16 & 0.40 & 0.83 & $0.00-1.00$ \\
T2 Leader showing concern & 0.08 & 0.24 & 0.66 & $0.00-1.00$ \\
T2 Leader leading by example & 0.19 & 0.45 & 0.74 & $0.00-1.00$ \\
T2 Leader monitoring & 0.08 & 0.25 & 0.66 & $0.00-1.00$ \\
T2 Team communication & 0.02 & 0.06 & 0.76 & $0.00-1.00$ \\
T2 Trust in teams & 0.07 & 0.22 & 0.72 & $0.00-1.00$ \\
T3 Trust in leaders & 0.14 & 0.39 & 0.72 & $0.00-1.00$ \\
T3 Team performance & 0.21 & 0.49 & 0.75 & $0.17-1.00$ \\
T3 Team voice behavior & -0.05 & -0.23 & 0.72 & $0.00-1.00$ \\
\hline
\end{tabular}

The trust variables and leader-related variables assumed a direct consens us model (Chan, 1998), with the item referent directed toward the individual and the measures aggregated to the team level. This is because individual members form their own perceptions of the leader based on their observation and experience, but the perceptions 
among team members can converge and be similar. When a construct resides in an individual's own perceptions, attitudes, feelings, and beliefs, it should be assessed with the "I" referent (James et al., 2008). The construct can then be aggregated from the individual level to the unit level. Another study variable that assumed the direct consensus model includes the team outcome of voice behavior. The measure of team voice behavior was aggregated to the team level assuming the direct consensus composition model because, as discussed, the construct of interest is whether members in a team shared the practice of speaking up and sharing opinions.

In contrast, the variables of team communication and team performance assumed a referent-shift consensus model (Chan, 1998), with the item referent directed toward the team as a whole, because these variables exist at the team level. In other words, the definitions of these constructs are collective in nature even though they are being assessed at the individual level. When team members perceive that they agree that certain team dynamics, team processes, and team outcomes occur, the construct at the team level emerges. Both sufficient within-group agreement and between-group variance are needed to justify aggregation to the team level.

Unlike the other key study variables in this study, the measure of leader history and reputation assumed an additive model because different members may have had divergent prior knowledge about or experiences with the leader, and there is no reason to expect that members in a unit would have similar prior experience with the leader before he or she takes the position. Because of this, demonstrating agreement is not necessary. An $r_{w g(j)}$ was calculated for each squad and the average score was obtained across squads. Scores of $r_{\mathrm{wg}(\mathrm{j})}$ demonstrate within-group agreement - the extent to which scores 
of members in a team are homogeneous in their perceptions or responses (Bliese, 2000; James, Demaree, \& Wolf, 1984). As Table 1 shows, the $r_{\mathrm{wg}(\mathrm{j})}$ values for each scale across teams ranged from 0 to 1 , except team performance with a range between .17 and 1 . Similar to the norms for reliability, it has been suggested that $r_{\mathrm{wg}(\mathrm{j})}$ values of .70 or greater are desirable (James et al., 1984; Kozlowski \& Klein, 2000). With the exception of leader showing concern and leader monitoring, the average $r_{\mathrm{wg}(\mathrm{j})}$ scores were above the 0.70 cutoff. For those below .70 (leader showing concern and leader monitoring), the $r_{w g(j)}$ was close to .70 . One-way analyses of variance (ANOVA) reveal whether the between-group variances are significantly different from zero. The one-way ANOVA results indicated that team communication and team voice behavior did not differ significantly between squads. All other variables showed significant between-group variation across squads. ICC1 scores indicate the extent to which variance in individual-level measures can be explained by group membership (Raudenbush \& Bryk, 2002). Bliese (1998) reports that the ICC 1 scores typically fall between 0.02 and 0.21 . With the exception of team voice behavior, the ICC1 values for all variables were within this range (Table 1). ICC2 scores can be interpreted to demonstrate reliability of the mean scores (Bliese, 2000). With the exception of team voice behavior, the ICC 2 values ranged between 0.06 and 0.19 . The ICC2 values in Table 1 indicate low reliability of the mean scores. Because ICC2 scores assume a subsample coming from an infinite pool of respondents and are related to group size, the limited number of respondents per team is one reason that ICC2 scores are low. The low reliability of group means should also be considered in conjunction with the high within-group homogeneity within squads, as indicated by the $r_{\mathrm{wg}(\mathrm{j})}$ values, as well as significant between-group differences and reasonable ICC1 values, 
which lend sufficient justification for aggregation. Prior studies (e.g., Bliese \& Halverson, 1998; Cole et al., 2011; Colquitt et al., 2002; Jarvenpaa \& Leidner, 1999) have also defined these variables to be theoretically meaningful at the team level. The relatively low ICC2 values can make detection of meaningful team-level relationships more difficult (Bliese, 1998; 2000) and, like low internal consistency reliability, may underestimate the magnitude of the true relationships.

\section{Analysis Plan}

All analyses in this research were conducted at the team level. Hence, all variables were aggregated to team level. The first set of hypotheses focused on the degree to which consensus in trust in leaders changes over time. The hypotheses were tested using paired samples t-tests. The second set of hypotheses asserted that different emergent processes would be related to the degree of consensus and changes in consensus, focusing on the difference between leader attributes and behaviors, and between the leader referent and the team referent. Hierarchical multiple regression models were conducted to test these hypotheses. For the concurrent models, T3 consensus in trust in leaders was regressed on the set of leader attributes, leader behaviors, and team variables assessed in $\mathrm{T} 2$. Because the time difference in data collection between $\mathrm{T} 2$ and $\mathrm{T} 3$ was only about 2 weeks and was done to help account for response bias, the models are considered concurrent models. For the change models, T3 consensus in trust in leaders was regressed on the T1 consensus in step 1, followed by the set of leader and team variables in step 2.

The third set of hypotheses proposed that the consensus would be related to outcomes, after controlling for the mean level of trust in leaders, and further that 
consensus and the mean level of trust would interact in their relationship with outcomes.

For the third set of hypotheses, following recommendations by Bliese and Hanges (2004), the mean level of trust in leaders was included when analyzing the relationship between consensus variables and team outcome variables. Bliese and Hanges (2004) concluded that mean and standard deviation are routinely non-independent in organizational research, a relation that had been theoretically and mathematically demonstrated by other researchers (Lindell \& Brandt, 2000). Therefore, to understand the effects of consensus on outcomes, it is crucial to control for the effects of the mean, otherwise there is "the possibility that observed variance effects are a spurious by-product of absolute level effects', (Bliese \& Britt, 2001, p. 433). This argument, however, only applies for analyses of effects of consensus when consensus is used as an independent variable. Consistent with prior research (e.g., Naumann \& Bennett, 2000; Zohar \& Luria, 2004), the analysis of predictors of consensus (i.e., when consens us is the dependent variable) did not control for the mean of trust. 


\section{Chapter 6. Results}

In this chapter, I first present descriptive and correlational statistics. Next, I present the results of analyses used to test the proposed hypotheses, including changes in consensus across time, antecedents of consensus, and consequences of consensus. For the antecedents and consequences of consensus in trust in leaders, I first present concurrent results, followed by results pertaining to the change in consens us between $\mathrm{T} 1$ and $\mathrm{T} 3$.

\section{Consensus Measures}

Theoretically and mathematically, the correlation between the mean and consensus is non-significant and zero because, as can be seen in Figure 2, consens us is very high when the mean is both very low (box a) or very high (box c) and when the mean is mid-scale, consens us can range from zero to very high (boxes b, d, and e).

\section{Figure 2}

The Theoretical Relationship between the Mean and Consensus

(Reprint from Lindell \& Brandt, 2000)

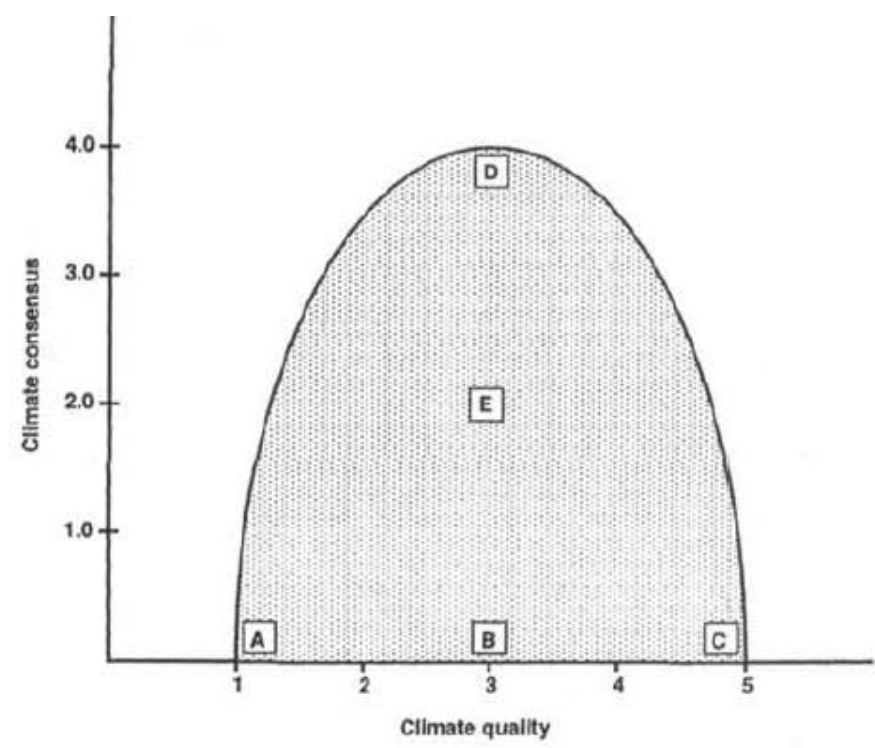

Figure 3. Functional relationship between climate quality and climate consensus for a polytomous variable. Note that climate consensus is measured by the variance, so smaller scores imply greater consensus. 
However, when there is significant attrition of units on one end of the scale, a significant linear or nonlinear relationship between the mean and consens us can result (Lindell \& Brandt, 2000). The range restriction on mean scores can make the distribution of consensus non-normal.

\section{Figure 3}

The Scatter Plot of T3 Consensus and Mean of Team Trust in Leaders

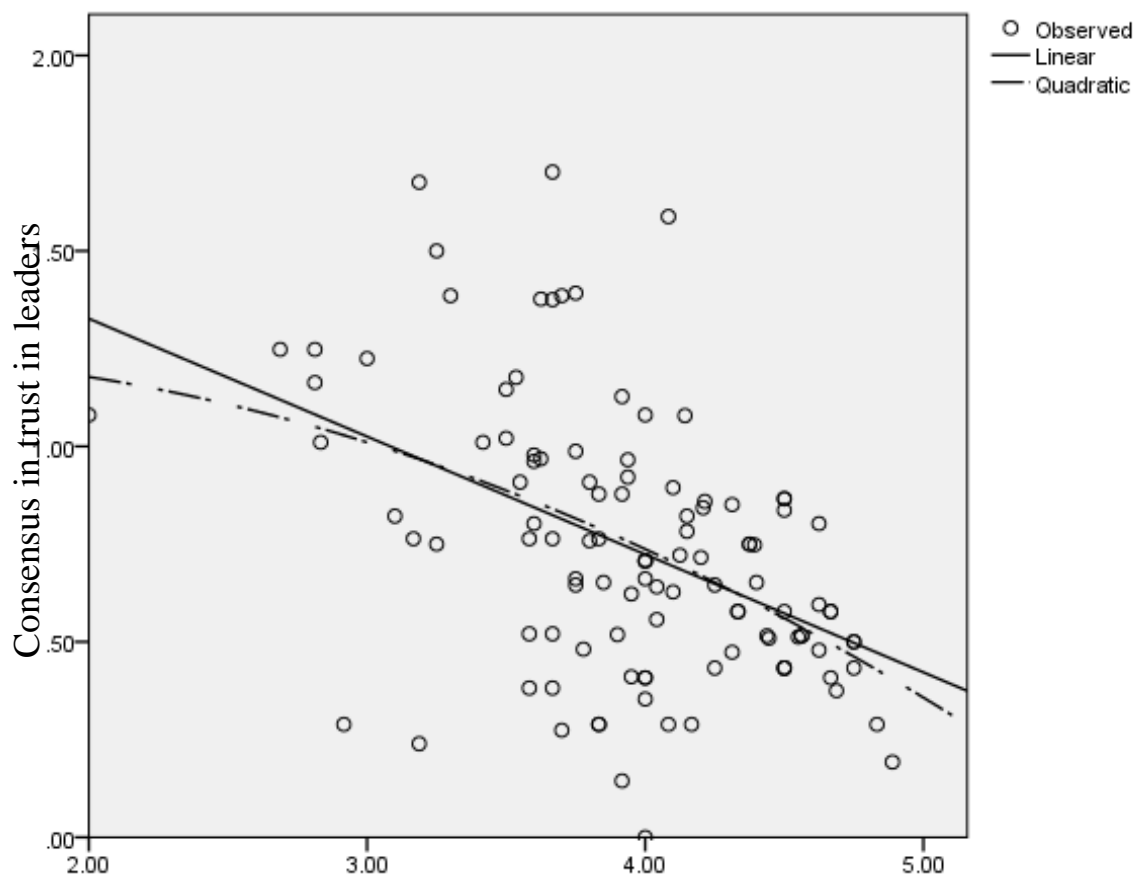

Mean of team trust in leaders

In the present study, the correlation between the T3 mean and T3 untransformed consensus (SD) of trust in leaders was $r=-0.47(\mathrm{p}<.01)$. The correlation between the T2 mean and T2 consensus (SD) of trust in teams was likewise negative though weaker $(r=-$ $.28, p<.01)$. The negative correlations suggest the presence of some range restriction. Figure 3 shows a scatter plot of the T3 means and T3 consensus in trust in leaders, with linear and quadratic trend lines. As consensus was operationalized as the SD of members' trust in a team, a higher SD value in Figure 3 represents a lower level of consensus and 
vice versa. As can be seen, the relationship is negative and appears to be linear rather than nonlinear due to attrition of teams with low mean scores for trust in leaders. Regression results confirmed the linearity, as including the quadratic term of consens us did not significantly improve the model fit when regressing the mean level on the consensus $\left(\mathrm{R}^{2} \Delta=.004\right.$, n.s.). The scatter plot of the consensus in trust in teams showed a similar pattern.

Further, the tests of normality (Kolmogorov-Smirnov Test and Shapiro-Wilk Test) confirmed that that the distributions were non-normal for T3 consensus in trust in leaders $(\mathrm{Dn}=.08, \mathrm{p}<.05 ; \mathrm{W}=.98, \mathrm{p}<.05)$ and $\mathrm{T} 2$ consens us in trust in teams $(\mathrm{Dn}=.14$, $\mathrm{p}<.001 ; \mathrm{W}=.96, \mathrm{p}<.01)$, which was supported by the normal Q-Q plots. In particular, the test statistics of $\mathrm{Z}_{\mathrm{g} 1}$ was greater than 2 for both consensus measures, indicating that their distributions were significantly and positively skewed $(\mathrm{p}<.05)$. Thus, I transformed both consensus measures using a natural logarithm operation. Reexami nation of normality indicated that both log-transformed consensus measures displayed normal distributions. The test of normality for consens us in trust in leaders in T1 was not significant ( $\mathrm{Dn}=.08$, n.s.; $\mathrm{W}=.99$, n.s.). However, for consistency, the T1 measure was also $\log$ transformed.

In addition to the skewed distributions, the consensus measures were also corrected for team size to avoid bias as discussed in Chapter 5. The number of respondents per squad was positively correlated with T3 untransformed consensus in trust in leaders $(\mathrm{r}=0.24, \mathrm{p}<.05)$. To keep the two consensus measures consistent, consensus in trust in leaders and trust in team members were both normalized to correct for bias due to group size, following the procedures recommended by Biemann and Kearney (2010): 


$$
S D_{N}=\sqrt{\frac{\sum\left(X_{i}-\bar{X}\right)^{2}}{q}}
$$

where $\mathrm{q}$ is

$$
q=\frac{(N-1)}{C_{N}^{2}}
$$

and $C_{N}$ is calculated using the gamma function as in the following expression

$$
C_{N}=\frac{\Gamma\left(\frac{N-1}{2}\right) \sqrt{\frac{N-1}{2}}}{\Gamma\left(\frac{N}{2}\right)}
$$

In all subsequent analysis for hypothesis testing, the transformed measures of consensus were utilized ${ }^{3}$.

\section{Means, Standard Deviations, and Intercorrelations}

Table 2 shows the means and standard deviations of the study variables at the team level of analysis. Recall that consens us measures are operationalized through the SD such that higher scores indicate lower consensus.

Examination of Table 2 indicates that the mean scores for the trust measures, leader attributes and behaviors, and team communication and outcomes (performance and voice) were above the scale midpoints (i.e., 3 on a 5-point scale). The mean level of trust in leaders at $\mathrm{T} 1$, when team leaders and some members had recently changed, were not correlated with other key study variables, except with team communication $(r=.27, p<$ .01). In contrast, the mean level of trust at T3, after months of interactions between leaders and members, revealed significant correlations with nearly all key study variables ( $\mathrm{r}$ ranged between .22 and $.74, \mathrm{p}<.05$ ), with the exception of team gender diversity and

\footnotetext{
${ }^{3}$ The analyses for hypothesis testing were repeated with the consensus measures without correction for team size and log transformation (i.e., untransformed SD). The results on antecedents were identical to that reported in this chapter, while the results on outcomes were not significant.
} 
team voice behavior. The degree of consensus in trust in leaders at T1 did not show signi ficant correlations with any of the predicted leadership behaviors or team outcome variables, but significant relationships were obtained between T3 consensus in trust in leaders and leadership and outcome variables. Together, this pattern suggests that emergence of team trust in leaders occurred and became meaningful over time, consistent with Hypothesis 1.

Table 2

Descriptive Statistics of the Key Study Variables

\begin{tabular}{lcrc}
\hline \multicolumn{1}{c}{ Variable } & $\mathrm{N}$ & $\mathrm{M}$ & $\mathrm{SD}$ \\
\hline T1 Trust in leaders mean & 105 & 3.55 & 0.41 \\
T1 Trust in leaders consens us & 105 & 0.69 & 0.28 \\
T1 Trust in leader transformed consensus & 105 & -0.27 & 0.59 \\
T3 Trust in leaders mean & 105 & 3.96 & 0.53 \\
T3 Trust in leaders consensus & 105 & 0.74 & 0.35 \\
T3 Trust in leaders transformed consensus & 105 & -0.18 & 0.63 \\
T2 Trust in teams mean & 105 & 3.57 & 0.47 \\
T2 Trust in teams consens us & 105 & 0.67 & 0.35 \\
T2 Trust in teams transformed consensus & 105 & -0.33 & 0.88 \\
T3 Team size & 105 & 4.10 & 1.14 \\
T1 Leader reputation/history & 105 & 3.50 & 0.48 \\
T2 Leader ability & 105 & 3.79 & 0.44 \\
T2 Leader integrity & 105 & 4.17 & 0.41 \\
T2 Leader showing concern & 105 & 3.72 & 0.56 \\
T2 Leader leading by example & 105 & 3.93 & 0.58 \\
T2 Leader monitoring & 105 & 3.70 & 0.48 \\
T2 Team communication & 105 & 3.86 & 0.39 \\
Team ethnic diversity & 105 & 0.32 & 0.14 \\
Team gender diversity & 105 & 0.26 & 0.14 \\
T3 Team performance & 65 & 3.67 & 0.54 \\
T3 Team voice behavior & 65 & 3.54 & 0.39 \\
\hline
\end{tabular}

Note: Consensus was operationalized as SD. Higher scores indicate lower consensus.

As Table 3 shows, the intercorrelations among the five leader variables assessed at T2 (leader ability, integrity, showing concern, leading by example, and monitoring) 
ranged between 0.62 and $0.76(\mathrm{p}<.01)$. This is not surprising because the variables assessed attributes about the same target leader and likely share similar underlying dimensions. Researchers have found that moderate to high correlations among leadership variables are common (e.g., Barnowe, 1975; Bass et al., 2003; Bycio, Hackett, \& Allen, 1995; Den Hartog, Van Muijen, \& Koopman, 1994). The pattern of correlations among the leadership variables indicates that the attributes are related but can still be considered independent constructs. The correlations between the five T2 leadership variables and the T3 mean level of trust in leaders were all significant, ranging between 0.55 and $0.74(\mathrm{p}<$ $.01)$. This pattern of results is consistent with prior research at the individual level whereby trust in leaders has been related to leader attributes and behaviors (e.g., Dirks \& Ferrin, 2002).

Further, these correlations between the T2 leader variables and T3 mean level of trust in leaders were larger than the correlation between the T2 team communication T3 mean of trust in leaders $(r=.39, \mathrm{p}<.01)$ or between the T3 mean of trust in leaders and team ethnic diversity $(\mathrm{r}=-.26, \mathrm{p}<.01)$ and team gender diversity $(\mathrm{r}=-.12$, n.s. $)$. Likewise, the correlation between team open communication and the T2 mean of team trust in teams was relatively strong $(\mathrm{r}=.57, \mathrm{p}<.01)$. It was larger than those between the $\mathrm{T} 2$ mean of team trust in teams and T2 leader variables ( $\mathrm{r}$ between .11 and $.33, \mathrm{p}<.05$ for values greater than .20). These patterns provided some support for the notion of target match between variables. However, the correlation between team ethnic diversity and T2 mean of team trust in teams was not significant $(r=-.19$ for gender and $r=-.02$ for ethnicity). 


\section{Table 3}

Correlations of the Key Study Variables (Excluding Team Outcomes)

\begin{tabular}{|c|c|c|c|c|c|c|c|c|c|c|c|c|c|c|c|c|c|c|}
\hline Variable & 1 & 2 & 3 & 4 & 5 & 6 & 7 & 8 & 9 & 10 & 11 & 12 & 13 & 14 & 15 & 16 & 17 & 18 \\
\hline $1 \mathrm{~T} 1$ Trust in leaders mean & & & & & & & & & & & & & & & & & & \\
\hline $\begin{array}{l}2 \text { T1 Trust in leaders consensus } \\
\text { (SD) }\end{array}$ & -.09 & & & & & & & & & & & & & & & & & \\
\hline $\begin{array}{l}31 \text { Trust in leader } \\
\text { transformed consensus (SD) }\end{array}$ & .02 & $.81^{* *}$ & & & & & & & & & & & & & & & & \\
\hline 4 T3 Trust in leaders mean & $.22^{*}$ & $-.22^{*}$ & -.19 & & & & & & & & & & & & & & & \\
\hline $\begin{array}{l}5 \text { T3 Trust in leaders consensus } \\
\text { (SD) } \\
\text { T3 Trust in leaders }\end{array}$ & -.07 & $.40^{* *}$ & $.22^{*}$ & $-.47^{* *}$ & & & & & & & & & & & & & & \\
\hline $\begin{array}{l}6 \text { transformed } \\
\text { Consensus }(\mathrm{SD})\end{array}$ & -.06 & $.29^{* *}$ & .15 & $-.32^{* *}$ & $.82^{* *}$ & & & & & & & & & & & & & \\
\hline 7 T2 Trust in teams mean & $.53^{* *}$ & .02 & .05 & $.22^{*}$ & .06 & .02 & & & & & & & & & & & & \\
\hline $\begin{array}{l}8 \text { (SD) } \\
\text { T2 Trust in teams transformed }\end{array}$ & -.15 & $.29^{* *}$ & $.23^{*}$ & $-.22^{*}$ & $.28^{* *}$ & .13 & $-.28^{* *}$ & & & & & & & & & & & \\
\hline 9 Consensus (SD) & -.15 & $.23^{*}$ & .17 & -.10 & $.28^{* *}$ & .19 & -.14 & $.77^{* *}$ & & & & & & & & & & \\
\hline 10 T3 Team size & .04 & .09 & .11 & -.05 & $.24^{*}$ & .16 & .06 & .06 & .09 & & & & & & & & & \\
\hline 11 T1 Leader reputation/history & -.12 & -.15 & $-.28^{* *}$ & $.34^{* *}$ & -.01 & .01 & -.05 & -.07 & -.02 & .13 & & & & & & & & \\
\hline 12 T2 Leader ability & .12 & .01 & -.06 & $.69^{* *}$ & -.17 & -.18 & $.35^{* *}$ & -.14 & -.06 & -.07 & $.27^{* *}$ & & & & & & & \\
\hline 13 T2 Leader integrity & .01 & .06 & -.03 & $.51^{* *}$ & -.07 & -.13 & $.23^{*}$ & -.02 & -.03 & .00 & $.31^{* *}$ & $.69^{* *}$ & & & & & & \\
\hline 14 T2 Leader showing concern & .10 & -.16 & $-.19^{*}$ & $.74^{* *}$ & $-.36^{* *}$ & $-.28^{* *}$ & $.25^{*}$ & $-.22^{*}$ & -.12 & -.01 & $.44^{* *}$ & $.74^{* *}$ & $.62 *^{*}$ & & & & & \\
\hline 15 T2 Leading by example & .05 & -.01 & -.06 & $.59^{* *}$ & $-.27^{* *}$ & $-.27^{* *}$ & .11 & -.09 & -.10 & .04 & $.33^{* *}$ & $.69^{* *}$ & $.76^{* *}$ & $.67^{* *}$ & & & & \\
\hline 16 T2 Leader monitoring & .09 & -.05 & -.07 & $.55^{* *}$ & $-.23^{*}$ & -.18 & $.33^{* *}$ & -.12 & -.03 & .01 & $.21^{*}$ & $.73^{* *}$ & $.62^{* *}$ & $.66^{* *}$ & $.67^{* *}$ & & & \\
\hline 17 T2 Team communication & $.27^{* *}$ & -.05 & -.05 & $.39^{* *}$ & -.10 & -.05 & $.57^{* *}$ & $-.23^{*}$ & -.12 & -.10 & .17 & $.54^{* *}$ & $.42^{* *}$ & $.48^{* *}$ & $.31^{* *}$ & $.44^{* *}$ & & \\
\hline 18 Team ethnic diversity & -.05 & .13 & .04 & $-.26^{* *}$ & $.30^{* *}$ & $.25^{*}$ & -.02 & .05 & -.01 & .11 & .02 & -.09 & -.06 & -.19 & -.03 & -.13 & .01 & \\
\hline 19 Team gender diversity & -.04 & -.05 & .07 & -.12 & .05 & .11 & -.19 & .08 & -.03 & .14 & -.15 & $-.21^{*}$ & $-.22^{*}$ & $-.22^{*}$ & -.06 & -.17 & $-.28^{* * *}$ & $.22^{*}$ \\
\hline
\end{tabular}

Note: Consensus was operationalized as SD. Higher scores indicate lower consensus.

$\mathrm{N}=105$ teams.

$* \mathrm{p}<.05 ; * * \mathrm{p}<.01$ 
With regard to the consensus, the $\mathrm{T} 1$ and $\mathrm{T} 3$ transformed consens us in trust in leaders was not significant $(\mathrm{r}=.15)$ indicating that the degree of co nsensus changed over time. Further, the correlation between the T3 transformed consensus in trust in leaders and $\mathrm{T} 2$ transformed consens us in trust in teams (assessed two weeks apart) was also not significant $(\mathrm{r}=.19)$, indicating that team consens us did not carry over from one trust referent to another. The correlations between emergent processes and transformed consensus in trust in leaders and in teams revealed some expected relationships. The correlations between T3 transformed consens us in trust in leaders and the leader behaviors of showing concern $(\mathrm{r}=-.28, \mathrm{p}<.01)$ and leading by example $(\mathrm{r}=-.27, \mathrm{p}<$ .01) were significant, indicating greater consens us when leaders exhibited such behaviors to a greater extent. However, T3 transformed consens us in trust in leaders was not significantly related to leader monitoring $(r=-.18)$. The correlations between consensus in trust in leaders with the leader attributes of leader ability $(r=-.18)$ and integrity $(r=-$ .13) were not significant, as expected. The results provide some initial support for Hypothesis 2.

Consistent with Hypothesis 3, which predicted that team emergent processes would be less influential on consensus in trust in leaders, the correlations between T3 transformed consensus in trust in leaders and team open communication $(r=-05)$ and team gender diversity $(\mathrm{r}=.11)$ were not significant, but the correlation with team ethnic diversity was $(\mathrm{r}=.25, \mathrm{p}<.05)$. Incidentally, the correlation of $\mathrm{T} 2$ transformed consensus in trust in teams and team open communication $(r=-.12)$, team ethnic diversity $(r=-.01)$, and team gender diversity $(r=-.03)$ were not significant. 
Table 4

Correlations between Team Outcomes and Other Key Study Variables

\begin{tabular}{lcc}
\hline \multicolumn{1}{c}{ Variable } & $\begin{array}{c}\text { T3 Team } \\
\text { performance }\end{array}$ & $\begin{array}{c}\text { T3 Team voice } \\
\text { behavior }\end{array}$ \\
\hline T1 Trust in leaders mean & .12 & .11 \\
T1 Trust in leaders consens us & -.20 & -.09 \\
T1 Trust in leader transformed consensus & -.23 & -.03 \\
T3 Trust in leaders mean & $.52^{* *}$ & .13 \\
T3 Trust in leaders consensus & $-.37^{* *}$ & -.10 \\
T3 Trust in leaders transformed consensus & $-.26^{*}$ & -.02 \\
T2 Trust in teams mean & -.05 & .22 \\
T2 Trust in teams consensus & $-.27^{*}$ & -.11 \\
T2 Trust in teams transformed consensus & -.14 & -.07 \\
T3 Team size & -.11 & $.25^{*}$ \\
T1 Leader reputation/history & .17 & -.22 \\
T2 Leader ability & $.34^{* *}$ & .03 \\
T2 Leader integrity & .16 & -.16 \\
T2 Leader showing concern & $.34^{* *}$ & .12 \\
T2 Leader leading by example & $.35^{* *}$ & -.04 \\
T2 Leader monitoring & .19 & .13 \\
T2 Team communication & $.25^{*}$ & .13 \\
Team ethnic diversity & -.05 & .00 \\
Team gender diversity & -.20 & $.29^{*}$ \\
\hline
\end{tabular}

Note: Consensus was operationalized as SD. Higher scores indicate lower consens us. $\mathrm{N}=65$ teams.

$* \mathrm{p}<.05 ; * * \mathrm{p}<.01$

With regard to the outcome of team performance (see Table 4), a higher T3 mean level of trust $(r=.52, \mathrm{p}<.01)$ and greater $\mathrm{T} 3$ transformed consensus $(\mathrm{r}=-.26, \mathrm{p}<.05)$ in trust in the leader was significantly related to member-rated performance. In addition, significant relations hips with performance were observed for the leader variables of ability $(\mathrm{r}=.34, \mathrm{p}<.01)$, showing concern $(\mathrm{r}=.34, \mathrm{p}<.01)$, and leading by example $(\mathrm{r}=$ $.35, \mathrm{p}<.01)$ and for team communication $(\mathrm{r}=.25, \mathrm{p}<.05)$. By comparison, only team size $(r=.25, \mathrm{p}<.05)$ and team gender diversity $(\mathrm{r}=.29, \mathrm{p}<.05)$ were significantly related to team voice behavior. 


\section{Hierarchical Nesting Effect}

The data in this study was nested whereby teams (squads) were nested within platoons, which in turn were nested within companies. ANOVAs were conducted to examine whether there were between-group differences based on the company or platoon level of analysis. For consens us in trust in leaders, results were not significant by either company $(\mathrm{F}=.86, \mathrm{n} . \mathrm{s}$.$) or platoon (\mathrm{F}=1.18, \mathrm{n} . \mathrm{s}$.$) . The results for consens us in trust in$ leaders were also not significant $(\mathrm{F}=1.10$, n.s. for company and $\mathrm{F}=1.10$, n.s. for platoon). Based on these results, the analyses below were conducted at the team level without accounting for the nesting effect at the platoon or company level.

\section{Change in Consensus over Time}

Hypothesis 1a predicted a decrease in consens us in trust in leader from T1 to T3. For this analysis, and all subsequent analyses, the transformed measure of consens us was used, whereby higher scores indicate lower consensus. To test Hypothesis 1a, a paired samples t-test was conducted. The results indicated that consensus in trust in leaders at T3 was not significantly different from the degree of consensus in trust in leaders at T1 $(\mathrm{t}[104]=-1.131, \mathrm{n} . \mathrm{s}$.$) . Note that this analysis focuses on the average level of consensus$ across teams at T1 and T3. Although the average level of consensus across teams remained consistent, the correlation between the T1 and T3 consensus measures was very low $(r=.15)$ highlighting that individual teams do not exhibit the same degree of consensus over time. Taken together, the findings suggest that some teams likely increased in their degree of consens us while others decreased in consensus, thereby producing similar average levels of consensus in leaders across teams, but a low correlation between $\mathrm{T} 1$ and $\mathrm{T} 3$ at the team level of analysis. 
Hypothesis $1 \mathrm{~b}$ predicted that the differences between teams in the amount of consensus in trust in leaders would become larger from T1 to T3. Consistent with Hypothesis $1 \mathrm{~b}$, ICC1 for team trust in leaders at $\mathrm{T} 1$ was .06 and at $\mathrm{T} 3$ was 0.14 , indicating an increase in the extent to which variance in individual trust in leaders can be explained by their group membership (Raudenbush \& Bryk, 2002). Because ICC1 concerns the relative variance within and between teams and reflects the ratio of between-group variance to total variance, increased values over time indicated that, relative to the between-group variance, the within-group variance decreased. Considering that ICC1 values typically range from .02 to .20 (Bliese, 2000), a change in ICC1 from .06 to .14 can be considered relatively large. These values suggest that group membership played an increasingly important role in influencing the consensus in trust in leaders over time so that the group means become more differentiated in relation to within-group variability. As mentioned earlier, the mean level of trust was not related to any of the emergent process variables or outcomes at $\mathrm{T} 1$, with the exception of team communication. Similarly, consens us in trust in leaders was not related to any key study variables at T1. However, both the mean level and consensus in trust in leaders at T3 were related to emergent process and outcome variables. This pattern of results lends some credence to the notion that consensus emerged and was meaningful at $\mathrm{T} 3$ but not at T1, shortly after the change of leadership.

Based on the above results, Hypothesis 1a was not supported. Although no inferential analyses could be run to explicitly test Hypothesis $1 \mathrm{~b}$, the pattern of results obtained from the ICC values and correlations provides some initial support. Further, these hypotheses focused on the average amount of consensus across all teams. It is 
important to also examine whether consensus can be predicted and if changes in the degree of consensus over time can be predicted using team level data in regression procedures. The results below focus on the emergent factors that could lead to a difference in consens us in trust in leaders across teams.

\section{Antecedents of Consensus.}

Hypotheses 2 and 3 focused on emergent processes related to the development of consensus in trust in leaders. In testing these hypotheses in hierarchical regression models, the eight emergent processes in this research-leader ability, integrity, showing concern, leading by example, monitoring, team open communication, team ethnic diversity, and team gender diversity_-were included in a hierarchical regression model simultaneously to examine their relative importance. Leader reputation and history was included as a control variable. Two sets of analyses were conducted, a concurrent model in which T3 consensus was regressed on T2 leader and team variables (Hypotheses 2a and 3a) and a change model in which $\mathrm{T} 3$ consens us was regressed on $\mathrm{T} 1$ consensus followed by $\mathrm{T} 2$ leader and team emergent process variables (Hypotheses $2 \mathrm{~b}$ and $3 \mathrm{~b}$ ).

Concurrent analyses for consensus in trust in leaders. Hypothesis 2 a proposed that leader behavior variables (leading by example, showing concern, and monitoring) would be more important for understanding the degree of consens us in trust in leaders than would leader attributes (ability, integrity). As the left side of Table 5 shows, the set of emergent process variables was related to consensus in trust in leader $(\mathrm{R} \Delta=.19, \mathrm{p}<$ $.01)$. Recall that lower scores indicate higher consensus, thus negative coefficients were expected for the leader variables and team communication and positive coefficients were 
Table 5

The Effects of Emergent Processes on the Consensus in Trust in Leaders

\begin{tabular}{|c|c|c|c|c|}
\hline \multirow[b]{2}{*}{ Variable } & \multicolumn{2}{|c|}{$\begin{array}{l}\text { Concurrent Model } \\
\text { T3 Consensus in } \\
\text { Trust in Leaders }\end{array}$} & \multicolumn{2}{|c|}{$\begin{array}{l}\text { Change Model } \\
\text { T3 Consens us in } \\
\text { Trust in Leaders }\end{array}$} \\
\hline & $\mathrm{B}$ & $\mathrm{SE}$ & $\mathrm{B}$ & SE \\
\hline (Constant) & -0.25 & 0.45 & -0.41 & 0.46 \\
\hline $\mathrm{T} 1$ Trust in leader consensus & & & $0.18 \dagger$ & 0.11 \\
\hline T1 Leader reputation/history & 0.02 & 0.13 & 0.08 & 0.13 \\
\hline $\mathrm{R}^{2}$ & \multicolumn{2}{|c|}{0.00} & \multicolumn{2}{|c|}{$0.03 * *$} \\
\hline (Constant) & -0.85 & 0.85 & -0.92 & 0.84 \\
\hline $\mathrm{T} 1$ Trust in leader consensus & & & 0.15 & 0.10 \\
\hline T1 Leader reputation/history & 0.22 & 0.14 & $0.27 \dagger$ & 0.14 \\
\hline T2 Leader ability & 0.12 & 0.25 & 0.10 & 0.25 \\
\hline T2 Leader integrity & 0.31 & 0.24 & 2.85 & 0.24 \\
\hline T2 Leader showing concern & $-0.33 \dagger$ & 0.19 & -0.29 & 0.19 \\
\hline T2 Leader leading by example & $-0.43 *$ & 0.19 & $-0.44 *$ & 0.19 \\
\hline T2 Leader monitoring & 0.10 & 0.19 & 0.10 & 0.19 \\
\hline T2 Team communication & 0.08 & 0.19 & 0.08 & 0.19 \\
\hline Team ethnic diversity & $0.87 \dagger$ & 0.46 & $0.86 \dagger$ & 0.46 \\
\hline Team gender diversity & 0.43 & 0.46 & 0.42 & 0.46 \\
\hline $\mathrm{R}^{2} \Delta$ & \multicolumn{2}{|c|}{$0.19 * *$} & \multicolumn{2}{|c|}{$0.18^{*}$} \\
\hline $\mathrm{R}^{2}$ & \multicolumn{2}{|c|}{$0.19 * *$} & \multicolumn{2}{|c|}{$0.21 *$} \\
\hline
\end{tabular}

Note: Consensus was operationalized as the transformed SD. Higher scores indicate less consensus.

$\mathrm{N}=105$ teams.

$\dagger \mathrm{p}<.10 ; * \mathrm{p}<.05 ; * * \mathrm{p}<.01$

expected for the diversity measures. Leading by example $(\beta=-.43, \mathrm{p}<.05)$ was

independently related to greater T3 consensus in trust in leaders. Showing concern was

marginally related to greater T3 consens us in trust in leaders $(\beta=-.33, p<.10)$. Contrary

to expectations, leader monitoring was not significant. As expected, the leader attribute

variables of leader ability and leader integrity were not significant. A follow-up test

comparing regression coefficients (Clogg, Petkova, \& Haritou, 1995; Paternoster, Brame,

Mazerolle, \& Piquero, 1998) indicated that the coefficient for leading by example was 
marginally different from leader ability $(Z=-1.75, p<.10)$ and was significantly different from leader integrity $(Z=-2.43, \mathrm{p}<.05)$. These results partially support Hypothesis 2a, that leader behavior and interaction factors were more influential on the emergence of team trust in leaders than leader attribute factors.

Hypothesis 3a predicted that that the leader factors of leading by example, showing concern, and monitoring would be more important for consens us in trust in leaders than team factors of communication and diversity. Team open communication and team gender diversity were not significant predictors $(\beta=.08$ and .43 , respectively) of consens us in trust in leaders. Results from the follow-up test comparing regression coefficients indicated that the coefficient for leading by example was marginally different from team open communication $(Z=-1.94, p<.10)$ and from team gender diversity $(Z=$ $-1.74, \mathrm{p}<.10)$. There results partially supported Hypothesis 3a. However, contrary to Hypothesis 3a, team ethnic diversity was marginally related to consensus in trust in leaders $(\beta=.87, \mathrm{p}<.10)$. The left side of Table 5 displays the concurrent regression results on the consensus in trust in leaders. Hypothesis 3a thus received mixed support.

Changes in consensus in trust in leaders. The concurrent results provided some support that emergent processes of leader behaviors and interactions are related to the degree of consensus in trust in leaders. However, emergence occurs over time and tests of emergence should include examination of changes in consensus over time (Kozlowski, 2012). To examine the effects of the emergent processes on changes in consensus in trust in leaders between $\mathrm{T} 1$ and $\mathrm{T} 3$ as stated in Hypothesis $2 \mathrm{~b}$ and $3 \mathrm{~b}$, the T3 consens us in trust in leaders was regressed on T1 consens us in trust in leaders in the first step along with the control variable of leader reputation/history, followed by the eight emergent process 
variables. Controlling for T1 consensus allows for examining change. A significant coefficient for the key variables, in this case the emergent process variables, would indicate that the variable is related to a change in consens us (Cohen, Cohen, West, \& Aiken, 2003). A negative beta would indicate an increase in consensus in trust in leaders between $\mathrm{T} 1$ and $\mathrm{T} 3$ while a positive beta would indicate a decrease in consensus.

After controlling for $\mathrm{T} 1$ consensus in trust in leaders and leader reputation/history, the set of emergent process variables accounted for a significant, additional $18 \%$ of the variance in leader trust consensus $(\mathrm{p}<.05)$. As the right side of Table 5 shows, results indicated that leader leading by example was related to an increase in consensus in trust in leaders, $(\beta=-.44, p<.05)$, however showing concern and monitoring were not significant. Team ethnic diversity was marginally related to a decrease in consensus in trust in leaders, as indicated by the positive coefficient $(\beta=.86, \mathrm{p}<.10)$. The follow-up tests indicated that the coefficient of leading by example was significantly different from the coefficient of team open communication $(\mathrm{Z}=-2.01, \mathrm{p}=.05)$ and team ethnic diversity $(Z=-1.30, p<.01)$, and marginally different from gender diversity $(Z=-1.74, p$ $<.10)$. The results provided mixed support for Hypothesis $2 \mathrm{~b}$ and $3 \mathrm{~b}$.

A follow-up analysis was conducted to examine whether the effects of leader showing concern and leading by example on the consensus in trust in leaders were stronger with fewer predictors in the regression model. When the set of five T2 leader variables were entered without the team variables of open communication and demographic diversity, the pattern of the results was the same. Consistent with Hypothesis 2, the results indicated a positive effect of leading by example and showing concern on the consensus in trust in leaders in both the concurrent model $(\beta=-.35$ for 
leading by example and $\beta=-.37$ for showing concern, $p<.05)$ and the change model $(\beta=$ -.36 for leading by example and $\beta=-.34$ for showing concern, $\mathrm{p}<.05)$. The coefficients for leader ability, integrity, and monitoring were not significant in either model. Hence, it appears that, with a smaller set of antecedents, there was more power in the analysis to detect the effects such that the coefficients of leading by example and showing concern were both significant.

Table 6

The Effects of Emergent Processes on the Consensus in Trust in Teams

\begin{tabular}{lrr}
\hline & \multicolumn{2}{c}{$\begin{array}{c}\text { Concurrent Model } \\
\text { T2 Consens us in }\end{array}$} \\
\cline { 2 - 3 } Variable & \multicolumn{2}{c}{ Trust in Teams } \\
\hline (Constant) & 0.58 & SE \\
T2 Leader ability & 0.15 & 0.38 \\
T2 Leader integrity & 0.25 & 0.36 \\
T2 Leader showing concern & -0.21 & 0.26 \\
T2 Leader leading by example & -0.26 & 0.28 \\
T2 Leader monitoring & 0.19 & 0.29 \\
T2 Team communication & -0.34 & 0.28 \\
T4 Team ethnic diversity & -0.34 & 0.70 \\
T4 Team gender diversity & -0.01 & 0.69 \\
\multicolumn{2}{c}{ R $^{2}$} & \multicolumn{2}{c}{0.04} \\
\hline
\end{tabular}

Note: Consensus was operationalized as the transformed SD. Higher scores indicate less consensus. $\mathrm{N}=105$ teams.

Post-hoc analyses. Although not previously hypothesized, I examined the set of emergent factors in relation to the consensus in trust in teams as a comparison to leader variables relating to the consensus in trust in leaders. $\mathrm{T} 2$ consens us in trust in teams was regressed on the eight leader and team emergent factors (Table 6). As would be expected, none of the leader variables were significantly related to consensus in trust in teams. However, contrary to the expectations based on the principle of target match, team open 
communication $(\beta=-.34)$, ethnic diversity $(\beta=-.34)$, and gender diversity $(\beta=-.01)$ were not significantly related to consensus in trust in teams. These results provide some posthoc comparison for the analyses for Hypotheses 2 and 3.

\section{Consequences of Consensus}

The results on the effects of consensus in trust in leaders on team performance and team voice behavior are reported below, followed by the results on the interactive effects of the consensus and level of team trust in leaders.

Main effect of consensus on team performance. Hypothesis $4 \mathrm{a}$ stated that consensus in trust in leaders should exert an independent effect on team performance, after controlling for mean level of trust in leaders, while Hypothesis $4 \mathrm{~b}$ predicted that a change in consensus in trust in leaders would be related to performance. As noted earlier, leader-rated performance data was only available for 15 teams and, thus, member-rated performance data $(n=65)$ was used. Team performance was regressed on both T3 consensus and mean of trust in leaders for the concurrent model and was regressed on T1 consensus, followed by T3 consensus and mean of trust in leaders for the change model. Although there was a significant zero-order correlation between T3 leader trust consens us and performance $(r=-.26, p<.05)$, as can be seen in step 2 of Table 7 , when the mean level of trust in leaders was included in the model, the T3 consens us in trust in leaders did not exert a significant and independent influence on team performance concurrently $(\beta=$ -.05 , n.s. $)$ or when examining changes in consensus $(\beta=-.04$, n.s. $)$. Thus, Hypotheses $4 \mathrm{a}$ and $4 \mathrm{~b}$ were not supported. 
Table 7

The Effects of Consensus in Trust in Leaders on Team Performance

\begin{tabular}{|c|c|c|c|c|}
\hline \multirow[b]{2}{*}{ Variable } & \multicolumn{2}{|c|}{$\begin{array}{l}\text { Concurrent } \\
\text { Model }\end{array}$} & \multicolumn{2}{|c|}{$\begin{array}{c}\text { Change } \\
\text { Model }\end{array}$} \\
\hline & $\mathrm{B}$ & SE & $\mathrm{B}$ & $\mathrm{SE}$ \\
\hline \multicolumn{5}{|l|}{ Step 1} \\
\hline$\overline{(\text { Constant })}$ & & & $3.64 * *$ & 0.07 \\
\hline T1 Trust in leader consens us & & & $-0.12 \dagger$ & 0.07 \\
\hline $\mathrm{R}^{2}$ & & & \multicolumn{2}{|c|}{$0.05 \dagger$} \\
\hline \multicolumn{5}{|l|}{ Step 2} \\
\hline$\overline{\text { (Constant) }}$ & $3.72 * *$ & 0.06 & $3.70 * *$ & 0.06 \\
\hline T1 Trust in leader consens us & & & -0.05 & 0.06 \\
\hline T3 Trust in leaders mean & $0.52 * *$ & 0.13 & $0.47 *$ & 0.14 \\
\hline T3 Trust in leaders consens us & -0.05 & 0.07 & -0.04 & 0.07 \\
\hline $\mathrm{R}^{2} \Delta$ & \multicolumn{4}{|c|}{$0.21^{* *}$} \\
\hline $\mathrm{R}^{2}$ & \multicolumn{2}{|c|}{$.27 * *$} & \multicolumn{2}{|c|}{$0.26^{* *}$} \\
\hline \multicolumn{5}{|l|}{ Step 3} \\
\hline (Constant) & $3.79 * *$ & 0.06 & $3.77 * *$ & 0.07 \\
\hline T1 Trust in leader consens us & & & -0.04 & 0.06 \\
\hline T3 Trust in leaders mean & $0.39 * *$ & 0.13 & $0.34 *$ & 0.14 \\
\hline T3 Trust in leaders consensus & $-0.14 \dagger$ & 0.08 & -0.13 & 0.08 \\
\hline T3 Trust in leaders mean*consensus & $0.28 *$ & 0.11 & $0.28 *$ & 0.11 \\
\hline $\mathrm{R}^{2} \Delta$ & \multicolumn{2}{|c|}{$0.07 *$} & \multicolumn{2}{|c|}{$0.07 *$} \\
\hline $\mathrm{R}^{2}$ & \multicolumn{2}{|c|}{$0.31 *$} & \multicolumn{2}{|c|}{$0.33 *$} \\
\hline
\end{tabular}

Note: Consensus was operationalized as the transformed SD. Higher scores indicate less consensus. Variables were centered.

$\mathrm{N}=65$ teams.

$\dagger \mathrm{p}<.10 ; * \mathrm{p}<.05 ; * * \mathrm{p}<.01$

Main effect of consensus on team voice behavior. Hypothesis 5a stated that consensus in trust in leaders should exert an independent effect on team voice behavior after controlling for the level of team trust in leaders, while Hypothesis $5 \mathrm{~b}$ stated the same relationship but focused on changes in consensus in trust in leaders. Team voice behavior was regressed on both $\mathrm{T} 3$ consens us and mean of trust in leaders for the concurrent model and was regressed on $\mathrm{T} 1$ consensus, followed by $\mathrm{T} 3$ consens us and mean of trust in leaders for the change model. As can be seen in step 2 of Table 8, after 
controlling for the level of team trust in leaders, the consensus in trust in leaders did not exert a significant and independent influence on team voice behavior concurrently $(\beta=$ .01$, n.s. $)$ or in the change model $(\beta=.03$, n.s.). Hypotheses $5 \mathrm{a}$ and $5 \mathrm{~b}$ were not supported.

Table 8

The Effects of Consensus in Trust in Leaders on Team Voice Behavior

\begin{tabular}{|c|c|c|c|c|}
\hline \multirow[b]{2}{*}{ Variable } & \multicolumn{2}{|c|}{$\begin{array}{l}\text { Concurrent } \\
\text { Model }\end{array}$} & \multicolumn{2}{|c|}{$\begin{array}{l}\text { Change } \\
\text { Model }\end{array}$} \\
\hline & B & SE & B & $\mathrm{SE}$ \\
\hline \multicolumn{5}{|l|}{ Step 1 } \\
\hline (Constant) & & & $3.55 * *$ & 0.05 \\
\hline T1 Trust in leader consensus & & & -0.01 & 0.05 \\
\hline $\mathrm{R}^{2}$ & & & \multicolumn{2}{|c|}{0.01} \\
\hline \multicolumn{5}{|l|}{ Step 2} \\
\hline (Constant) & $3.5 * *$ & 0.1 & $3.56^{* *}$ & 0.05 \\
\hline T1 Trust in leader consensus & & & 0.00 & 0.05 \\
\hline T3 Trust in leaders mean & 0.1 & 0.1 & 0.12 & 0.11 \\
\hline T3 Trust in leaders consens us & 0.1 & 0.1 & 0.03 & 0.06 \\
\hline $\mathrm{R}^{2} \Delta$ & & & \multicolumn{2}{|c|}{0.01} \\
\hline $\mathrm{R}^{2}$ & \multicolumn{2}{|c|}{.02} & \multicolumn{2}{|c|}{0.02} \\
\hline \multicolumn{5}{|l|}{ Step 3} \\
\hline (Constant) & $3.51 * *$ & 0.05 & $3.51 * *$ & 0.06 \\
\hline T1 Trust in leader consensus & & & 0.00 & 0.05 \\
\hline T3 Trust in leaders mean & $0.20 \dagger$ & 0.11 & $0.21 \dagger$ & 0.12 \\
\hline T3 Trust in leaders consens us & 0.07 & 0.07 & 0.09 & 0.07 \\
\hline T3 Trust in leaders mean*consensus & $-0.19 \dagger$ & 0.10 & $-0.19 *$ & 0.10 \\
\hline $\mathrm{R}^{2} \Delta$ & \multicolumn{2}{|c|}{$0.06 \dagger$} & \multicolumn{2}{|c|}{$0.06^{*}$} \\
\hline $\mathrm{R}^{2}$ & \multicolumn{2}{|c|}{$0.08 \dagger$} & \multicolumn{2}{|c|}{$0.08 *$} \\
\hline
\end{tabular}

Note: Consens us was operationalized as the transformed SD. Higher scores indicate less consensus. Variables were centered.

$\mathrm{N}=65$ teams.

$\dagger \mathrm{p}<.10 ; * \mathrm{p}<.05 ; * * \mathrm{p}<.01$

Interaction effect of consensus and level on team performance. Hypotheses $6 \mathrm{a}$ and $6 \mathrm{~b}$ concerned the interactive effect of consens us and mean of trust in leaders in their relationship to team performance. Step 3 in Table 7 indicates that the cross-product term between the consensus and the level of team trust in leaders was significant and 
accounted for an additional $7 \%$ of the variance in member-rated performance $(\beta=.28$, $F \Delta=6.45, \mathrm{p}<.05)$ concurrently and explained an additional $7 \%$ of the variance in the change model $(\beta=.28, F \Delta=5.88, \mathrm{p}<.05)$. Figure 4 displays the interaction. As predicted, there was a positive relationship between the level of trust in leaders and team performance such that teams with a higher level of trust performed better than teams with a lower level of trust in leaders, and the relationship was stronger for teams with low consensus in trust in leaders than for teams with high consens us in trust in leaders. In addition to plotting the interaction, a simple slope test was also conducted (Aiken \& West, 1991). The simple slope of the regression of team performance on the level of team trust in leaders within low consens us in trust in leaders was significant (simple slope $=$ $.49, \mathrm{t}=3.30, \mathrm{p}<.01)$, and the simple slope within high consensus in trust in leaders was also significant ( simple slope $=.29, \mathrm{t}=2.37, \mathrm{p}<.05)$.

For the change model, the pattern of the interaction was identical to Figure 4. A simple slope test was also conducted. The relationship between the level of team trust in leaders and team performance was significant and positive when the increase in consensus was small ( simple slope $=.44, \mathrm{t}=2.90, \mathrm{p}<.01)$, but the relationship was not significant when the increase in consensus was large ( Hypotheses $6 \mathrm{a}$ and $6 \mathrm{~b}$ were supported.

Follow-up analyses were conducted to examine whether there was a nonlinear relationship between the predictors and team performance to rule out the possibility that the observed interactive effect is due to nonlinear relationships between one of the predictors and the outcome (Lubinski \& Humphrey, 1990). Using the procedure from Dickson and his colleagues (2006), the quadratic terms of consens us and level of team 
trust in leaders were entered after the main effects and before the cross-product term. The results of the quadratic terms were not significant in both the concurrent and change models, while the cross-product term of consens us and level of trust in leaders remained significant $(\beta=.41$ in the concurrent model and $\beta=.37$ in the change model, $\mathrm{p}<.05)$. The results indicated that the relationships between the main effects of the consensus and mean level of trust in leaders and team performance were linear.

\section{Figure 4}

The Interaction between Consensus and Mean of Team Trust in Leaders on Team Performance

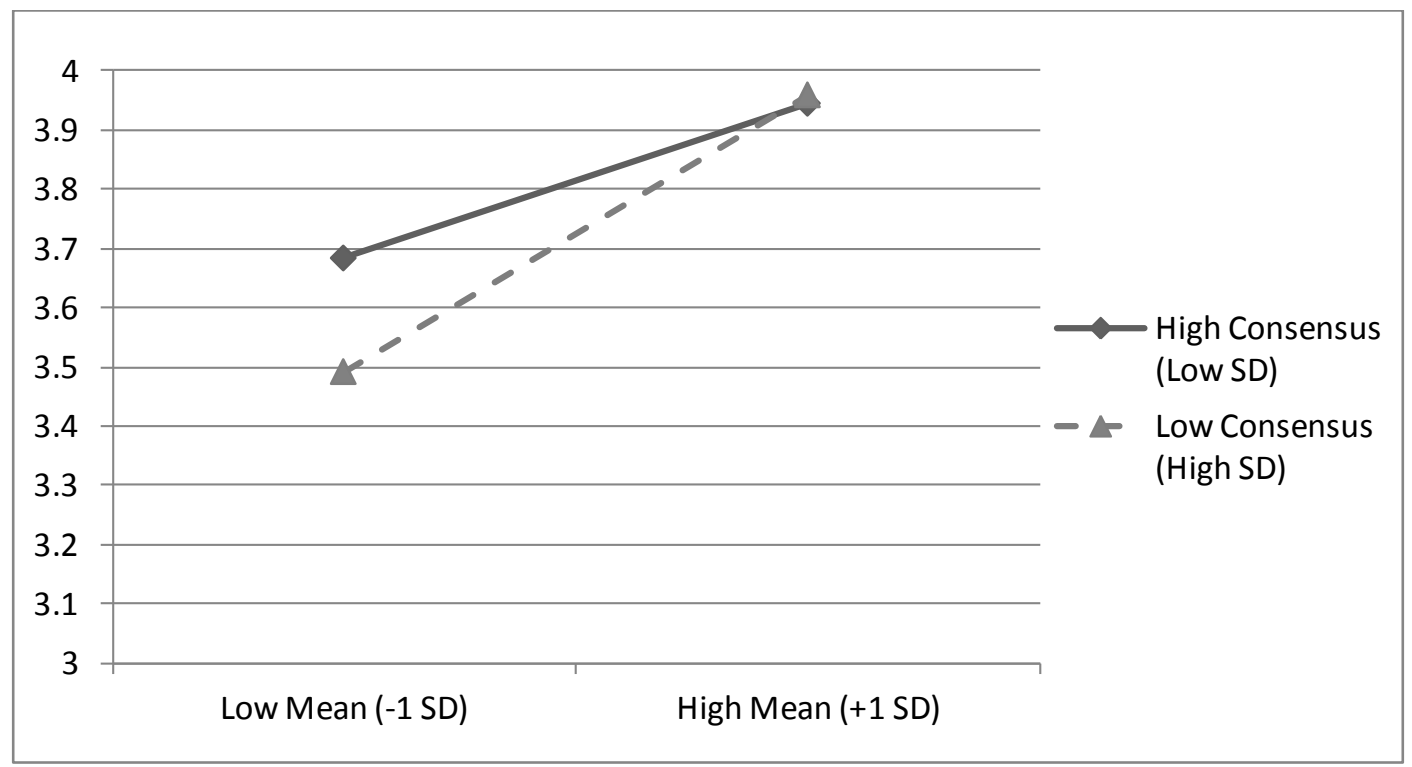

Interaction of consensus and level on team voice behavior. Hypotheses $7 \mathrm{a}$ and

$7 \mathrm{~b}$ proposed that the mean level of trust in leaders and consensus in trust in leaders would interact in relation to voice behavior. Results in step 3 of Table 8 indicate that the cross product term between the consensus and level accounted for an additional $6 \%$ of the variance in team voice behavior in the concurrent model $(\beta=-.19, F \Delta=4.57, \mathrm{p}<.05)$ and in the change model $(\beta=-.19, F \Delta=4.92, p<.05)$. 
As can be seen in Figure 5, the positive relationship between mean level of trust in leaders and team voice behavior was stronger for teams with high consensus in trust in leaders than for teams with low consensus in trust in leaders. The pattern is consistent with Hypothesis 7a. This pattern is supported by results from a simple slope test (Aiken $\&$ West, 1991). The simple slope of the regression of team voice behavior on the level of team trust in leaders within low consensus in trust in leaders was not significant (simple slope $=.14, \mathrm{t}=1.06$, n.s.) but the simple slope within high consensus in trust in leaders was significant $($ simple slope $=.27, \mathrm{t}=2.59, \mathrm{p}<.05)$.

\section{Figure 5}

The Interaction between Consensus and Mean of Team Trust in Leaders on Team Voice Behavior

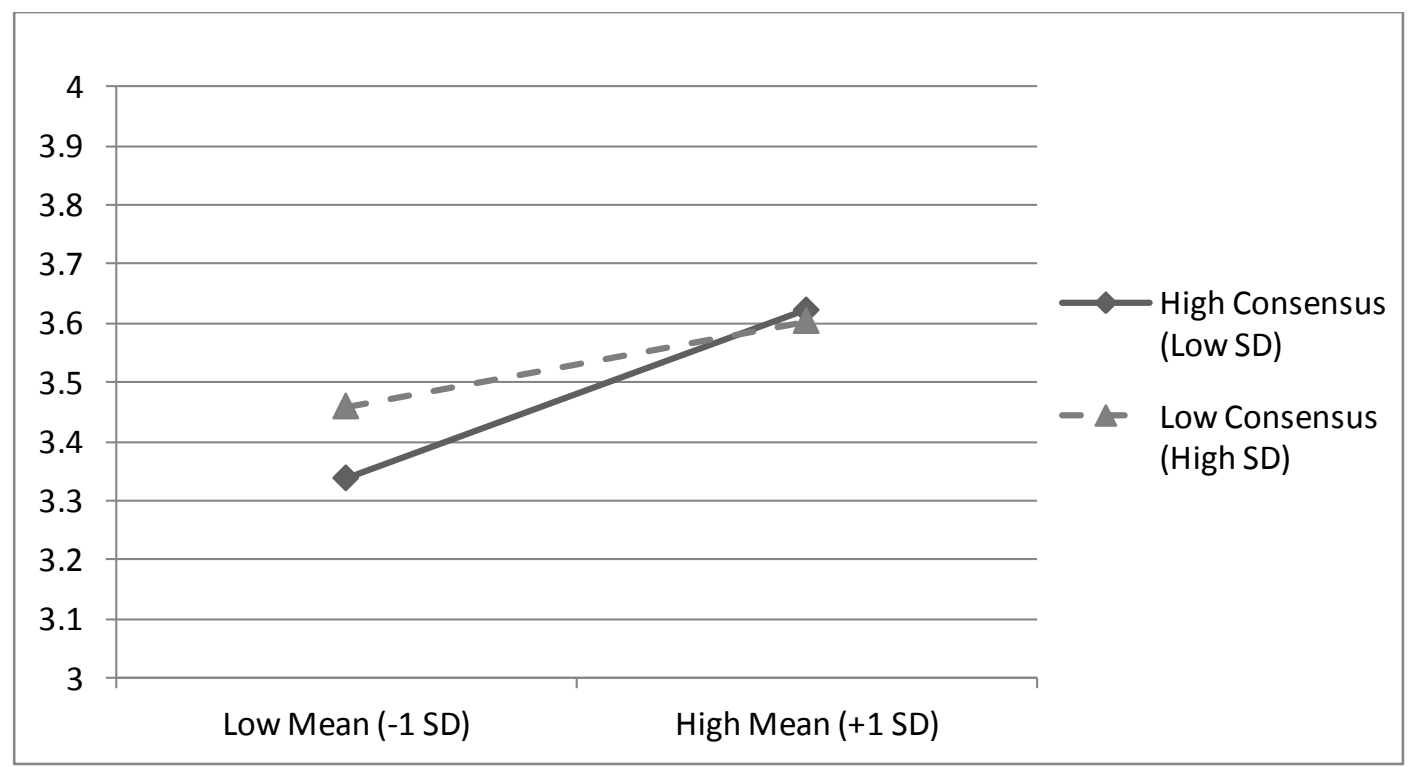

The pattern of the interaction in the change model is almost identical to that in

Figure 5. A simple slope test was also conducted for the change model. The relationship between the level of team trust in leaders and team voice behavior was significant and positive when the increase in consensus was large ( simple slope $=.28, \mathrm{t}=2.56, \mathrm{p}<.05)$, 
but the relationship was not significant when the increase in consensus was small (simple slope $=.14, \mathrm{t}=1.08$, n.s.). Hypothesis and $7 \mathrm{a}$ and $7 \mathrm{~b}$ were thus supported.

As with team performance, a follow-up analysis was conducted to examine the quadratic terms of the consensus and mean level of team trust in leaders, following the procedure from Dickson and his colleagues (2006). The quadratic terms were entered after the main effects and before the cross-product term. Together the two quadratic terms accounted for significant incremental variance in team voice behavior $(\mathrm{R} \Delta=.09, \mathrm{p}=.05)$, but only the quadratic term of level of team trust in leaders was significant $(\beta=.34, p<$ $.05)$. The positive quadratic coefficient for the mean level of trust indicated a U-shaped relationship such that team voice behavior was high when teams had a high or a low level of team trust in leaders. Further, after controlling for the main effects and quadratic terms, the linear interaction term remained significant $(\beta=-.27, p<.05)$. These findings suggest that the relationship between the level of team trust in leaders and team voice behavior was nonlinear but there was also a linear interactive effect of the consensus and level of team trust in leaders on team voice behavior.

For the change mode, the results on the quadratic terms were similar to those from the concurrent analysis: the quadratic term of the level of team trust in leaders was signi ficant and positive $(\beta=.35, \mathrm{p}<.05)$ but not the quadratic term for increased consensus in trust in leaders $(\beta=-.04$, n.s.). Further, after controlling for the quadratic terms, the linear interaction term between the mean level of trust and consensus remained marginally significant $(\beta=-.27, p<.10)$. Therefore, while the relationship between the level of team trust in leaders and team voice behavior was nonlinear, there was also a linear interactive effect of the increased consensus and level of team trust in leaders on 
team voice behavior after controlling for the nonlinear effects of the level of trust in leaders. It is important to note that the results for voice are tenuous given the poor aggregation statistics and should be interpreted with caution. 


\section{Chapter 7. Discussion}

In this final chapter of the dissertation, I summarize the impetus and contributions of this study. I then provide a detailed summary of my findings, some of which are consistent with the proposed hypotheses while others are not. Potential reasons for the inconsistent findings are discussed. I next turn to the limitations of this study. Finally, the theoretical implications, directions for future research, and practical implications of this research are discussed.

\section{Overall Summary}

In understanding the impact of leadership on employee outcomes, researchers have increasingly focused their attention on the effect of trust in leaders (e.g., Dirks \& Ferrin, 2002; Fulmer \& Gelfand, 2012). A small but growing number of studies on trust in leaders has moved from examining the individual level to the team level of analysis to investigate relationships between collective trust in leaders and team outcomes. This study builds on past research on team-level trust in leaders through its focus on better explicating how a collective state of trust in leaders emerges among team members and the consequences of consensus in trust in leaders for team outcomes. In general support of the hypotheses, results indicated that some leader behaviors (leading by example and showing concern) were relatively more important for the development of consensus in trust in leaders while leader attributes (ability and integrity) and team factors (open communication and diversity) were not. Further, although the degree of consens us in trust in leaders was not related to team performance and voice behavior, consens us moderated the relationship between the mean level of trust in leaders and outcomes. 
These results contribute to our understanding of trust in leaders at the team level in three ways. First, similar results were obtained for the role of leader behaviors in consensus in trust in leaders and for the interactive role of consensus and mean level of trust in leaders on team outcomes when examining consens us concurrently and changes in consensus over time. The emergence of a construct from individual level components to a construct that resides at a higher level is a dynamic process defined by changes over time (Kozlowski \& Klein, 2000; Kozlowski \& Chao, in press). Because trust in leaders was examined in natural teams after a change in leadership and some changes in team membership, as opposed to examining stable teams and longer-standing leaders, relationships between leader behaviors and the degree of consensus are more likely to reflect an emergence of trust in leaders. Further, by examining trust in leaders shortly after new leaders began their position and again several months later, factors related to a change in consensus could be examined more directly. Results partially supported the notion that the degree of consensus changes over time.

Second, the paths through which collective constructs develop can vary (Kozlowski \& Chao, in press). With few exceptions that have focused on consens us in climate perceptions (e.g., González-Romá et al., 2002; Zohar \& Tenne-Gazit, 2008), research has been silent on the relative effects of divergent emergent processes on the consensus in a given collective construct. The findings in this study for leader behavior are consistent with the notion that the content and target of the factors that are purported to promote consensus should be commensurate with and meaningfully related to the target of the collective construct. Thus, for consensus in trust in a leader, leader variables should be most important. Further, the finding that leader behaviors that involve some 
form of interaction between the leader and team members were more important than general leader attributes is supportive of the notion of event cycles (Morgeson \& Hofmann, 1999) and the assumption that interactions play a critical role in consensus (Kozlowski \& Klein, 2000). While tentative, these findings begin to suggest that a more refined conceptualization of the relations hip between emergent processes and collective constructs are needed.

Third, the findings from this research shed additional light on the consequences of consensus in team trust in leaders. Prior research has indicated that the level of trust in leaders is important for unit performance and effectiveness (Davis et al., 2000; Dirks, 2000; Simons \& McLean-Parks, 2002). Here, the degree of consens us in trust in leaders was also expected to play a role in influencing team outcomes, as it can represent factors that concern team dynamics in addition to the factors that are directly related to trust in leaders. While consens us did not exhibit a main effect on team performance or voice behavior, the significant moderating effect suggests that consensus in trust in leaders may act as a boundary condition for the effect of the level of trust in leaders on team outcomes. These findings provide some support to the notion that both the consensus and level of a collective construct should be considered in understanding its impact (e.g., Cole et al., 2011; Lindell \& Brandt, 2000).

\section{Hypotheses Results}

Antecedents of consensus. Based on prior work and theory on consensus (e.g., Naumann \& Bennett, 2000, Ostroff et al., 2012; Zohar \& \& Tenne-Gazit, 2008), a range of potential factors were examined in relation to consensus in trust in leaders, including the leader behavior variables of showing concern, leading by example, and monitoring, 
the leader attributes of ability and integrity, and the team variables of communication and team diversity. Combining the principle of compatibility in the target of two variables (Ajzen, 1988) with the theory and research highlighting that interactions among actors are a key to emergence and consensus (e.g., Kozlowski \& Klein, 2000; Morgeson \&Hofmann, 1999; Schneider et al., 2002) yielded a prediction that leader behaviors that involve interactions between leaders and members would be relatively more important than static leader attributes or interaction variables where the target is other team members. Results generally support the important role of interactions with leaders in the emergence of collective trust in leaders. The leader behaviors of showing concern and leading by example were found to play a stronger role in consensus than leader attributes of ability and integrity. These findings are consistent with the idea that trust contains a relational component that requires some form of interaction between the trustor and trustee in order develop trust (Nooteboom et al., 1997; Tyler \& DeGoey, 1996).

The leader behavior of monitoring was not related to consensus in trust in leaders as expected. The lack of finding for this variable may be due to its importance relative to other leader behaviors as the zero-order correlation was close to significant $(\mathrm{r}=-.18, \mathrm{p}<$ .10). In addition, the weak finding could be due to underlying complexities in the relationship between leader monitoring and trust in leaders, as discussed by Ferrin and his colleagues (2007). These authors suggest that the effect of another's monitoring on one's trust depends on the perceived appropriateness of the behavior. Some may find it difficult to be monitored by another, particular by someone who is a more senior officer-intraining at the same institution, while others welcome monitoring from their team leader. Thus, leader monitoring may lead to divergent levels of trust across members in a team 
and would not act as emergent factor to coalesce team members' trust in the leader. Future research is needed to explore potential contextual factors and individual characteristics for the relationship among leader monitoring, trust level, and trust consensus at the unit level.

The findings were also consistent with the principle of compatibility (Ajzen, 1988) in that the referent target of emergent processes should match the referent target of trust. Leader-targeted variables, particularly those concerning behaviors and interactions between leaders and members (showing concern, leading by example, and monitoring) are expected to be more relevant to the emergence of trust in leaders at the team level than team member-targeted variables (open communication and team diversity). A corollary is that the team-targeted interaction factors should be more relevant to the emergence of team trust in teams than leader-targeted variables. Weak support was found for this notion in the present study. Open communication among team members was unrelated to consens us in trust in leaders as expected, while team ethnic diversity was significant, contrary to predictions. Post-hoc analyses also revealed that neither leader variables nor team variables were related to consensus in trust in teams.

There are several explanations for the weak results of target matched variables. First, there were no significant between-group differences evidenced for team open communication, indicating that teams had similar levels of communication. As such, the predicted lack of results for consens us in trust in leaders might be interpreted as supportive of the hypothesis. Further, failure to find a positive relationship between communication and consensus in trust in teams may be due to low between-group differences. Units within the same organization may be more likely to possess similar 
characteristics than units from different organizations (Schneider, 1987). Given past initial support for the role of communication and interactions among team members in climate consensus (e.g., González-Romá et al., 2002; Zohar \& Tenne-Gazit, 2008) and the relational component of trust (Nooteboom et al., 1997; Tyler \& DeGoey, 1996), additional research in other organizations or situations in which there is greater betweengroup differences in communication is needed to more adequately address the role of communication on consensus in trust.

Second, the finding that team ethnic diversity was related to the consensus in team trust in leaders but not to the consens us in team trust in teams was surprising. One explanation for the relationship between team ethnic diversity and consensus in trust in leaders is that diversity may influence the nature of the dyadic relationship and exchanges between the leader and members. For example, research has shown a positive relationship between rater-ratee racial similarity and performance ratings (Kraiger \& Ford, 1985). When a supervisor and a subordinate are of the same ethnicity, the supervisor's liking of the subordinate also tends to be a little higher (Tsui \& O'Reilly, 1989). However, a posthoc regression showed that neither leader ethnicity nor the interaction between leader ethnicity and team ethnic diversity, based on the Caucasian vs. non-Caucasian categorization, was related to the consens us in team trust in leaders. It is therefore possible that leaders, regardless of their own ethnicity, interact with ethnic-homogenous and ethnic-heterogeneous teams differently. For example, different leadership styles have been associated with diverse versus non-diverse teams (Watson, Johnson, \& Zgourides, 2002). Interacting with a more diverse team might be more demanding for a leader as he or she may need to adapt the manner interacting with members from different ethnic 
groups. More research is needed to understand the effect of team ethnicity on consensus in trust at the team level.

Finally, a limited range of leader-targeted and team-targeted emergent processes were included which may explain some of the weak results. While support was found for the leader-targeted variables of showing concern and leading by examples, additional leader-targeted behaviors may also be relatively more important than team-targeted variables for consensus in trust in leaders. For example, procedural justice reflects a leader behavior of treating all members fairly and consistently which could engender trust and consens us in trust in leaders while team-targeted interaction variables such as cohesion or collaboration could be relatively more important for consensus in trust in teams. Clearly more research is needed to examine the duality of target match and interaction-based variables for consensus in trust.

Outcomes of consensus. Because consensus in trust in leaders represents information on the team dynamics and dynamics with the leader that differs from the information represented by the mean level of trust in leaders, the effect of consensus was examined on the outcome variables of team performance and voice behavior. It was predicted that consensus in trust in leaders would exert influence on consensus above and beyond the effects of the level of trust in leaders. Specifically, drawing on the notions from social influence theory (Festinger, 1973) that consens us is valued by team members and promotes cooperation, and from strong situation (Mischel, 1973) and groupthink (Janis, 1972) that consens us could inhibit speaking up and raising concerns, consensus in trust in leaders was expected to be positively related to team performance but negatively related to team voice behavior. However, results did not support this prediction. After 
controlling for the mean level of trust in leaders, consens us in trust in leaders was not a significant predictor for team performance or team voice behavior. One explanation for the lack of the independent effect is that the outcome measures in this study might not be strongly influenced by the degree of consensus and the team dynamics it represents. For example, research on the effect of LMX differentiation on team performance has found the level of task interdependence to be an important moderator (Liden et al., 2006). Future research is needed to examine additional outcomes that entail a higher level of interdependence.

Further, following prior work that examined consensus in other areas (Cole et al., 2011; Lindell \& Brandt, 2000), the interactive effect of the consensus and the level of trust in leaders was examined. Based on the research that supports a positive link between trust in leaders and performance (e.g., Davis et al., 2000; Dirks, 2000) and between similar attitudes, regardless whether it is positive or negative, and positive affect and cooperation (e.g., Byrne, 1971; Festinger, 1950), it was predicted that team performance would be positively related to the level of trust in leaders and the relationship would be stronger for teams with low consensus than teams with high consensus. The results on team performance were consistent with this notion. The finding that the positive relationship was stronger for teams with low consensus may seem counterintuitive. However, the smaller difference in team performance between high and low levels of trust in leaders for teams with high consensus underlies the potential benefits of consensus in trust in leaders, regardless of the level, for team performance when team members' trust in leader is low. 
For team voice behavior, the pattern of the interaction was expected to be somewhat different. Based on the role leaders play in influencing employee voice (e.g., Premeaux \& Bedeian, 2003; Edmondson, 2003) and again on the notions of strong situation (Mischel, 1973) and groupthink (Janis, 1972), it was predicted that trust in leader would be positively related to the level of trust in leaders, but the relationship would be stronger when teams have high consensus rather than low consensus. The results supported this pattern. The relationship between the level of trust in leaders and team voice behavior was stronger for teams with high consensus, suggesting that consensus amplified the effect of the level of trust in leaders. In particular, when a team has a low level of trust in the leader, team members look to each other to decide whether to engage in voice behavior. When team members agree on their low levels of trust in leader, they are less likely to speak up than when team members share consensus. However, it should be noted that these results for team voice behavior need to be interpreted with caution because of the subpar aggregation statistics. Nevertheless, the patterns of interaction between consensus and level on both outcomes highlight the importance of considering the consens us in a collective construct in understanding the impact of the collective construct, a point I will return to in the discussion of theoretical implications of the present research.

Changes in consensus over time. An important feature of the present study is the examination of both the consensus concurrent with the emergent processes as well as changes in consensus over time. Due to the expectation that leaders will have more opportunities to interact with all team members over time, it was predicted that the consensus in team trust in a leader would increase from an initial change in leadership to 
after months of interaction. However, the results did not provide support for this prediction. One possible explanation is that the consensus in team trust in leaders might converge in some, but not all teams. In other words, some teams could have increased consensus over time, but other teams could maintain a similar level of consens us or have decreased consensus during this time. These differences led to a lack of observable overall changes in consensus in trust in leaders across teams. The increased variability in consensus across teams over time, as discussed below, lends some support to this notion. Differences in leader behaviors and leader interactions with team members might be related to how teams varied in the emergence in trust in leaders. The results on the effects of emergent processes obtained in this study began to shed light on this process.

In addition, it was also expected that there would be an increase in the variability in degrees of consensus in trust in leaders during the same period of time. Consistent with this prediction, I found that the between-group variance in the consensus in team trust in leaders increased over time, as indicated by the change in the SD of team trust in leaders and by the ICC1 statistics in relation to the within-group variances. This suggests that, as teams had more opportunities to interact, the difference in the degrees of their consensus in trust in leaders grew larger. Further, this pattern is consistent with the rationale discussed above that as time passed, some teams were able to increase their consensus in trust in leaders while others were not. That is, if all teams were to have increased consensus, the variation in the degree of consensus should be lower. Based on the findings that the degree of consensus did not change across time but the variability in consensus among teams changed and that the correlation between the consensus in two time periods were low, it appears that the consensus in trust in leaders was not a static 
construct between the time when leaders assumed the position and after months of interactions but instead went through some changes.

For the antecedents and outcomes of consensus, the results from the concurrent and the change models were largely similar, with the exception of subtle differences. One finding from the comparison of the concurrent and the change models is that leading by example was most critical, among the factors examined in this study, in bringing about the consensus in trust in leaders. In contrast, leader showing concern was only significant in the concurrent model. However, the difference in results may be due to the relatively large number of predictors in the model. More research is needed to investigate whether the effects of emergent processes differ for the degree of consensus and the emergence of consensus over time.

Patterns for the interaction between the consensus and mean level of trust in leaders on outcomes were largely the same for the concurrent and the change models. However, it was found in the change model that teams with high consensus did not differ in their levels of team performance whereas, in the concurrent model, teams with high trust and high consensus performed better than teams with low trust and high consensus. The difference in results suggests some possibility that the effect of consensus is stronger over time, and that the outcomes of the degree of consensus and the changes in consensus may exert somewhat different effects. However, it is possible that the two time periods with an interval of a few months were not sufficiently far apart to allow other differences between the two models to emerge. Future research on emergence should track teams over a more extensive period of time to reveal whether there is a substantial difference between concurrent consensus and changes in consensus. 


\section{Limitations}

Despite some revealing findings and the contributions of this study, there are limitations that should be considered when interpreting these results. The limitations of the present research are primarily related to its sample, design, and measures. First, this study is limited by its sample from a single organization with a strong military culture. The strong organizational culture may reduce the observed variance in the measured variables, particularly between units. Although there were significant differences between teams for all study variables, except open communication and team voice behavior, the amount of variability was sometimes low. Further, the low ICC2 values for most of the study variables indicated low reliability of the mean scores at the team level (Bliese, 2000). Both lower between-group differences and low reliability of mean scores can decrease the likelihood of finding significant results. Obtaining more respondents per team can help raise ICC2 values and inclusion of teams from different organizations could help create larger between-group variances.

It is also possible that the present sample of squads is different from teams in civilian organizations. Prior research on leadership has reported no significant differences between the military and civilian samples (Bass, Avolio, Jung, \& Berson, 2003; Shamir, Zakay, Breinin, \& Popper, 1998). Nevertheless, more research is needed to test the generalizability of the proposed theoretical model in a range of different work teams and organizational samples.

Second, the research design of the present study was lagged rather than longitudinal. The time lagged design is unable to fully reveal the causal directions of the relationship examined. It is possible, for example, that team performance influences team 
trust in the leader instead of the direction proposed. However, this issue was mitigated, at least to an extent, by a notable feature of this research: T1 data collection took place shortly after teams were just assigned with new leaders and had some membership changed. This allowed examination the consensus in team trust in leaders from a naturally-occurring initial stage of emergence. Teams were presumed to have a relatively low level of consensus, as team members knew little about the new leader and mostly relied on their idiosyncratic perceptions and attitudes toward the leader given the changes in some membership. Therefore, the concurrent results should still represent an indirectly test of emergence. This is in comparison with most studies on consensus that assessed intact leaders and teams who already worked together for some time (e.g., Naumann \& Bennett, 2000; Zohar \& Tenne-Gazit, 2008), making tracing the factors that enhance emergence difficult. Nevertheless, additional research that employs longitudinal designs and assesses constructs across multiple time periods is needed to more explicitly track the dynamic nature of emergence (Kozlowski \& Chao, 2012) and the causal relationships among emergent processes, consensus in trust, and team outcomes (Singer \& Willett, 2003; Ployhart \& Vandenberg, 2010).

While this study is unable to support causal claims about the effects examined, the lagged design of this study could potentially lower the threat of response bias. Response bias can be minimized by incorporating a time delay between measures (Ostroff et al., 2002). In this study, assessment of leader behaviors and attributes (T2) took place approximately two weeks prior to the assessment of trust in leaders (T3). To estimate the degree of response bias, correlations between concurrent relationships and lagged relationships were compared. The correlations between various leadership variables at T2 
and team trust in leaders assessed at T2 were about .10 higher than the correlations between the leadership variables at T2 and team trust in leaders at T3 (e.g., .77 and .56 for leader ability; .60 and .49 for leader monitoring). The magnitude was similar for outcomes: the correlations between trust in leaders at T3 and outcomes at T3 were about .10 higher for the correlations between the trust in leaders at T2 and outcomes at T3. Although the time delay did help to mitigate response bias, it may not have been completely elimi nated as the measures in this study were largely self-reported. While the source of attitudes and perceptions reside within the individual and hence it is the appropriate source of measurement (Kozlowski \& Klein, 2000), future research should incorporate more objective measures, such as leader actual behaviors and objective performance measures. In this study, the number of teams with matched leader-rated performance was too low to afford meaningful analysis. Examination of consensus using factors from multiple sources, including unit members, unit leader, and the organization, would be instrumental and could shed additional light on the phenomenon.

\section{Theoretical Implications and Future Research}

The literature on team trust in leaders and on emergence has just begun to accumulate. The present study represents the first effort to explore how members in a unit develop shared trust in the unit leader and begins to reveal the linking mechanism between trust in leaders at the individual level and at the team level. As discussed, theory and research thus far have largely neglected to compare the effects of multiple emergent processes simultaneously and explicate why some emergent processes may be more relevant than others for the consensus in a given collective construct (see González-Romá et al., 2002; Zohar \& Tenne-Gazit, 2008 for exceptions). The conceptual model of the 
present research provides an initial framework to organize different emergent processes in relation to the consens us in team trust in leaders based on the target match (Ajzen, 1988) between the emergent factor and target consensus variables as well as factors that entail event cycles and greater interactions (Morgeson \& Hofmann, 1999). Future research should continue to examine the effects of additional emergent processes on the emergence of diverse collective constructs.

More broadly, this study highlights the importance of considering emergent processes that are specific to the content and nature of the collective construct. In this dissertation, I proposed a theoretical rationale for why leader behavior factors should be more important to the consensus in trust in leaders than leader attributes and team factors. It is assumed that the emergent processes of leader behaviors are relevant to trust in leaders in particular and may not be relevant to emergence and consensus of all collective constructs. For other constructs that can be shared, such as organizational identity or cynicism, different emergent processes should play a more influential role than do the leadership behaviors examined in this study. To test this notion, I conducted a follow-up analysis on the influence of the set of eight emergent factors (leader ability, integrity, showing concern, leading by example, monitoring, team open communication, and team ethnic and gender diversity) on two collective constructs, organizational identity (Mael \& Ashforth, 1992) and organizational cynicism(Ostroff et al., in preparation) at the team level. The results indicated that none of these factors significantly influenced the consensus in these two constructs. This finding provides some indication that the emergent factors found important in the present study (leader showing concern and leading by example) are specific to the consensus of trust in leaders. 
The findings from the present study on the effects of consensus in trust in leaders points to an alternative way to think about collective trust. Rather than treating variation in levels of trust in a leader among team members as error, consensus in trust in leaders should be considered as a boundary condition of the effect of mean level of trust in leaders. In other words, without consensus, the model of trust in leaders at the unit level and outcomes may be underspecified. As noted, consensus among team members on the levels of a construct can be understood as a social context (Bliese \& Britt, 2001; Bliese \& Halverson, 1998). It can influence and constrain the relationship between the relationship between a construct and an outcome both at the individual and the unit levels. In other words, consensus at the team level should be regularly considered as an important moderator that could amplify or suppress the effect of the level of the construct.

Further, the present research represents an initial effort to understand the emergence of consensus in team trust in leaders. As Kozlowski and Klein (2000) highlighted, emergence can take on different forms ranging from composition-in which individual members contribute the same amount and type of trust—-to compilation-in which individual members may contribute dissimilar amounts and dissimilar types of trust that form a meaningful pattern at the unit level. There are also a number of models in between these two types. For example, in addition to shared consensus, a team level psychological construct can emerge at the team level in the forms of minority belief, bimodal, and fragmented (Harrison \& Klein, 2007; Kozlowski \& Klein, 2000; DeRue, Hollenbeck, Ilgen, \& Feltz, 2010). Moreover, some research has suggested different types of trust, including cognitive trust and affective trust (Mc Allister, 1995) as well as trust and distrust (Lewicki, Tomlinson, \& Gillespie, 2006) that could be examined jointly in a 
compilation model, such as the implications of divergent patterns of affective and cognitive trust in the leader among team members.

To examine the various forms of emergence, future research should extend the methodology from the survey method of the present research to other methods including interviews, observation, and computational modeling. The typical assessment method can only infer the emergence process indirectly and post hoc (Kozlowski \& Chao, in press). As future research and findings on emergence continues to accumulate, computational modeling in particular offers a direct method to examine the dynamics of emergence (Kozlowski \& Chao, in press). Utilizing multiple methods will afford triangulation of this complex phenomenon.

\section{Practical Implications}

The findings from the present research also hold practical implications for organizations. Practitioner wisdom posits that trust in leaders as a necessary condition for leadership success. It also indicates that this trust needs to be developed for each member in a team, suggesting that the consensus in trust in leadership in a team is equally important as the level of trust in leader. As the extant research has not examined the process by which members in a team come to agreement in their levels of trust in a leader, the present research is unique in that it provides leaders and managers with concrete suggestions to start building trust in teams. In particular, the findings from this research suggest that showing concern and leading by example may be particularly relevant for promoting team members' consensus in trust in a leader.

The findings of this research also reveal the impact of leadership and team membership changes. Organizational managers and leaders should be aware that, while 
such changes have been commonly implemented in some industries and organizations to promote innovation and cross-training (Grossman, 2007; Hargreaves \& Fink, 2005; Nickol, 1999), it likely breaks down the existing team consensus in trust in the original leader. As suggested by the finding from this research, without leader actively facilitating the emergent process through interactions with team members, a low degree of team consensus in trust in leaders may develop and may have negative implications for team performance.

\section{Conclusion}

Former Secretary of State Colin Powell once remarked that, "Trust is the essence of leadership." Many practitioners and researchers would agree with his observation. A growing number of studies have indeed shown that, at the individual level, followers' trust in leaders has a strong and consistent relationship with positive work attitudes and discretionary behaviors (Dirks \& Ferrin, 2002; Colquitt et al., 2007). More recently, research at the team level has indicated that trust in leaders at the unit level is related to a unit's bottom-line outcomes, including performance and profits (Davis et al., 2000; Dirks, 2000; Simons \& McLean-Parks, 2002). Together, these findings provide optimism about the potential that trust in leaders at the unit level holds for organizations and for a deeper knowledge of trust through scholarly research.

As research on trust at the team level is still in its infancy, no research has yet examined the antecedents and consequences of team consensus in trust in leaders. From the levels of analysis perspective, the level and consensus in team trust go hand in hand, not only because the team level construct does not meaningfully exist without a sufficient degree of consensus, but also because the degree of consensus and changes in consensus 
over time can interact with the level to affect team outcomes. The present research provides some initial evidence suggesting that this is the case. This research also offers some insight as to why teams differ in their degrees of consensus in trust in leaders. Importantly, these findings may inform leaders of what they can do to promote team consensus to the desirable degree. Consideration of both the level and consensus in team trust acknowledges the distinction of trust at the unit level from its individual level counterpart and affords a more complete picture of the construct at higher levels. 


\section{Appendix A}

Examples of Trust in Leader Definitions at the Individual and Team Levels

(Reprint from Fulmer \& Gelfand, 2012)

\begin{tabular}{|c|c|c|}
\hline Level & Source & Sample Definition \\
\hline \multirow[t]{5}{*}{ Individual } & $\begin{array}{l}\text { Oreg \& Sverdlik } \\
(2011)^{2}\end{array}$ & $\begin{array}{l}\text { "The degree of faith employees... have concerning management's } \\
\text { ability to steer the organization (Oreg, 2006, p.87)." }\end{array}$ \\
\hline & $\begin{array}{l}\text { Dirks \& Ferrin } \\
(2002)^{1}\end{array}$ & $\begin{array}{l}\text { "A psychological state comprising the intention to accept } \\
\text { vul nerability based upon positive expectations of the intentions or } \\
\text { behavior of another (Rousseau et al., 1998: 395)." }\end{array}$ \\
\hline & $\begin{array}{l}\text { Simmons, } \\
\text { Gooty, Nelson, } \\
\& \text { Little }(2009)^{3}\end{array}$ & $\begin{array}{l}\text { "The willingness to be vulnerable to the actions of another (Mayer, } \\
\text { Davis, \& Schoorman, 1995)." }\end{array}$ \\
\hline & $\begin{array}{l}\text { Van Dijke, De } \\
\text { Cremer, \& } \\
\text { Mayer }(2010)^{1}\end{array}$ & $\begin{array}{l}\text { "Acceptance of vulnerability out of positive expectations of the } \\
\text { other's intentions (e.g., Mayer, Davis, \& Schoorman, 1995; } \\
\text { Rousseau, Sitkin, Burt, \& Camerer, 1998)." }\end{array}$ \\
\hline & $\begin{array}{l}\text { Korsgaard, } \\
\text { Brodt, \& } \\
\text { Whitener }(2002)^{1}\end{array}$ & $\begin{array}{l}\text { "A willingness to be vulnerable to another person based on the } \\
\text { expectation, but not certainty, that he or she will act benevolently } \\
\text { (Whitener et al., 1998). It also reflects an assessment of a person's } \\
\text { motives, intentions, and character (Tyler \& Lind, 1992), including } \\
\text { jud gments of a person's benevolence, integrity, fairness, and } \\
\text { reliability (e.g., Butler, 1991; Mayer \& Davis, 1999)." }\end{array}$ \\
\hline \multirow[t]{3}{*}{ Team } & Dirks $(2000)^{2}$ & $\begin{array}{l}\text { "An expectation or belief that the team can rely on the leader's } \\
\text { actions or words and that the leader has good intentions toward the } \\
\text { team." }\end{array}$ \\
\hline & $\begin{array}{l}\text { Davis, } \\
\text { Schoorman, } \\
\text { Mayer, \& Tan } \\
(2000)^{1}\end{array}$ & $\begin{array}{l}\text { "The willingness of a party (trustor) to be vulnerable to the actions } \\
\text { of another party (trustee) based on the expectation that trustee will } \\
\text { perform an action important to the trustor, regardless of the trustor's } \\
\text { ability to monitor or control the trustee (Mayer et al., 1995)." }\end{array}$ \\
\hline & $\begin{array}{l}\text { Schaubroeck, } \\
\text { Lam, \& Peng } \\
(2011)^{2}\end{array}$ & $\begin{array}{l}\text { "Members' beliefs about the leader's competence." "Members have } \\
\text { a strong and favorable emotional connection with the leader." }\end{array}$ \\
\hline
\end{tabular}

Note: Citations were coded according to the reference's definition using the dimensions: positive expectations of trustworthiness, willingness to accept vulnerability.

${ }^{1}$ Both positive expectations and willingness to accept vulnerability.

${ }^{2}$ Positive expectations of trustworthiness only.

${ }^{3}$ Willingness to accept vulnerability only. 


\section{Appendix B}

\section{Predictors}

Survey Measure Items

\section{Leader Ability}

My squad leader can tell if something is going wrong.

My squad leader is able to effectively think through complex problems.

My squad leader has a thorough understanding of the institution and its goals.

My squad leader can solve problems with new or creative ideas.

\section{Leader Ethics}

My squad leader holds high ethical standards.

My squad leader is always honest.

My squad leader would not compromise ethical principles in order to achieve success.

My squad leader values what's right more than performance.

\section{Leader Showing Concern}

I would seek help from my squad leader if I had a personal problem.

My squad leader cares about my personal well-being.

My squad leader takes time to talk to me on a personal level.

My squad leader can recognize when I'm down without asking me.

\section{Leading by Example}

My squad leader sets high standards for performance by his/her own behavior.

My squad leader works as hard as anyone in my squad.

My squad leader sets a good example by the way he/she behaves.

\section{Leader Monitoring}

My squad leader checks to make sure that the squad members continue to work on unit projects.

My squad leader monitors our progress on unit projects.

My squad leader checks whether everybody is meeting their obligation to the squad.

My squad leader watches to make sure everyone in the squad meets their deadlines.

\section{Team Open Communication}

My squad members are very willing to share information with other members about our duties.

There is a great deal of understanding when my squad members talk to each other.

My squad members are comfortable talking to each other about what needs to be done. 


\section{Trust in Team Leader}

I believe my leader will look out for my welfare.

I feel I can count on my leader to act in my best interests.

I am willing to let my leader have influence over matters that are critical to me.

I feel comfortable when my leader makes decisions that will affect me personally.

\section{Trust in Team Members}

I believe my team members will look out for my welfare.

I feel I can count on my team members to act in my best interests.

I am willing to let my team members have influence over matters that are critical to me.

I feel comfortable when my team members make decisions that will affect me personally.

\section{Outcomes}

\section{Team Performance}

The performance of my squad is among the best.

The competence of my squad is among the best.

The professionalism of my squad is among the best.

\section{Team Voice Behavior}

I have developed and made recommendations concerning issues that affect this squad.

I have spoken up and encouraged others in this squad to get involved in issues that affect the squad.

I have communicated my opinions about issues to others squad members even if my opinion is different and others disagree with me.

I have spoken up in this squad about ideas for changes in task/duty procedures.

\section{Control Variables}

\section{Leader History/Reputation}

Before he/she took the current billet, I heard that my squad leader had a good reputation. I met my squad leader before he/she took the current billet.

Before he/she took the current billet, I had positive personal interaction with my squad leader.

I worked directly with my squad leader before he/she took the current billet.

Before he/she took the current billet, I had a positive experience working with my squad leader. 


\section{References}

Aiken, L., \& West, S. (1991) Multiple regression: Testing and interpreting interactions. Newbury Park, CA: Sage.

Ajzen, I. (1988). Attitudes, personality, and behavior. Chicago: Dorsey Press.

Ajzen, I. (2012). Attitudes and persuasion. In K. Deaux \& M. Snyder (Eds.), the Oxford handbook of personality and social psychology (pp. 367-394). Oxford, UK: Oxford University Press.

Ajzen, I., \& Sexton, J. (1999). Depth of processing, belief congruence, and attitudebehavior correspondence. In S. Chaiken, \& Y. Trope (Eds.) Dual-process theories in social psychology (pp. 117-138). New York, NY: Guilford Press.

Allport, F. (1954). The structuring of events: Outline of a general theory with applications to psychology. Psychology Review, (61), 281-303. doi: $10.1037 / \mathrm{h} 0062678$

Ambrose, M., \& Schminke, M. (2003). Organization structure as a moderator of the relationship between procedural justice, interactional justice, perceived organizational support, and supervisory trust. Journal of Applied Psychology, 88, 295-305. doi: 10.1037/0021-9010.88.2.295 An examination of eta-squared and ICC values. Journal of Management, 24, 157172. doi: $10.1177 / 014920639802400202$

Anderson, J. C., \& Gerbing, D. W. (1991). Predicting the performance of measures in a confirmatory factor analysis with a pretest assessment of their substantive validities. Journal of Applied Psychology, 76(5), 732-740. doi:10.1037/00219010.76 .5 .732 
Antonakis, J., Cianciolo, A., \& Sternberg, R. (2004). The nature of leadership. Thousand Oaks, CA: Sage Publications, Inc.

Arnold, J., Arad, S., Rhoades, J., \& Drasgow, F. (2000). The empowering leadership questionnaire: The construction and validation of a new scale for measuring leader behaviors. Journal of Organizational Behavior, 21, 249-269. doi:10.1002/(SICI)1099-1379(200005)21:3<249::AID-JOB10>3.0.CO;2-\#

Aryee, s., Budhwar, P., \& Chen, Z. (2002). Trust as a mediator of the relationship between organi zational justice and work outcomes: Test of a social exchange model. Journal of Organizational Behavior, 23, 267-286. doi:10.1002/job.138

Ashforth, B. (1985). Climate formation: Issues and extensions. Academy of Management Review, (10), 837-847. Retrieved from http://www.jstor.org/stable/258051

Avolio, B., Gardner, W., Walumbwa, F., Luthans, f., \& May, D. (2004). Unlocking the mask: A look at the process by which authentic leaders impact follower attitudes and behaviors. The Leadership Quarterly, 15, 801-823. doi:10.1016/j.leaqua.2004.09.003

Ballinger, G., Schoorman, F., \& Lehman, D. ( 2009). Will you trust your new boss? The role of affective reactions to leadership succession. The Leadership Quarterly, 20, 219-232. doi:10.1016/j.leaqua.2009.01.012

Bandura, A. (1962). Social learning through imitation. In J. Marshall (Eds.) Nebraska symposium on motivation (pp. 211-274). Oxford, England: Nebraska Press.

Bandura, A. (2001). Social cognitive theory: An agentic perspective. Annual Review of Psychology, 52, 1-26. doi: 10.1146/annurev.psych.52.1.1 
Bantel, K., \& Jackson, S. (1989). Top management and innovations in banking: Does the composition of the top team make a difference? Strategic Management Journal, 10, 107-124. doi:10.1002/smj.4250100709

Barnowe, J. (1975). Leadership and performance outcomes in research organizations: The supervisor of scientists as a source of assistance. Organizational Behavior and Human Performance, 14, 264-280. doi:10.1016/0030-5073(75)90029-X

Barrick, M. R., Stewart, G. L., Neubert, M. J., \& Mount, M. K. (1998). Relating member ability and personality to work-team processes and team effectiveness. Journal of Applied Psychology, 83, 377-391.

Barry, B., \& Stewart, G. (1997). Composition, process, and performance in self-managed groups: The role of personality. Journal of Applied Psychology, 82, 62-78. doi:10.1037/0021-9010.82.1.62

Bass, B. M., Avolio, B. J., Jung, D. I., \& Berson, Y. (2003). Predicting unit performance by assessing transformational and transactional leadership. Journal of Applied Psychology, 88, 207-218.

Bass, B., Avolio, B., Jung, D., \& Berson, Y. (2003). Predicting unit performance by assessing transformational and transactional leadership. Journal of Applied Psychology, 88, 207-218. doi: 10.1037/0021-9010.88.2.207

Bennis, Y., \& Nanus, B. (1997). Leaders: Strategies for taking charge. New York, NY: Harper Business.

Biemann, T., \& Kearney, E. (2010). Size does matter: How varying group sizes in a sample affect the most common measures of group diversity. Organizational Research Methods, 13, 582-599. 
Blake, R., \& Mouton, J. (1964). The managerial grid: The key to leadership excellence. Houston, TX: Gulf Publishing.

Blau, P. (1977). Inequality and heterogeneity: A primitive theory of social structure. New York: Free Press.

Bliese, P. (1998). Group size, ICC values, and group-level correlations: A simulation. Organizational Research Methods, 1, 355-373. doi:10.1177/109442819814001

Bliese, P. D. \& Hanges, P. J. (2004). Being both too liberal and too conservative: The perils of treating grouped data as though they were independent. Organizational Research Methods, 7, 400-417.

Bliese, P. D. (2000). Within-group agreement, non-independence, and reliability: Implications for data aggregation and analysis. In K. J. Klein \& S. J. Kozlowski (Eds.), Multilevel theory, research, and methods in organizations: Foundations, extensions, and new directions (pp. 349-381). San Francisco: Jossey-Bass.

Bliese, P. D., \& Halverson, R. R. (1998). Group size and measures of group-level properties: An examination of eta-squared and ICC values. Journal of Management, 24(2), 157-172. Retrieved from EBSCOhost

Bliese, P., \& Britt, T. (2001). Social support, group consensus and stressor-strain relationships: Social context matters. Journal of Organizational Behavior, 22, 425-436. doi:10.1002/job.95

Boies, K., \& Howell, J.M. (2006). Leader-member exchange in teams: An examination of the interaction between relationship differentiation and mean LMX in explaining team-level outcomes. Leadership Quarterly, 17, 246-257. 
Bowen, D., \& Ostroff, C. (2004). Understanding HRM-Firm performance linkages: The role of the "strength" of the HRM system. The Academy of Management Review, (29), 203-221. Retrieved from http://www.jstor.org/stable/20159029

Brass, D., (1995). A social network perspective on human resources management. Research in Personnel and Human Resources Management, 13, 39-79.

Brockner, J., Siegel, P., Daly, J., Tyler, T., \& Martin, C. (1997). When trust matters: The moderating effect of outcome favorability. Administrative Science Quarterly, 42, 558-583. Retrieved from http://www.jstor.org/stable/2393738

Bromiley, P., \& Cummings, L. (1995). Transaction costs in organizations with trust. In R. Bies, B. Sheppard, and R. Lewicki (Eds.) Research on Negotiation in organizations. Greenwich, CT: JAI Press.

Brower, H., Schoorman, F., \& Tan, H. H. (2000). A model of relational leadership: The integration of trust and leader-member exchange. Leadership Quarterly, 11, 227250. doi:10.1016/S1048-9843(00)00040-0

Brown, M., Trevino, L., \& Harrison, D. (2005). Ethical leadership: A social learning perspective for construct development and testing. Organizational Behavior and Human Decision Processes, 97, 117-134. doi:10.1016/j.obhdp.2005.03.002

Browne, M. W. \& Chudeck, R. (1993). Alternative ways of assessing model fit. In K. A. Bollen \& J. S. Long (Eds.), Testing structural equation models (pp. 445-455). Newbury Park, CA: Sage.

Bruner, J. (1957). On perceptual readiness. Psychological Review, (64), 123-152. doi: $10.1037 / \mathrm{h} 0043805$ 
Burke, C. S., Stagl, K. C., Klein, C., Goodwin, G. F., Salas, E., \& Halpin, S. M. (2006). What types of leadership behaviors are functional in teams? A meta-analysis. Leadership Quarterly, 17, 288-307.

Burke, C., Sims, D., Lazzara, E., \& Salas, E. (2007). Trust in leadership: A multi-level review and integration. The Leadership Quarterly, 18, 606-632. doi:10.1016/j.leaqua.2007.09.006

Burks, C., Sims, D., Lazzara, E., \& Salas, E. (2007). Trust in leadership: A multi-level review and integration. The Leadership Quarterly, 18, 606-632. doi:10.1016/j.leaqua.2007.09.006

Bycio, P., Hackett, R., \& Allen, J. (1995). Further assessments of Bass's (1985) conceptualization of transactional and transformational leadership. Journal of Applied Psychology, 80, 468-478. doi:10.1037/0021-9010.80.4.468

Byrne, N., (1971). Psychologism: A psychology or a politic? Some reflections on Mr. Halpern's paper. Ontario Psychologist, 3, 215-222. Retrieved from http://psycnet.apa.org/psycinfo/1972-11825-001

Byrne, D. (1971). The attraction paradigm. New York: Academic Press.

Caldwell, C., \& Dixon, D. (2010). Love, forgiveness, and trust: Critical values of the modern leader. Journal of Business Ethics, 93, 91-101. doi:10.1007/s10551-0090184-Z

Carley, K., \& Krackhardt, D. (1996). Cognitive inconsistencies and non-symmetric friendship. Social Networks, 18, 1-27. doi:10.1016/0378-8733(95)00252-9 
Carnevale, P., \& Probst, T. (1998). Social values and social conflict in creative problem solving and categorization. Journal of Personality and Social Psychology, 74, 1300-1309. doi:10.1037/0022-3514.74.5.1300

Castaldo, S., Premazzi, K., \& Zerbini, F. (2010). The meaning of trust. A content analysis on the diverse conceptualizations of trust in scholarly research on business relationships. Journal of Business Ethics, 96, 657-668. doi:10.1007/s10551-010$0491-4$

Cattell, R.B. (1966) The scree test for the number of factors. Multivariate Behavioral Research, 1, 245-276.

Chan, D. (1998). Functional relations among constructs in the same content domain at different levels of analysis: A typology of composition models. Journal of Applied Psychology, (83), 234-246. doi:10.1037/0021-9010.83.2.234

Clogg, C. C., Petkova, E., \& Haritou, A. (1995). Statistical methods for comparing regression coefficients between models. American Journal of Sociology, 100, 1261-1293.

Cohen, J., Cohen, P., West, S. G., \& Aiken, L. S. (2003). Applied multiple regression/correlation analysis for the behavioral sciences (3rd ed.). Mahwah, NJ: Lawrence Erlbaum Associates Publishers. Retrieved from EBSCOhost.

Cole, M., \& Bedeian, A. (2007). Leadership consensus as a cross-level contextual moderator of the emotional exhaustion-work commitment relationship. The Leadership Quarterly, 18, 447-462. doi: 10.1016/j.leaqua.2007.07.002

Cole, M., Bedeian, A., \& Bruch, H. (2011). Linking leader behavior and leadership consensus to team performance: Integrating direct consensus and dispersion 
models of group composition. The Leadership Quarterly, 22, 383-398. doi:10.1016/j.leaqua.2011.02.012

Colquitt, J., LePine, J., Zapata, C., \& Wild, E. (2011). Trust in typical and high-reliability contexts: Building and reacting to trust among firefighters. Academy of Management Journal, 54, 999-1015. doi: 10.5465/amj.2006.0241

Colquitt, J., Noe, R., \& Jackson, C. (2002). Justice in teams: Antecedents and consequences of procedural justice climate. Personnel Psychology, 55, 83-109. doi:10.1111/j.1744-6570.2002.tb00104.x

Colquitt, J.A., Scott, B.A., \& LePine, J.A. (2007). Trust, trustworthiness, and trust propensity: A meta-analytic test of their unique relationships with risk taking and job performance. Journal of Applied Psychology, 92, 909-927. doi: 10.1037/00219010.92.4.909

Conger, J., Kanungo, R., \& Menon, S. (2000). Charismatic leadership and follower effects. Journal of Organizational Behavior, 21, 747-767. doi:10.1002/10991379(200011)21:7<747::AID-JOB46>3.0.CO;2-J

Cortina, J. M. (1993). What is coefficient alpha? An examination of theory and applications. Journal of Applied Psychology, 78(1), 98-104. doi:10.1037/00219010.78.1.98

Creed, W., \& Miles, R. (1996). Trust in organizations: A conceptual framework linking organizational forms, managerial philosophies, and the opportunity costs of controls. In R. Kramer, \& T. Tyler (Eds.) Trust in organizations: Frontiers of theory and research (16-38). Thousand Oaks, CA: Sage Publications. 
Dalton, D. R., Daily, C. M., Ellstrand, A. E., \& Johnson, J. L. 1998. Meta-analytic reviews of board composition, leadership structure, and performance. Strategic Management Journal, 19, 269-290.

Dansereau, F., Yammarino, F., \& Kohles, J. (1999). Multiple levels of analysis from a longitudinal perspective: Some implications for theory building. Academy of Management Review, 24, 346-357. Retrieved from http://www.jstor.org/stable/259086

Davis, J., Schoorman, F., Mayer, R., \& Tan, H. (2000). The trusted general manager and business unit performance: Empirical evidence of a competitive advantage. Strategic Management Journal, 21, 563-576. doi: 10.1002/(SICI)10970266(200005)21:5<563::AID-SMJ99>3.0.CO;2-0

Dawson, J., González-Romá, V., Davis, A., \& West, M. (2008). Organizational climate and climate strength in UK hospitals. European Journal of Work and Organizational Psychology, 17, 89-111. doi: 10.1080/13594320601046664

De Dreu, C. K. W., \& Weingart, L. R. (2003). Task versus relationship conflict and team effectiveness: A meta-analysis. Journal of Applied Psychology, 88, 741-749.

De Jong, B. A., \& Elfring, T. (2010). How does trust affect the performance of ongoing teams? The mediating role of reflexivity, monitoring, and effort. Academy of Management Journal, 53, 535-549. doi:10.5465/AMJ.2010.51468649

De Jong, B., \& Dirks, K. (2011). Beyond shared perceptions of trust and monitoring in teams: Implications of asymmetry and dissensus. Journal of Applied Psychology, 97, 391-406. doi: 10.1037/a0026483 
Den Hartog, D., van Muijen, J. \& Koopman, P.L. (1994). Transactioneel versus transformationeel leiderschap, een analyse van de MLQ in de Nederlandse situatie. [Transactional versus transformational leadership, an analysis of the MLQ in a Dutch situation]. Gedrag en Organisatie, 7, 155-166.

DeRue, D., Nahrgang, J., Wellman, N., \& Humphrey, S. (2011). Trait and behavioral theories of leadership: An integration and meta-analytic test of their relative validity. Personnel Psychology, 64, 7-52. doi:10.1111/j.1744-6570.2010.01201.x

Deutsch, M., \& Gerard, H. B. (1955). A study of normative and informational social influences upon individual judgment. Journal of Abnormal Social Psychology, 51, 629-636. doi:10.1037/h0046408

DeVellis, R. F. (2003). Scale development: Theory and applications (2nd ed.). Thousand Oaks, CA: Sage Publications.

Dickson, M., Resick, C., \& Hanges, P. (2006). When organizational climate is unambiguous, it is also strong. Journal of Applied Psychology, 91, 351-364. doi: $10.1037 / 0021-9010.91 .2 .351$

Dietz, G., \& Dan Hartog, D., (2006). Measuring trust inside organi zations. Personnel Review, 35, 557-588. doi:10.1108/00483480610682299

Dineen, B., Noe, R., Shaw, J., Duffy, M., \& Wiethoff, C. (2007). Level and dispersion of satisfaction in teams: Using foci and social context to explain the satisfactionabsenteeism relationship. The Academy of Management Journal, 50, 623-643. doi:10.5465/AMJ.2007.25525987 
Dirks, K. T. (2000). Trust in leadership and team performance: Evidence from NCAA basketball. Journal of Applied Psychology, 85, 1004-1012. doi: 10.1037/00219010.85.6.1004

Dirks, K., \& Ferrin, D. (2002). Trust in leadership: Meta-analytic findings and implications for research and practice. Journal of Applied Psychology, 87, 611628. doi: $10.1037 / 0021-9010.87 .4 .61$

Edmondson, A. (1999). Psychological safety and learning behavior in work teams. Adminsitrative Science Quarterly, 44, 350-383. doi:10.2307/2666999

Edmondson, A. (2003). Speaking up in the operating room: How team leaders promote learning in interdisciplinary action teams. Journal of Management Studies, 40, 1419-1452. doi:10.1111/1467-6486.00386

Eisenberger, R., Huntington, R., Hutchison, S., \& Sowa, D. (1986). Perceived organizational support. Journal of Applied Psychology, 71, 500-507. doi:10.1037/0021-9010.71.3.500

Esser, J. (1998). Alive and well after 25 years: A review of groupthink research. Organizational Behavior and Human Decision Processes, 73, 116-141. doi:10.1006/obhd.1998.2758

Ferrin, D. L., \& Dirks, K. T. (2003). The use of rewards to increase and decrease trust: Mediating processes and differential effects. Organization Science, 14(1), 18-31.

Ferrin, D., Bligh, M., \& Kohles, J. (2007). Can I trust you to trust me? A theory of trust, monitoring, and cooperation in interpersonal and intergroup relationships. Group and Organization Management, 32, 465-499. doi:10.1177/1059601106293960 
Ferrin, D., Bligh, M., \& Kohles, J. (2008). It takes two to tango: An interdependence analysis of the spiraling of perceived trustworthiness and cooperation in interpersonal and intergroup relationships. Organizational Behavior and Human Decision Process, 107, 161-178. doi:10.1016/j.obhdp.2008.02.012

Festinger, L. (1950). Informal social communication. Psychological Review, 57, 271-282. doi:10.1037/h0056932

Festinger, L. (1954). A theory of social comparison processes. Human Relations, 7, 117140. doi:10.1177/001872675400700202

Firebaugh, G. (1979). Assesssing group effect: A comparison of two methods. Sociological Methods Research, 7, 384-395. doi:10.1177/004912417900700402

Fishbein, M., \& Ajzen, I. (1974). Attitudes towards objects as predictors of single and multiple behavioral criteria. Psychological Review, 81, 59-74.

Ford, L. R., \& Seers, A. (2006). Relational leadership and team climates: Pitting differentiation versus agreement. Leadership Quarterly, 17, 258-270.

Frazier, L., \& Bowler, M. (2012). Voice climate, supervisor undermining, and work outcomes: A group-level examination. Journal of Management. doi: $10.1177 / 0149206311434533$

Fulmer, C. A., \& Gelfand, M. J. (2012). At what level (and in whom) we trust: Trust across multiple organizational level. Journal of Management, 38, 1167-1230. doi: $10.1177 / 0149206312439327$

Fulmer, C. A., \& Gelfand, M. J. (in press). How do I trust thee? Dynamic trust patterns and their individual and social contextual determinants. In K. Sycara, M. J. 
Gelfand, \& A. Abbe (Eds.), Modeling intercultural collaboration and negotiation. New York: Springer.

Gächter, S., \& Thöni, C. (2005). Social learning and voluntary cooperation among likeminded people. Journal of the European Economic Association, 3, 303-314. doi:10.1162/jeea.2005.3.2-3.303

Gilbert, D. T. (1989). Thinking lightly about others: Automatic components of the social inference process. In J. S. Uleman \& J. A. Bargh (Eds.), Unintended thought (pp. 189-211). New York: Guilford Press.

Gillespie, N. (2005, October). Are perceptions of trust shared? Examining agreement in trust ratings within dyads and teams. Paper presented at the 3rd EIASM Workshop on Trust within and between Organizations, Amsterdam, Netherlands.

Gillespie, N., \& Mann, L. (2004). Transformational leadership and shared values: The building blocks of trust. Journal of Managerial Psychology, 19, 588-607. doi: $10.1108 / 02683940410551507$

Goldstein, E. (2001). Object relations theory and self psychology in social work practice. New York, NY: The Free Press.

Goldstein, J. (1999). Emergence as a construct: History and issues. Emergence: Complexity and Organization, 1, 49-72

González-Romá, V., Peiró, J., \& Tordera, N. (2002). An examination of the antecedents and moderator influences of climate strength. Journal of Applied Psychology, 87, 465-473. doi:10.1037/0021-9010.87.3.465

Graen, G., \& Uhl-Bien, M. (1995). Relationship-based approach to leadership: Development of leader-member exchange (LMX) theory of leadership over 25 
years: Applying a multi-level multi-domain perspective. The Leadership Quarterly, 6, 219-247. doi:10.1016/1048-9843(95)90036-5

Grant, A. (2008). The significance of task significance: Job performance effects, relational mechanisms, and boundary conditions. Journal of Applied Psychology, 93, 108-124. doi:10.1037/0021-9010.93.1.108

Greene, C., \& Schriesheim, C. (1980). Leader-group interactions: A longitudinal field investigation. Journal of Applied Psychology, 65, 50-59. doi:10.1037/00219010.65 .1 .50

Grossman, S.C. (2007). Mentoring in nursing: A dynamic and collaborative process. New York: Springer Publishing.

Guzzo, R. A., \& Dickson, M. W. 1996. Teams in organizations: Recent research on performance and effectiveness. Annual Review of Psychology, 47, 307-338.

Hackman, M. Z., \& Johnson, C. E. (1996). Leadership: A communication perspective (2nd Ed.). Prospect Heights, IL: Waveland Press.

Hamilton, V. L. (1980). Intuitive psychologist or intuitive lawyer? Alternative models of the attribution process. Journal of Personality and Social Psychology, 39, 767772.

Hardin, R. (2001). Conceptions and explanations of trust. In K. S. Cook ( Ed.), Trust in Society: The Russell Sage Foundation Series on Trust (pp. 3-39). New York: Russell Sage Foundation.

Hargreaves, A. \& Fink, D. (2006). Sustainable leadership, San Francisco: Jossey Bass. 
Harrison, D. A. \& Klein, K. J. (2007). What's the difference? Diversity constructs as separation, variety, or disparity in organizations. Academy of Management Review, 32, 1199-1228.

Harrison, D., Price, K., \& Bell, P. (1998). Beyond relational demography: Time and the effects of surface- and deep- level diversity on work group cohesion. Academy of Management, 41, 96-107. Retrieved from http://www.jstor.org/stable/256901

Heider, F. (1958). The psychology of interpersonal relations. New York: John Wiley \& Sons.

Hernandez, M. 2008. Promoting stewardship behavior in organi zations: A leadership model. Journal of Business Ethics, 80, 121-128. doi:10.1007/s10551-007-9440-2

Hinkin, T. R. (1998). A brief tutorial on the development of measures for use in surveys and questionnaires. Organizational Research Methods, 1, 104-121.

Hofmann, D., \& Jones, L. (2005). Leadership, collective personality, and performance. Journal of Applied Psychology, 90, 509-522. doi:10.1037/0021-9010.90.3.509

Hofstede, G. (1998). Attitudes, values and organizational culture: Disentangling the concepts. Organization Studies, 19, 477-492.

Hofstede, G. (1998). Attitudes, values and organizational culture: Disentangling the concepts. Organizational Studies, 1, 477-493. doi:10.1177/017084069801900305

Hogan, R., Curphy, G., \& Hogan, J. (1994). What we know about leadership: Effectiveness and personality. American Psychologist, 49, 493-504. doi: 10.1037/0003-066X.49.6.493 
Hong, I. B. (1999). Information technology to support any-time, any-place team meetings in Korean organizations. Industrial Management \& Data Systems, 99, 18-24. doi: $10.1108 / 02635579910247145$

Hooper, D., \& Martin, R. (2008). Beyond personal Leader-Member Exchange (LMX) quality: The effects of perceived LMX variability on employee reactions. Leadership Quarterly, 19, 20-30.

Hosmer, L. T. (1995). Trust: The connecting link between organizational theory and philosophical ethics. Academy of Management Review, 20, 379-403.

House, R. (1971). A path goal theory of leader effectiveness. Administrative Science Quarterly, 16, 321-339. Retrieved from http://www.jstor.org/stable/2391905

House, R., Rousseau, D., \& Thomas-Hunt, M. (1995). The meso paradigm: A framework for the integration of micro and macro organizational behavior. Research in Organizational Behavior, 17, 71. Retrieved from British Library Direct.

Hovland, C., \& Weiss, W. (1953). Transmission of information concerning concepts through positive and negative instances. Journal of Experimental Psychology, 45, 175-182. Retrieved from http://www.ncbi.nlm.nih.gov/pubmed/13052849

Huang, X., Iun, J., Liu, A., \& Gong, Y. (2010). Does participative leadership enhance work performance by inducing empowerment or trust? The differential effects on managerial and non-managerial subordinates. Journal of Organizational Behavior, 31, 122-143. doi: 10.1002/job.636

Huff, L., \& Kelley, L. (2003). Levels of organizational trust in individualist versus collectivist societies: A seven-nation study. Organization Science, 14, 81-90. doi:10.1287/orsc.14.1.81.12807 
Jackson, S., Brett, J., Sessa, V., Cooper, D., Julin, J., \& Peyronnin, K. (1991). Some differences make a difference: Individual dissimilarity and group heterogeneity as correlates of recruitment, promotions, and turnover. Journal of Applied Psychology, 76, 675-689. doi:10.1037/0021-9010.76.5.675

James, L. R., Choi, C. C., Ko, C. E., McNeil, P. K., Minton, M. K., Wright, M. A., \& Kim, K. (2008). Organizational and psychological climate: A review of theory and research. European Journal of Work and Organizational Psychology, 17, 532.

James, L., Demaree, L., \& Wolf, G. (1984). Estimating within-group interrater reliability with and without response bias. Journal of Applied Psychology, 69, 85-98. doi:10.1037/0021-9010.69.1.85

Janis, I. (1972). Victims of groupthink: A psychological study of foreign-policy decisions and fiascoes. Boston, MA: Houghton, Mifflin.

Jansen, K., \& Kristof-Brown, A. (2005). Marching to the beat of a different drummer: Examining the impact of pacing congruence. Organizational Behavior and Human Decision Processes, 97, 93-105. doi:10.1016/j.obhdp.2005.03.005

Jarvenpaa, S. L., \& Leidner, D. E. (1999). Communication and trust in global virtual teams. Organization Science, 10(6), 791-815. Retrieved from EBSCOhost.

Jehn, K. (1995). A multimethod examination of the benefits and detriments of intragroup conflict. Administrative Science Quarterly, 40, 256-282. Retrieved from http://www.jstor.org/stable/2393638 
Jehn, K., Rispens, S., \& Thatcher, S. (2010). The effects of conflict asymmetry on work group and individual outcomes. The Academy of Management Journal, 53, 596616. doi:10.5465/AMJ.2010.51468978

Jung, D., \& Avolio, B., (2000). Opening the black box: An experimental investigation of the mediating effects of trust and value congruence on transformational and transactional leadership. Journal of Organizational Behavior, 21, 949-964. doi:10.1002/1099-1379(200012)21:8<949::AID-JOB64>3.0CO;2-F

Jung, D., Yammarino, F., \& Lee, J. (2009). Moderating role of subordinates' attitudes on transformational leadership and effectiveness: A multi-cultural and multi-level perspective. The Leadership Quarterly, 20, 586-603.

doi:10.1016/j.leaqua.2009.04.011

Kalshoven, K., Den Hartog, D., \& De Hoogh, A. (2011). Ethical leadership at work questionnaire (ELW): Development and validation of a multidimensional measure. The Leadership Quarterly, 22, 51-69. doi: 10.1016/j.leaqua.2010.12.007

Kanter, R. (1977). Some effects of proportions on group life: Skewed sex ratios and responses to token women. American Journal of Sociology, 82, 965-990. Retrieved from http://www.jstor.org/stable/2777808

Katz, D., \& Kahn, R. (1978). The social psychology of organizations. Oxford, England: Wiley

Kelley, H. (1967). Attribution theory in social psychology. In D. Levine (Ed.), Nebraska Symposium on Motivation. Lincoln: University of Nebraska Press.

Kenny, D. A. (2012). Measuring model fit. Retrieved from http://davidakenny.net/cm/fit.htm. 
Kenny, D. A., Kaniskan, B., \& McCoach, D. B. (2011). The performance of RMSEA in models with small degrees of freedom. Unpublished paper, University of Connecticut.

Kirkman, B., Rosen, B., Tesluk, P., \& Gibson, C. (2004). Impact of team empowerment on virtual team performance: The moderating role of face-to-face interaction. The Academy of Management Journal, 47, 175-192. Retrieved from http://www.jstor.org/stable/20159571

Klauss, R., \& Bass, B. (1982). Interpersonal communication in organizations. New York, NY: Academic Press.

Klein, K. J., \& House, R. J. (1995). On fire: Charismatic leadership and levels of analysis. Leadership Quarterly, 6, 183-198.

Klein, K., Conn, A., Smith, D., \& Sorra, J. (2001). Is everyone in agreement? An exploration of with-group agreement in employee perceptions of the work environment. Journal of Applied Psychology, (86), 3-16. doi: 10.1037/00219010.86 .1 .3

Klein, K., Dansereau, F., \& Hall, R. (1994). Levels issues in theory development, data collection, and analysis. Academy of Management Review, (19), 195-229. Retrieved from http://www.jstor.org/stable/258703

Korsgaard, M., Brodt, S., \& Whitener, E. (2002). Trust in the face of conflict: The role of managerial trustworthy behavior and organizational context. Journal of Applied Psychology, 87, 312-319. doi:10.1037/0021-9010.87.2.312

Korsgaard, M., Schweiger, D., \& Sapienza, H. (1995) Building commitment, attachment, and trust in strate gic decision-making teams: The role of procedural justice. 
Academy of Management Journal, 38, 60-84. Retrieved from http://www.jstor.org/stable/256728

Kouzes, J., \& Posner, B. (1993). Transformational leadership: The credibility factor. Healthcare Forum Journal, 36, 16-24. Retrieved from Ebscohost.com

Kozlowski, S. W. J. (2012). Groups and teams in organizations: Studying the multilevel dynamics of emergence. In A. B. Hollingshead \& M. S. Poole (Eds.), Methods for studying small groups: A behind-the-scenes guide (pp. 260-183). New York: Routledge Academic.

Kozlowski, S. J., \& Ilgen, D. R. (2006). Enhancing the effectiveness of work groups and teams. Psychological Science in the Public Interest, 7, 77-124. doi:10.1111/j.1529-1006.2006.00030.x

Kozlowski, S., \& Bell, B. (2003). Work groups and teams in organizations Handbook of Psychology - book

Kozlowski, S., \& Chao, G. (in press). The dynamics of emergence: Cognition and cohesion in work teams. Managerial and Decision Economics. doi: 10.1002/mde. 2552

Kozlowski, S., \& Doherty, M. (1989). Integration of climate and leadership: Examination of a neglected issue. Journal of Applied Psychology, 74, 546-553. doi:10.1037/0021-9010.74.4.546

Kozlowski, S., \& Klein, K. (2000). Multilevel theory, research, and methods in organizations: Foundations, extensions, and new directions. San Francisco, CA: Jossey-Bass. 
Kraiger, K., \& Ford, J. K. (1985). A meta-analysis of ratee race effects in performance ratings. Journal of Applied Psychology, 70, 56-65.

Langfred, C. (2004). Too much of a good thing? Negative effects of a high trust and individual autonomy in self-managing teams. The Academy of Management Journal, 47, 385-399. Retrieved from http://www.jstor.org/stable/20159588

Langfred, C. W. (2004). Too much of a good thing? Negative effects of high trust and individual autonomy in self-managing teams. The Academy of Management Journal, 47(3), 385-399 Retrieved from JSTOR.

LePine, J., \& Van Dyne, L. (1998). Predicting voice behavior in work groups. Journal of Applied Psychology, 83, 853-868. doi:10.1037/0021-9010.83.6.853

Leventhal, H. (1980). Toward a comprehensive theory of emotion. In L. Berkowitz (Ed.) Advances in experimental social psychology. New York: Academic Press.

Levin, J., \& Moreland, R. (1990).Conflicts within small groups. Annual Review of Psychology, 41, 585-634. doi:10.1146/annurev.ps.41.020190.003101

Lewin, K. (1951). Field theory in social science. New York: Harper \& Row.

Lewis, J., \& Weigert, A. (1985). Trust as a social reality. Social Forces, 63, 967-985. doi:10.1093/sf/63.4.967

Liden, R., Wayne, S., Zhao, H., \& Henderson, D. (2008). Servant leadership: Development of a multidimensional measure and multi-level assessment. The Leadership Quarterly, 19, 161-177. doi:10.1016/j.leaqua.2008.01.006

Liden, R.C., Erdogan, B., Wayne, S. J., \& Sparrowe, R. T. (2006). Leader-member exchange, differentiation, and task interdependence: implications for individual and group performance Journal of Organizational Behavior, 27, 723-746. 
Likert, R. (1967). The human organization: its management and values. New York, NY: McGraw-hill.

Lindell, M. K., \& Brandt, C. J. (2000). Climate quality and climate consensus as mediators of the relationship between organizational antecedents and outcomes. Journal of Applied Psychology, 85(3), 331-348. doi:10.1037/0021-9010.85.3.331

Lubinski, D., \& Humphreys, L. G. (1990). Assessing spurious "moderator effects": Illustrated substantively with the hypothesized ("synergistic") relation between spatial visualization and mathematical ability. Psychological Bulletin, 107, 385393.

Luhmann, N. (1979). Trust and power. Chichester, Toronto: Wiley.

Luria, G. (2008). Climate strength - how leaders form consensus. The Leadership Quarterly, (19), 42-53. doi: 10.1016/j.leaqua.2007.12.004

Mael, F., \& Ashforth, B. E. (1992). Alumni and their alma mater: A partial test of the reformulated model of organizational identification. Journal of Organizational Behavior, 13, 103-123. Retrieved from EBSCOhost.

Marks, M., Zaccaro, S., \& Mathieu, J. (2000). Performance implications of leader briefings and team-interaction training for team adaptation to novel environments. Journal of Applied Psychology, (85), 971-986. doi: 10.1037/0021-9010.85.6.971

Mayer, R. C., \& Gavin, M. B. (2005). Trust in management and performance: Who minds the shop while the employees watch the boss? Academy of Management Journal, 48, 874-888. Retrieved from http://www.jstor.org/stable/20159703

Mayer, R., Davis, J., \& Schoorman, F. (1995). An integrative model of organizational trust. Academy of Management Review, 20, 709-734. doi:10.2307/258792 
McAllister, D. (1995). Affect- and cognition-based trust as foundations for interpersonal cooperation in organi zations. Academy of Management Journal, 38, 24-59. Retrieved from http://www.jstor.org/stable/256727

McGrath, J. E. (1964). Social psychology: A brief introduction. New York: Holt, Rinehart and Winston

McGregor, D. (1960). Human side of enterprise. New York, NY: McGraw Hill.

McKnight, D., Choudhury, V., \& Kacmar, C. 2002. Developing and validating trust measures for e-commerce: An integrative typology. Information Systems Research, 13, 334-359. doi: 10.1287/isre.13.3.334.81

McPherson, M., Smith-Lovin, L., \& Cook, J. (2001). Birds of a feather: Homophily in social networks. Annual Review of Sociology, 27, 415-444. doi:10.1146/annurev.soc.27.1.415

Medsker, G., Williams, L., \& Holahan, P. (1994). A review of current practices for evaluating causal models in organizational behavior and human resources management research. Journal of Management, 20, 439-464. doi:10.1016/01492063(94)90022-1

Meglino, B. M., Lester, S. W., \& Korsgaard, M. (2002). The antecedents and consequences of group potency: A longitudinal investigation of newly formed work groups. Academy of Management Journal, 45(2), 352-368. doi:10.2307/3069351

Milliken, F., Morrison, E., \& Hewlin, P. (2003). An exploratory study of employees silence: Issues that employees don't communicate upward and why. Journal of Management Studies, 40, 1453-1476. doi:10.1111/1467-6486.00387 
Mischel, W. (1973). Toward a cognitive social learning reconceptualization of personality. Psychological Review, 80, 252-283. doi:10.1037/h0035002

Mishra, A. (1996). Organizational responses to crisis: The centrality of trust. In R. Kramer \& T. Thomas (Eds.) Trust in Organizations (pp. 261-287). Newbury Park, CA: Sage.

Mohammed, S., \& Nadkarni, S. (2011). Temporal diversity and team performance: The moderating role of team temporal leadership. The Academy of Management Journal, 54, 489-508. doi:10.5465/AMJ.2011.61967991

Morgeson, F., \& Hofmann, D. (1999). The structure and function of collective constructs: Implications for multilevel research and theory development. The Academy of Management Review, 24, 249-265. Retrieved from http://www.jstor.org/stable/259081

Morrison, E., Wheeler-Smith, S., \& Kamdar, D. (2011). Speaking up in groups: A crosslevel study of group voice climate and voice. Journal of Applied Psychology, 96, 183-191. doi:10.1037/a0020744

Moussavi, F., \& Evans, D. (1993). Emergence of organizational attributions: The role of a shared cognitive schema. Journal of Management, (19), 79-95. doi:10.1016/0149-2063(93)90046-P

Muthén, L. K., \& Muthén, B. O. (1998-2011). Mplus user's guide (6th ed.). Los Angeles, CA: Muthén \& Muthén.

Naumann, S., \& Bennett, N. (2000). A case for procedural justice climate: Development and test of a multilevel model. Academy of Management Journal, (45), 881-889. doi: $10.2307 / 1556416$ 
Neubert, M., Kacmar, M., Carlson, D., Chonko, L., \& Roberts, J. (2008). Regulatory focus as a mediator of the influence of initiating structure and servant leadership on employee behavior. Journal of Applied Psychology, 93, 1220-1233. doi:10.1037/a0012695

Newman, D. A., Hanges, P. J., Duan, L., \& Ramesh, A. (2008). A network model of organizational climate: Friendship, clusters, subgroup agreement, and climate schemas. In D. B. Smith (Ed.), The people make the place: Dynamic linkages between individuals and organizations (pp. 101-126). Mahwah, NJ: Erlbaum.

Nickol, B. (1999). Insurance for ailing teams. National Public Accountant, 44, 39.

Nooteboom, B., Berger, B. J. \& Noorderhaven, N. G. (1997). Effects of trust and governance on relational risk. Academy of Management Journal, 40, 308-338.

Nooteboom, B., Berger, H., \& Nooderhave, N. (1997). Effects of trust and governance on relational risk. The Academy of Management Journal, 40, 308-338. Retrieved from http://www.jstor.org/stable/256885

Oreg, S., \& Sverdlik, N. (2011). Ambivalence toward imposed change: The conflict between dispositional resistance to change and the orientation toward the change agent. Journal of Applied Psychology, 96, 337-349. doi:10.1037/a0021100

O'Reilly III, C. A., \& Roberts, K. H. (1976). Relationships among components of credibility and communication behaviors in work units. Journal of Applied Psychology, 61(1), 99-102. Retrieved from EBSCOhost.

Ostroff, C. (1992). The relationship between satisfaction, attitudes, and performance: An organizational Level Analysis. Journal of Applied Psychology, 77, 963-974. 
Ostroff, C., \& Bowen, D. (2000). Moving HR to a higher level: HR practices and organizational effectiveness. In K. Klein, \& S. Kozlowski (Eds.), Multilevel theory, research, and methods in organizations: Foundations, extensions, and new directions (pp. 211-266). San Francisco, CA: Jossey-Bass

Ostroff, C., \& Fulmer, C. A. (in press). Variance as a construct for understanding organizational phenomena. In Ryan, A. M. \& Ford, J. K. (Eds), Work behavior in organizations. Washington, DC: American Psychological Association.

Ostroff, C., Kinicki, A. J., \& Clark, M. A. (2002). Substantive and operational issues of response bias across levels of analysis: An example of climate-satisfaction relationships. Journal of Applied Psychology, 87(2), 355-368. doi:10.1037/00219010.87 .2 .355

Ostroff, C., Kinicki, A. J., \& Muhammad, R. S. (2012). Organi zational culture and climate. In W. C. Borman, D. R. Ilgen, R. J. Klimoski, \& I. B. Weiner (Eds.), Handbook of psychology (Vol. 12). Hoboken, NJ: Wiley, John, \& Sons.

Palanski, M., \& Yammarino, F. (2009). Integrity and leadership: A multilevel conceptual framework. The Leadership Quarterly, 20, 405-420. doi:10.1016/j.leaqua.2009.03.008

Palanski, M., \& Yammarino, F. (2011). Impact of behavioral integrity on follower job performance: A three-study examination. The Leadership Quarterly, 22, 765-786. doi: 10.1016/j.leaqua.2011.05.014

Paternoster, R., Brame, R., Mazerolle, P., \& Piquero, A. (1998). Using the correct statistical test for the equality of regression coefficients. Criminology, 36,859866. 
Pelled, L., Eisenhardt, K., \& Xin, K. (1999). Exploring the black box: An analysis of work group diversity, conflict and performance. Administrative Science Quarterly, 4, 1-28. doi:10.2307/2667029

Pillai, R., Schriesheim, C., \& Williams, E. (1999). Fairness perceptions and trust as mediators for transformational and transactional leadership: A two-sample study. Journal of Management, 25, 897. doi:10.1177/014920639902500606

Ployhart, R. E., \& Vandenberg, R. J. (2010). Longitudinal research: The theory, design, and analysis of change. Journal of Management, 36, 94-120. doi: $10.1177 / 0149206309352110$

Podsakoff, P. M., MacKenzie, S. B., Lee, J., \& Podsakoff, N. P. (2003). Common method biases in behavioral research: A critical review of the literature and recommended remedies. Journal of Applied Psychology, 88(5), 879-903. doi:10.1037/00219010.88.5.879

Podsakoff, P., MacKenzie, S., \& Bommer, W., (1996) Transformational leader behaviors and substitutes for leadership as determinants of employee satisfaction, commitment, trust, and organizational citizenship behaviors. Journal of Management, 22, 259-298. doi: 10.1177/014920639602200204

Premeaux, S., \& Bedeian, A. (2003). Breaking the silence: The moderating effects of self-monitoring in predicting speaking up in the workplace. Journal of Management Studies, 40, 1537-1562. doi:10.1111/1467-6486.00390

Raudenbush, S. W., \& Bryk, A. S. (2002). Hierarchical linear models: Applications and data analysis methods (2nd ed.). Newbury Park, CA: Sage. 
Reichers, A., Wanous, J., \& Austin, J. (1997). Understanding and manaqging cynicism about organizational change. The Academy of Management Executive, 11, 48-59. Retrieved from http://www.jstor.org/stable/4165371

Rempel, J., Holmes, J., \& Zanna, M. (1985). Trust in close relationships. Journal of Personality and Social Psychology, 49, 95-112. doi:10.1037/0022-3514.49.1.95

Rentsch, J. (1990). Climate and culture: Interaction and qualitative differences in organizational meanings. Journal of Applied Psychology, (75), 668-681. doi: $10.1037 / 0021-9010.75 .6 .668$

Rentsch, J., \& Klimoski, R. (2001). Why do 'great minds' think alike?: Antecedents of team member schema agreement. Journal of Organizational Behavior, 22, $107-$ 120. Retrieved from http://www.jstor.org/stable/3649585

Roberson, Q., \& Colquitt, J. (2005). Shared and configural justice: A social network model of justice in teams. Academy of Management Review, 30, 595-607. Retrieved from http://www.jstor.org/stable/20159146

Roberson, Q., Sturman, M., \& Simons, T. (2007). Does the measure of dispersion matter in multilevel research? A comparison of the relative performance of dispersion indexes. Organizational Research Methods, 10, 564-588.

doi:10.1177/1094428106294746

Rokeach, M., Smith, P., \& Evans, R. (1960). Two kinds of prejudice or one? In M. Rokeach (Ed.) The open and closed mind. New York, NY: Basic Books.

Romano, D. M. 2003. The nature of trust: Conceptual and operational clarification. Louisiana State University and Agricultural \& Mechanical College. ProQuest 
Dissertations. Retrieved from

http://search.proquest.com/docview/305321071?accountid=14696

Rousseau, D. (1985). Issues of level in organizational research: Multi-level and crosslevel perspectives. Research in Organizational Behavior, 7, 1-37. Retrieved from http://psycnet.apa.org/index.cfm?fa=search.displayRecord\&uid=1986-02679-001

Rousseau, D., Sitkin, S., Burt, R., \& Camerer, C. (1998). Not so different after all: A Cross discipline view of trust. Academy of Management Review, 23, 393-404. doi:10.5465/AMR.1998.926617

Roussin, C. (2008). Increasing trust, psychological safety, and team performance through dyadic leadership discovery. Small Group Research, 39, 224-248.

doi:10.1177/1046496408315988

Rubin, R., Bommer, W., \& Bachrach, D. (2010). Operant leadership and employee citizens hip: A question of trust? The Leadership Quarterly, 21, 400-408. doi:10.1016/j.leaqua.2010.03.005

Salancik, G., \& Pfeffer, J. (1978). A social information processing approach to job attitudes and task design. Administrative Science Quarterly, 23, 224-253. doi: $10.2307 / 2392563$

Sax, L., Gilmartin, S., \& Bryant, A. (2003). Assessing response rates and nonresponse bias in web and paper surveys. Research in Higher Education, 44, 409-432.

Schaubroeck, J., Lam, S., \& Peng, A. (2011). Cognition-based and affect-based trust as mediators of leader behavior influences on team performance. Journal of Applied Psychology, 96, 863-871. doi:10.1037/a0022625 
Schaubroeck, J., Lam, S., \& Peng, A. (2011). Cognition-based and affect-based trust as mediators of leader behavior influences on team performance. Journal of Applied Psychology, 96, 863-871. doi:10.1037/a0022625

Schein, E. (1990). Organizational culture. American Psychologist, 45, 109-119. doi:10.1037/0003-066X.45.2.109

Schein, E. H. (2010).Organizational culture and leadership (4th ed.). San Francisco: Jossey-Bass.

Schneider, B. (1987). The people make the place. Personnel Psychology, 40, 437-453.

Schneider, B., \& Reichers, A. (1983). On the etiology of climates. Personnel Psychology, (36), 19-39. doi:10.1111/j.1744-6570.1983.tb00500.x

Schneider, B., Salvaggio, A., \& Subirats, M. (2002). Climate strength: A new direction for climate research. Journal of Applied Psychology, (87), 220-229. doi:10.1037/0021-9010.87.2.220

Schriesheim, C. A., Powers, K. J., Scandura, T. A., Gardiner, C. C., \& Lankau, M. J. (1993). Improving construct measurement in management research: Comments and a quantitative approach for assessing the theoretical content adequacy of paper-and-pencil survey-type instruments. Journal of Management, 19, 385. Retrieved from EBSCOhost.

Schulte, M., Ostroff, C., \& Kinicki, A. (2006). Organizational climate systems and psychological climate perceptions: A cross-level study of climate-satisfaction relationships. Journal of Occupational and Organizational Psychology, (79), 645671. doi:10.1348/096317905X72119 
Shamir, B., Zakay, E., Breinin E. B., \& Popper, M. (1998). Correlates of charismatic leader behavior in military units: Subordinates' attitudes, unit characteristics, and superiors' appraisals of leader performance. Academy of Management Journal, 41, 387-409.

Simmons, B., Gooty, J., Nelson, D., \& Little, L. (2009). Secure attachment: Implications for hope, trust, burnout, and performance. Journal of Organizational Behavior, 30, 233-247. doi:10.1002/job.585

Simons, T. 2002. Behavioral integrity: The perceived alignment between managers' words and deeds as a research focus. Organization Science, 13, 18-35. doi: $10.1287 /$ orsc. 13.1 .18 .543

Simons, T., \& McLean Parks, J. (2002). Empty words: The impact of perceived managerial integrity on employees, customers and profits. Paper presented at the annual meeting of the Academy of Management, Denver, CO.

Singer, D., \& Willett, J. B. (2003). Applied longitudinal data analysis: Modeling change and event occurrence. New York: Oxford University Press.

Smircich, L., \& Morgan, G. (1982). Leadership: The management of meaning. Journal of Applied Behavioral Science, (18), 257-273. doi:10.1177/002188638201800303

Smith, P., Kendall. L., \& Hulin, C. (1969). The measurement of satisfaction in work and behavior. Chicago, IL: Rand McNally.

Spell, C., \& Arnold, T. (2007). A multi-level analysis of organizational justice climate, strucute, and employee mental health. Journal of Management, (33), 724-751. doi: $10.1177 / 0149206307305560$ 
Srivastava, A., Bartol, K., \& Locke, E. (2006). Empowering leadership in management teams: Effects on knowledge sharing, efficacy, and performance. The Academy of Management Journal, 49, 1239-1251. Retrieved from http://www.jstor.org/stable/20159830

Stewart, G. (2006). A meta-analytic review of relationships between team design features and team performance. Journal of Management, 32, 29-55. doi:10.1177/0149206305277792

Tajfel, H., \& Turner, J. (1979). An integrative theory of intergroup conflict. In M. Hogg \& D. Abrams (Eds.), Intergroup Relations: Essential readings. Key readings in social psychology (pp. 94-109). New York, NY: Psychology Press.

Teachman, J. (1980). Analysis of population diversity measures of qualitative variation. Sociological Methods Research, 8, 341-362. doi:10.1177/004912418000800305 teams. Psychological Science in the Public Interest, 7, 77-124.

Trope, Y. (1986). Identification and inferential processes in dispositional attribution. Psychological Review, 93, 239-257.

Tschannen-Moran, M., \& Hoy, W. (2000). A multidisciplinary analysis of the nature, meaning, and measurement of trust. Review of Educational Research, 70, 547593. doi:10.3102/00346543070004547

Tsui, A., \& O’Reilly, C. (1989). Beyond simple demographic effects: The importance of relational demography in superior- subordinate dyads. The Academy of Management Journal, 32, 402-423. Retrieved from http://www.jstor.org/stable/256368 
Tsui, A., Egan, T., \& O’Reilly, C. (1992). Being different: Relational demography and organizational attachment. Administrative Science Quarterly, (37), 549-579. Retrieved from http://www.jstor.org/stable/2393472

Turner, J. (1987). Toward a sociological theory of motivation. American Sociological Review, 52, 15-27. Retrieved from http://www.jstor.org/stable/2095389

Turner, J., Hogg, M., Oakes, P., Reicher, S., \& Wetherell, M. (1987). Rediscovering the social group: A self-categorization theory. Cambridge, MA: Basil Blackwell

Tyler, T. R., \& Degoey, P. (1996). Trust in organizational authorities: The influence of motive attributions on willingness to accept decisions. In R. M. Kramer, T. R. Tyler, R. M. Kramer, T. R. Tyler (Eds.), Trust in organizations: Frontiers of theory and research (pp. 331-356). Thousand Oaks, CA US: Sage Publications, Inc.

Uhl-Bien, M. (2006). Relational leadership theory: Exploring the social processes of leadership and organizing. The Leadership Quarterly, 17, 654-676. doi:10.1016/j.leaqua.2006.10.007

Ulrich, D. (1996). Credibility x capability. In F. Hesselbein, M. Goldsmith, \& R. Beckhard (Eds.), The leader of the future (pp. 209-219). San Francisco: JosseyBass.

Van Dierendonck, D. (2011). Servant leadership: A review and synthesis. Journal of Management, 37, 1228-1261. doi:10.1177/0149206310380462

Van Dijke, M., De Cremer, D., \& Mayer, D. M. (2010). The role of authority power in explaining procedural fairness effects. Journal of Applied Psychology, 95, 488502. doi:10.1037/a0018921 
Van Dyne, L., \& LePine, J.A. (1998). Helping and voice extra-role behavior: Evidence of construct and predictive validity. Academy of Management Journal, 41, 108-119.

Van Dyne, L., \& Saavedra, R. (1996). A naturalistic minority influence experiment: Effects on divergent thinking, conflict and originality in work-groups. British Journal of Social Psychology, 35, 151-167. doi:10.1111/j.20448309.1996.tb01089.x

von Bertalanffy, L. (1968). General system theory: Essays on its foundation and development. New York: George Braziller.

Walumbwa, F. O., Luthans, F., Avey, J. B., \& Oke, A. (2011). Authentically leading groups: The Behavior, 32, 4-24. doi:10.1002/job.653

Walumbwa, F., \& Schaubroeck, J. (2009). Leader personality traits and employee voice behavior: Mediating roles of ethical leadership and work group psychological safety. Journal of Applied Psychology, 94, 1275-1286. doi:10.1037/a0015848

Walumbwa, F., Cropanzano, R., \& Hartnell, C. (2009). Organizational justice, voluntary learning behavior, and job performance: A test of the mediating effects of identification and leader-member exchange. Journal of Organizational Behavior, 30, 1103-1126. doi:10.1002/job.611

Walumbwa, F., Hartnell, C., \& Oke, A. (2010). Servant leadership, procedural justice climate, service climate, employee attitudes, and organi zational citizenship behavior: A cross-level investigation. Journal of Applied Psychology, 95, 517529. doi:10.1037/a0018867 
Watson, W.E., Johnson, L., \& Zgourides, G. (2002). The influence of ethnic diversity on leadership, group process, and performance: An examination of learning teams. The International Journal of Intercultural Relations, 26, 1-16.

Weick, K. (2001). Gapping the relevance bridge: Fashions meet fundamentals in management research. British Journal of Management, 12, s71-s75. doi:10.1111/1467-8551.12.s1.9

Whitener, E. (2001). Do 'high commitment' human resource practices affect employee commitment? A cross-level analysis using hierarchical linear modeling. Journal of Management, 27, 515-535. doi:10.1016/S0149-2063(01)00106-4

Williams, K., \& O’Reilly, C. (1998). Demography and diversity in organizations: A review of 40 years of research. In B. Staw \& L. Cummings (Eds.) Research in Organizational Behavior. Greenwich, CT: JAI Press.

Wright, A., \& Ehnert, I. 2010. Making sense across cultural contexts. In M. N. K. Saunders, D. Skinner, G. Dietz, N. Gillespie, \& R. J. Lewicki (Eds.), Organizational Trust: A Cultural Perspective: 107-126. Cambridge: Cambridge University Press.

Wu, J., Tsui, A., \& Kinicki, A. (2010). Consequences of differentiated leadership in groups. The Academy of Management Journal, 53, 90-106. doi:10.5465/AMJ.2010.48037079

Yang, J., \& Mossholder, K. (2010). Examining the effects of trust in leaders: A base-andfoci approach. The Leadership Quarterly, 21, 50-63. doi:10.1016/j.leaqua.2009.10.004

Yukl, G. (1989). Leadership in organizations. Englewood Cliffs, NJ: Prentice-Hall. 
Yukl, G., \& Lepsinger, R. (2004). Flexible leadership: Creating value by balancing multiple challenges and choices. San Francisco: Jossey-Bass.

Yukl, G., Wall, S., \& Lepsinger, R. (1990). The validation of the managerial practices survey. In K. Clark \& M. Clark (Eds.) Measures of leadership (pp. 121-139). West Orange, NJ: Leadership Library of America.

Zaccaro, S. J. (2001). The nature of executive leadership: A conceptual and empirical analysis of success. Washington, DC: American Psychological Association.

Zaccaro, S. J., Rittman, A. L., \& Marks, M. A. (2001). Team leadership. Leadership Quarterly, 12, 451-483.

Zohar, D., \& Luria, G. (2004). Climate as a social-cognitive construction of supervisory safety practices. Journal of Applied Psychology, 89, 322-333. doi:10.1037/00219010.89 .2 .322

Zohar, D., \& Luria, G. (2005). A multilevel model of safety climate: Cross-level relationships between organization and group-level climates. Journal of Applied Psychology, 90, 616-628. doi:10.1037/0021-9010.90.4.616

Zohar, D., \& Tenne-Gazit, O. (2008). Transformational leadership and group interaction as climate antecedents: A social network analysis. Journal of Applied Psychology, 93,744-757. doi:10.1037/0021-9010.93.4.744 